University of Nebraska - Lincoln

DigitalCommons@University of Nebraska - Lincoln

Educational Administration: Theses,

Dissertations, and Student Research

Educational Administration, Department of

Spring 4-5-2011

\title{
Cosmopolitans or Locals: Who Will Lead The Next Generation of Community Colleges?
}

Melanie O. Anderson

University of Nebraska-Lincoln, moanders@pitt.edu

Follow this and additional works at: https://digitalcommons.unl.edu/cehsedaddiss

Part of the Community College Education Administration Commons, and the Organizational Behavior and Theory Commons

Anderson, Melanie O., "Cosmopolitans or Locals: Who Will Lead The Next Generation of Community Colleges?" (2011). Educational Administration: Theses, Dissertations, and Student Research. 58. https://digitalcommons.unl.edu/cehsedaddiss/58

This Article is brought to you for free and open access by the Educational Administration, Department of at DigitalCommons@University of Nebraska - Lincoln. It has been accepted for inclusion in Educational Administration: Theses, Dissertations, and Student Research by an authorized administrator of DigitalCommons@University of Nebraska - Lincoln. 
COSMOPOLITANS OR LOCALS: WHO WILL LEAD THE NEXT GENERATION OF COMMUNITY COLLEGES?

by

Melanie Oakes Anderson

\section{A DISSERTATION}

Presented to the Faculty of

The Graduate College at the University of Nebraska

In Partial Fulfillment of Requirements

For the Degree of Doctor of Philosophy

Major: Educational Studies

(Educational Leadership and Higher Education)

Under the Supervision of Professors William J. Nunez and Professor Richard E. Hoover

Lincoln, Nebraska

May, 2011 


\title{
COSMOPOLITANS OR LOCALS: WHO WILL LEAD THE NEXT GENERATION OF COMMUNITY COLLEGES?
}

\author{
Melanie Oakes Anderson, Ph.D. \\ University of Nebraska, 2011
}

Advisers: William J. Nunez and Richard E. Hoover

Scholars have identified a potential community college leadership crisis as a large percentage of community college presidents prepare to retire (Shults, 2001; Weisman \& Vaughan, 2007). The most common pathway to the community college presidency has been through the chief academic officer (CAO) position (Vaughan, 1990).

Selection of future leaders often focuses on manifest social roles or the expectations that are universally shared and relevant to a given context (Grimes \& Berger, 1970). Latent social roles are the internalized shared expectations that are not always seen as relevant on face value, but are predicted to affect an individual's attitudes and behaviors (Gouldner, 1957).

The purpose of this quantitative study was to determine if there was a relationship between Gouldner's $(1957,1958)$ theory of cosmopolitan and local latent social roles and the selection of the public community college CAO, as well as the CAO's job satisfaction, intent to turnover, and intent to pursue a presidency. The population studied was 932 public community college CAOs in the United States; 293 responses were received.

The research reported that CAOs had higher local latent social role scores and lower cosmopolitan scores. A significant positive correlation was identified between 
CAO's with local latent social roles and higher levels of job satisfaction. Cosmopolitan CAOs were negatively correlated and local CAOs were positively correlated with an intention to pursue a presidency. There was a significant difference in community college size, the number of locations, age and the CAO's local latent social role. There was a significant difference in the state population and in married or divorced marital status and the CAO's cosmopolitan latent social role.

CAOs with a local latent social role may be a good match for the organization when stability is needed; a CAO with a cosmopolitan latent social role may be a better match when significant change is needed. CAOs may also balance their cosmopolitan or local latent social role tendency through self awareness and professional development opportunities. 


\section{ACKNOWLEDGEMENTS}

When I started this program six years ago, I did not realize the many people who would be involved in supporting me through this process. I am privileged to have worked with two advisors, William Nunez and Richard Hoover. They have provided coaching, feedback, and support in navigating the program and the dissertation process. Their sage advice, and patience in reading my dissertation drafts, was always helpful and supportive. The other members of my dissertation committee, Miles Bryant and Kathleen Farrell, were generous of their time and support in reading and providing feedback on my dissertation proposal and draft. I am appreciative of the many other faculty, staff members and administrators who are The University of Nebraska-Lincoln, for the opportunity to earn my $\mathrm{PhD}$ at this outstanding institution.

Two cosmopolitan colleagues, Jon Serra and Richard Mulcahy, have been supportive in listening to my endless talk of cosmopolitans and locals and providing statistical advice and support.

I have a strong local orientation, in part due to my devotion to my family and their endless support of me in this endeavor. Working full-time and earning a $\mathrm{PhD}$ is a difficult process, and one that can stretch a person very thin. They have been behind me throughout this process, and have encouraged me, as well as provided me with the free time necessary to do the work. My sisters and mother and father in-law have helped in ways too numerous to mention over the last six years.

Our three children deserve special mention for their support. We have completed our homework together. Dan II will graduate from high school a month after I graduate. Dan II, Tara and Jack have all become teenagers over the last six years, and we are proud 
of their many accomplishments. My husband and best friend, Dan, has been supportive and patient. He may finish his six year project at the same time I finish mine. Thank you, Dan, Dan II, Tara and Jack for being my biggest local champions! 
Table of Contents

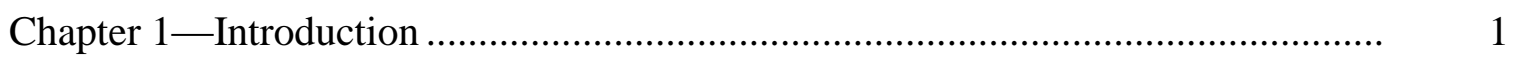

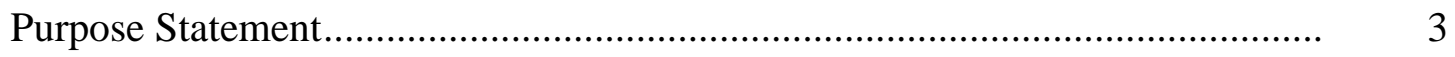

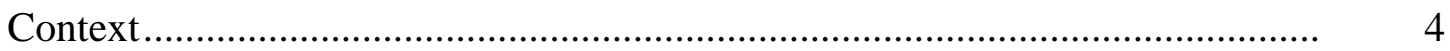

Delimitations ................................................................................... 4

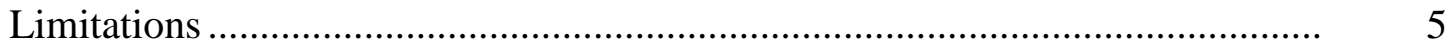

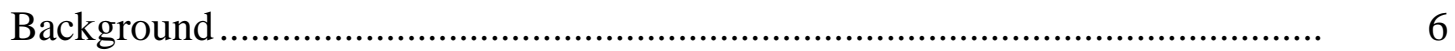

Latent Social Roles ....................................................................... 6

The Community College Chief Academic Officer ................................... 10

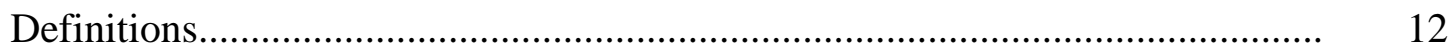

Research Questions and Hypotheses ........................................................ 17

Research Question 1 ....................................................................... 18

Research Question 2 ................................................................. 18

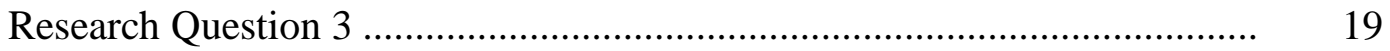

Research Question 4 ........................................................................ 19

Research Question 5 ...................................................................... 20

Research Question 6 ................................................................ 20

Research Question 7 .................................................................. 23

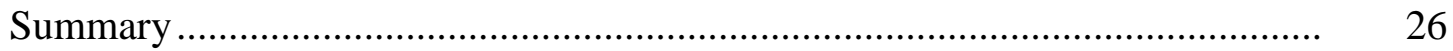

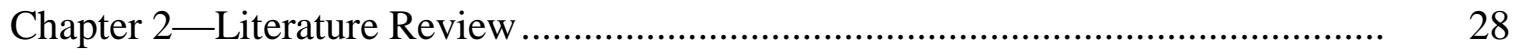

Community Colleges ...................................................................... 28

Community College History ........................................................ 28

Community College Demographics.................................................... 30

Community College Leadership ........................................................ 31

Community College Leadership Crisis ................................................. 32 
The Chief Academic Officer................................................................... $\quad 35$

Pathway to the Community College Presidency ....................................... 35

Community College Chief Academic Officer Demographics .................... 35

Summary Chief Academic Officer Demographics ............................. 42

Chief Academic Officer Career Paths......................................................... 44

Career Paths - Administrator Mobility ........................................... 46

Career Paths - Community College Labor Markets .............................. 47

Career Paths - Career Lines and Entry Ports .................................... 48

Career Paths to the Presidency ........................................................ 56

Chief Academic Officer Job Satisfaction ............................................. $\quad 58$

Chief Academic Officer Turnover ............................................................. $\quad 59$

The Chief Academic Officer - Summary ….............................................. 61

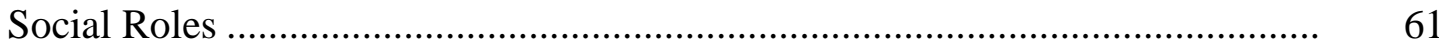

Manifest Social Roles of Chief Academic Officers................................... 61

Latent Social Roles Theory Development ............................................. 65

Latent Social Roles - Professional Groups and Problems Studied.............. $\quad 74$

Summary of Literature Review ............................................................ 79

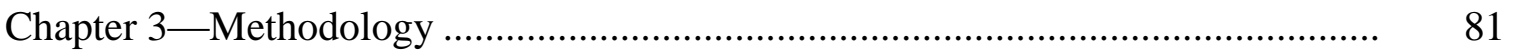

Research Questions and Hypotheses .......................................................... 81

Research Question 1 ...................................................................... 81

Research Question 2 ...................................................................... 82

Research Question 3 ...................................................................... 82

Research Question 4 ....................................................................... 83

Research Question 5 ................................................................. 83

Research Question 6 .................................................................. 84 
Research Question 7 ...................................................................... 87

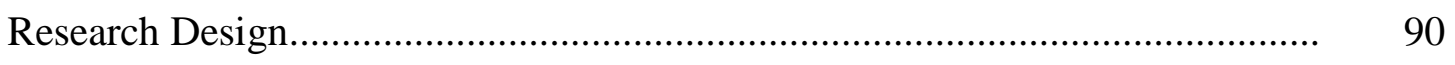

Population of the Study........................................................................ 90

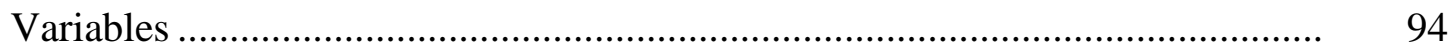

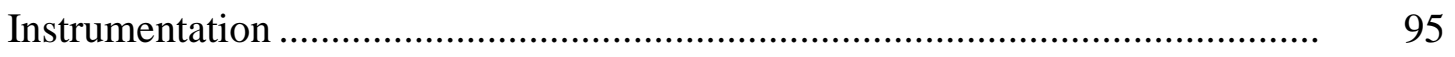

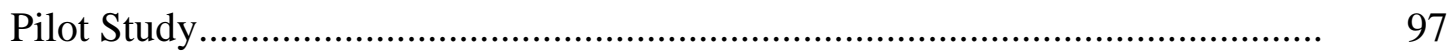

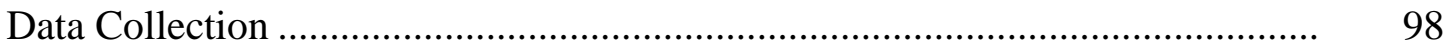

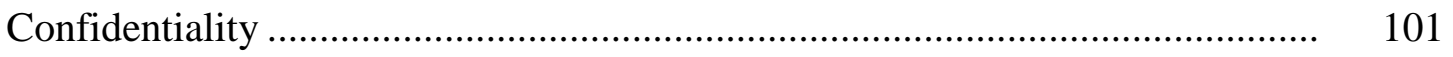

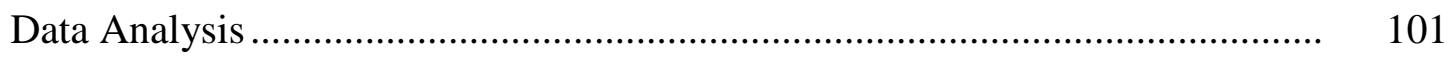

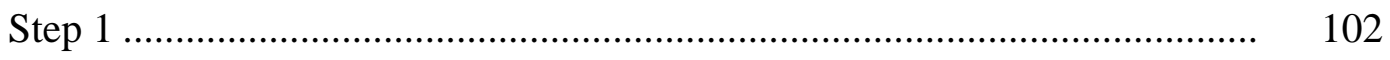

Step 2 ................................................................................. 102

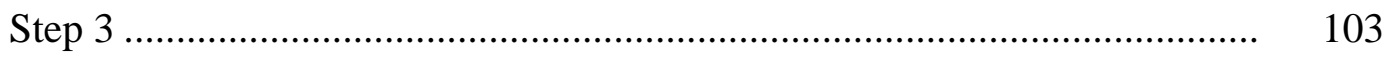

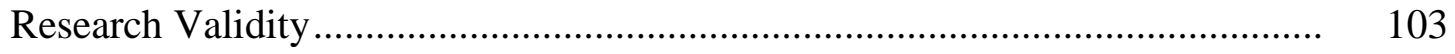

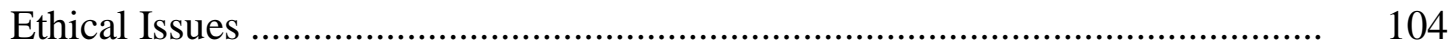

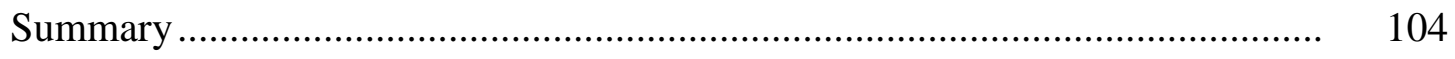

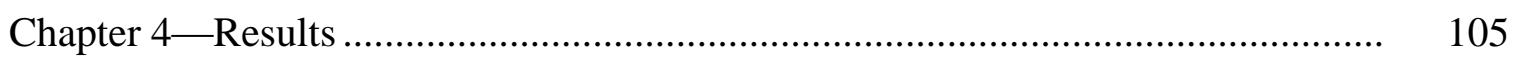

Latent Social Role Scale Confirmation.................................................... 107

Cosmopolitan Latent Social Role Scale.............................................. 108

Local Latent Social Role Scale ........................................................... 109

Summary - Latent Social Role Scale Confirmation .............................. 111

Cosmopolitan and Local latent Social Roles ............................................... 111

Cosmopolitan Social Roles ............................................................ 113

Local Social Roles ........................................................................... 114

Summary - Cosmopolitan and Local Latent Social Roles ....................... 116

Research Questions and Hypotheses ...................................................... 117 
Research Hypotheses 1, 2, 3, and 4 ...................................................... 117

Research Question 1 .............................................................................. 119

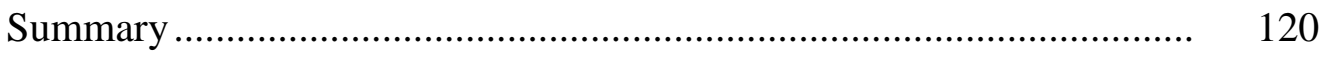

Research Question 2 .................................................................. 120

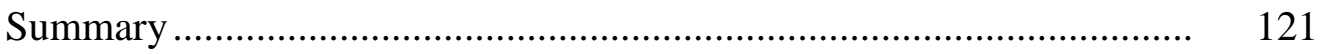

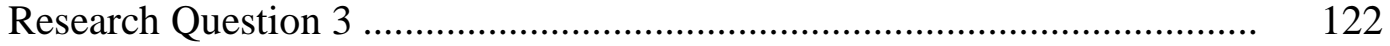

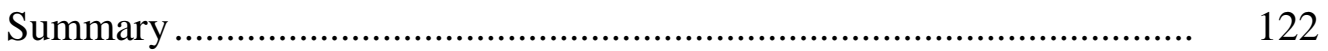

Research Question 4 ..................................................................... 123

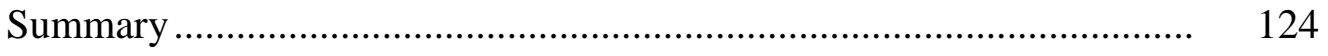

Research Question 5 ................................................................. 124

Summary ........................................................................... 129

Research Question 6 ........................................................................ 130

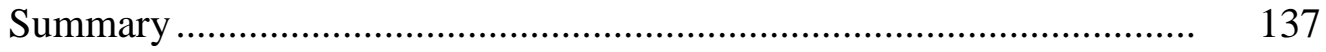

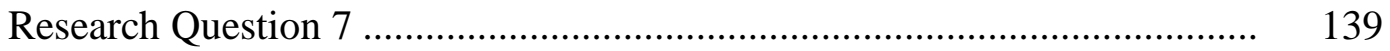

Summary of Demographic Findings ............................................ 150

Summary of All Findings............................................................ 151

Chapter 5-Conclusions and Discussion ................................................... 154

Summary of Study ............................................................................. 154

Sample, Procedure and Instruments.......................................................... 154

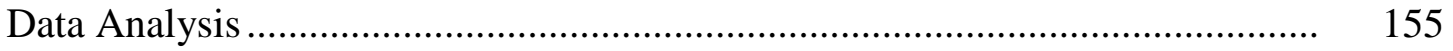

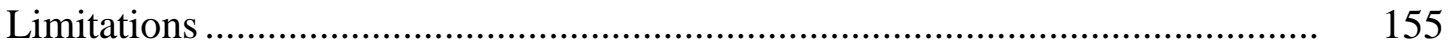

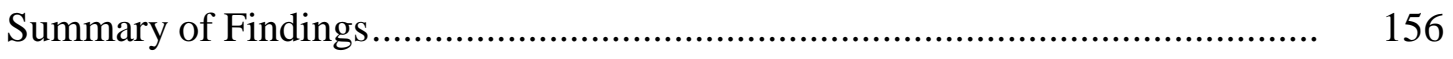

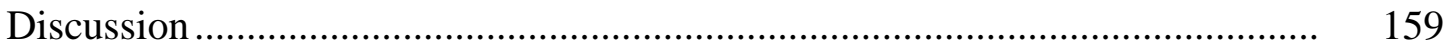

Research Question 1 .................................................................. 159

Research Question 2 ..................................................................... 160 
Research Question 3 ......................................................................... 161

Research Question 4 ........................................................................ 163

Research Question 5 ................................................................. 164

Research Question 6 ................................................................. 164

Research Question 7 .................................................................... 169

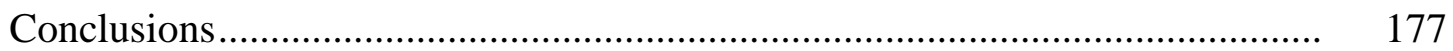

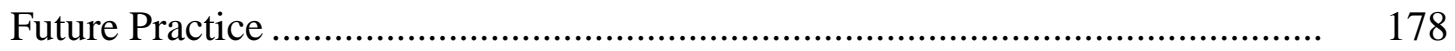

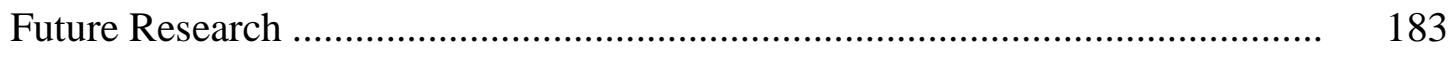

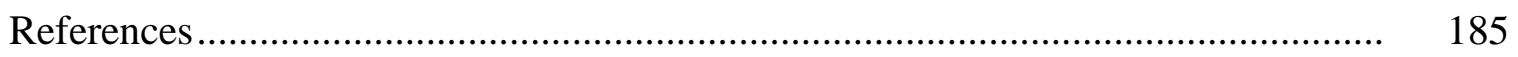

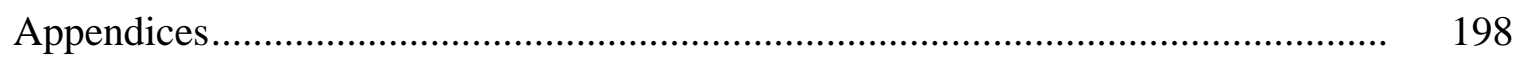




\section{List of Tables}

Table 1 National Research on CAO Demographics .............................................. 37

Table 2 Carnegie Classification of Institutions in Population .............................. 93

Table 3 Confirmatory Factor Analysis - Goodness of Fit Indicators for Cosmopolitan and Local Scales....

Table 4 Confirmatory Factor Analysis - Model Results for Cosmopolitan Questions

Table 5 Confirmatory Factor Analysis - Model Results for Local Questions.

Table 6 Descriptive Statistics - Cosmopolitan Scale Questions

Table 7 Descriptive Statistics - Cosmopolitan Scale.

Table 8 Descriptive Statistics - Local Scale Questions.....

Table 9 Descriptive Statistics - Local Scale

Table 10 Mean and Standard Deviation - Cosmo and Local Latent

Social Roles and Study Variables

Table 11 Pearson Correlation between Cosmopolitan and Local Latent

Social Roles and Study Variables

Table 12 Descriptive Statistics - Internal/External CAO Candidates

Table 13 ANOVA Results - Intent to Pursue a Community College Presidency and Latent Social Roles

Table 14 Tukey HSD Post Hoc - Cosmopolitan Latent Social Role by Intent to Pursue a Presidency.....

Table 15 Tukey HSD Post Hoc Procedure - Local Latent Social Role by Intent to Pursue a Presidency

Table 16 Descriptive Statistics - Intent to Pursue a Community College Presidency.

Table 17 Means and Standard Deviations - Community College Environmental Variables

Table 18 ANOVA Results - Community College Size and Latent Social Role 
Table 19 Descriptive Statistics and t test Results - Number of Employees and Latent Social Role

Table 20 ANOVA Results - Community College Location and Latent

Social Role

Table 21 Descriptive Statistics and t test Results - Number of Locations and Latent Social Role

Table 22 Descriptive Statistics and t test Results - Population of State and Latent Social Role

Table 23 Descriptive Statistics - Demographic Factors for CAOs

Table 24 Demographic Factors - ANOVA Results for CAO Age

Table 25 Tukey HSD Post Hoc Results - Cosmopolitan Latent Social Role by CAO Age

Table 26 Tukey HSD Post Hoc Results - Local Latent Social Role by CAO Age

Table 27 Demographic Factors and t test Results - CAO Birth Month

Table 28 Demographic Factors and t test Results - CAO Gender.

Table 29 Demographic Factors and ANOVA Results - CAO Marital Status

Table 30 Tukey HSD Post Hoc Results - Cosmopolitan Latent Social Role by Marital Status

Table 31 Demographic Factors and ANOVA Results - CAO Highest Level of Education

Table 32 Demographic Factors and t test Results - CAO Tenure

Table 33 Demographic Factors and t test Results - Year of Last Publication

Table 34 Community College Chief Academic Officer Future Plans

Table 35 Comparison of Total Community College per State to Survey Response by State 


\section{List of Figures}

Figure 1 Number of Institutions by State .................................................... 92

Figure 2 CAO Intention to Pursue a Community College Presidency .................. 165

Figure 3 CAO Latent Social Role Score and Number of Employees ................... 166

Figure 4 CAO Latent Social Role Score and Number of Locations ..................... 166

Figure 5 CAO Latent Social Role Score and State Population Where Institution is Located......................................................................... 167

Figure 6 CAO Latent Social Role Score and Institution Unduplicated Headcount

Figure 7 CAO Latent Social Role Score and Institution Location

Figure 8 CAO Latent Social Role Score and Age

Figure 9 CAOs Responding by Age.....

Figure 10 CAO Latent Social Role Score and Marital Status

Figure 11 CAO Latent Social Role Score and Birth Month

Figure 12 CAO Latent Social Role Score and Gender

Figure 13 CAO Latent Social Role Score and Highest Degree Earned

Figure 14 CAO Latent Social Role Score and Tenure as CAO

Figure 15 CAO Latent Social Role Score and Research 


\section{List of Appendices}

Appendix A Initial E-mail Contact............................................................... 198

Appendix B Informed Consent Form and Survey Instrument ............................ 200

Appendix C $\quad$ First Follow-up E-mail.............................................................. 208

Appendix D Second Follow-up Email............................................................. 210

Appendix E Tukey HSD Post Hoc Procedure................................................... 212 


\section{Chapter 1}

\section{Introduction}

Community colleges have flourished in the last 50 years, almost doubling in number from 677 in 1960 to more than 1,200 in 2008 (AACC, 2008). These community colleges serve an important role in the education of students in the United States; fully one-half of all college graduates attended a community college during their college career (AACC, 2008). The expansion and growth of community colleges has relied heavily on dedicated leaders, including the community college president and chief academic officer.

As community colleges have grown in number, size, and popularity, they have matured organizationally. The once ambiguous community college leadership roles are now well-defined positions that are part of a professional career path for individuals interested in academic administration (Twombly, 1986; Vaughan, 1990). Community college leadership pathways have expanded beyond the dedicated faculty member who reluctantly agrees to serve his or her turn as a community college leader, and then subsequently returns to the faculty ranks. The pathway to community college leadership is well established and depends on a regular flow of professional and qualified leadership candidates to succeed the previous generation of leaders.

Scholars have identified a potential community college leadership crisis (Duree, 2007; Kelly, 2002; Shults, 2001; Weisman \& Vaughan, 2007) as a large percentage of community college administrators are near retirement age. It is vital to understand the pathways to leadership positions to assure a steady supply of qualified and professional community college administrators. The community college presidency is an important leadership position that has been extensively studied. The most common pathway to the 
presidency has been through the chief academic officer (CAO) position (Amey, VanDerLinden, \& Brown, 2002b; McKenney \& Cejda, 2000; Twombly, 1990; Vaughan, 1990). The community college CAO position, however, has not been the subject of extensive research.

"Leadership is one of the most observed and least understood phenomena on earth" (McGregor Burns, 1979). Community college leaders are crucial to the success of community colleges. Identifying and selecting leaders, such as the president and the $\mathrm{CAO}$, is a critical process for community colleges. The bulk of leadership research has focused on leader's manifest social roles. Manifest roles are the expectations that were universally shared and relevant to a given context (Grimes \& Berger, 1970). Manifest roles in the community college leadership search process could include the candidates work experience and formal roles as faculty member, department chair, chief academic officer, and president, for example.

Latent social roles underlay these manifest social roles. Latent social roles are the internalized shared expectations that are not always seen as relevant on face value, but are predicted to affect an individual's attitudes and behaviors (Gouldner, 1957). Latent social roles are developed based on the individual's background, education and experience. The two most widely recognized latent social roles are those of cosmopolitan and local (Abrahamson, 1965; Berger \& Grimes, 1973; Brumbaugh \& Flango, 1973; Friedlander, 1971; Goldberg, 1976; Goldberg, Baker, \& Rubenstein, 1965; Gouldner, 1957, 1958; Grimes \& Berger, 1970; Merton, 1957; Rotundi, 1977; Tuma \& Grimes, 1981). 
The impact of latent social roles on community college leadership has not been studied. The latent social roles of cosmopolitan and local may impact the selection of community college leaders. Latent social roles may also impact community college leader's job satisfaction, intent to turnover, and intent to pursue additional academic leadership opportunities. Community colleges spend significant resources, both in time and money, in the selection of a leader. Community colleges must carefully scan and understand their environment to identify and select leaders who can succeed in that environment (Vaughan, 1990). Information is crucial in matching the community college leadership candidate to the organization. Community college search committees have ready access to a candidate's manifest social roles and the impact of these roles on a potential leader's success. Committees and candidates have not had the benefit of research on the impact of latent social roles with community college environments. This research may help community college search committees and administration evaluate potential leadership candidates fit with the environment and needs of the community college. The examination of how latent social roles impact community college leadership will also help potential leaders evaluate their compatibility for leadership roles.

\section{Purpose Statement}

The purpose of this quantitative study was to determine if there was a relationship between Gouldner's $(1957,1958)$ theory of cosmopolitan and local latent social roles and the selection of the public community college chief academic officer, as well as the chief academic officer's subsequent job satisfaction, intent to turnover, and intent to pursue a community college presidency. The differences between the community college chief academic officer's latent social roles and their demographic and environmental factors 
were also studied. The outcome of this research has relevance to community college faculty and administrators who are considering pursuing the public community college chief academic officer position, as well as to the search committee and board of trustees involved in the selection of the chief academic officer. The study adds to the body of research that has been developed in relation to Gouldner's theory of cosmopolitan and local latent social roles.

\section{Context}

Cohen and March (1974) noted that the "American college president arrives at the presidency after previous experience that conditions his behavior as a college leader" (p. 7). Gouldner's theory of latent social roles provides a framework to examine this conditioned behavior. Specifically, Gouldner's theory is that individuals are influenced by their previous experiences in relation to their loyalty to the organization, their commitment to professional goals, and their identification with reference groups. The community college CAO's latent social role may impact their selection as a community college leader, as well as impact the CAO's behavior after they obtain a community college leadership position. This subsequent impact could include the CAO's job satisfaction, their intent to turnover, and their intent to pursue a community college presidency.

\section{Delimitations}

Delimitations narrow the scope of the study (Creswell, 2008). There were several delimitations that restricted this study. 
1. Public community colleges in the United States were selected for this study, based on the availability of data from the Higher Education Directory (HED). Private two-year institutions were not included.

2. This study was narrowed to focus on one academic leadership position that is often a pathway to the presidency, the chief academic officer (CAO). However, this study will not be used to examine or measure the job performance of community college CAOs.

3. No attempt was made to predetermine the latent social role of the research subjects.

\section{Limitations}

The potential limitations of this study are identified here, but will be reviewed in more detail in a later chapter. Limitations help readers judge the extent to which the findings can be generalized to other people and situations (Creswell, 2008). Limitations of a study may include the possible inadequate measurement of variables, lack of participants, and errors in measurement of independent variables (p. 207).

1. The results of this study were limited to CAOs serving public, comprehensive community colleges reporting information to the HED.

2. The results of this study provided a snapshot of community college CAOs serving in 2009/2010.

3. Information from the study was limited to aggregated results.

4. The survey was designed to be distributed and administered electronically.

5. There was little control over responses. Responses to survey items will reflect the individual opinions of each CAO. 


\section{Background}

Latent Social Roles. Community colleges need a steady supply of willing and qualified community college leaders. Individuals may decide to pursue a community college leadership position on their own or they may be directed and mentored to that pathway by others in the community college organization.

Organizations seek to identify those individuals in the leadership pipeline at the community college or identify those individuals from outside the organization who will be the most effective leaders. One way to research and understand this selection process, including both self selection and organization selection, is through the study of social roles. The job satisfaction of sitting CAOs will impact their intent to turnover, and may also influence their decision to pursue a community college presidency.

Gouldner (1958) defined social roles as "a shared set of expectations directed toward people who are assigned a given social identity" (p. 283). He noted it was "too easy to focus on more evident manifest identities and roles” (p. 285). Gouldner (1958) researched latent social roles and how these roles impact the individual's organizational roles. Social roles or identities are the way individuals are perceived and classified by others in our culture. Manifest social roles are those that are collectively regarded as relevant to a given social situation (student, teacher, parent, supervisor) and latent social roles are those that group members consciously consider irrelevant or inappropriate to consider (p. 284), but may still influence their actions. Gouldner (1957) noted that latent social roles were influential in almost all situations, but were not formally acknowledged as relevant. 
This study used Gouldner's $(1957,1958)$ theory on latent social roles. The latent social roles identified by Gouldner $(1957,1958)$ were labeled "cosmopolitans” and "locals." Latent social roles were delineated on the basis of three variables: (a) loyalty to the employing organization, (b) commitment to specialized or professional skills, and (c) reference group orientations (Gouldner, 1957, p. 290). Cosmopolitans are low on loyalty to the employing organization, high on commitment to specialized skills, and use an outer reference group orientation. Locals are high on loyalty to the organization, low on commitment to specialized skills, and use an inner reference group orientation (Gouldner, 1957, p. 290).

Loyalty to the employing organization was the first of Gouldner's (1957) three criteria. Gouldner noted that loyalty tends to be taken for granted (p. 290). Loyalty to the organization was a latent social identity in that loyalty was not consistently formally recognized with rewards, other than gold watches for faithful years of service. Gouldner noted that the importance of loyalty was one of the major dilemmas for organizations; promotions are often not based on seniority but on competence and skill. Gouldner noted "loyalty to the organization often implies the other two criteria, (1) a willingness to limit or relinquish the commitment to a specialized professional task and (2) a dominant career orientation to the employing organization as a reference group" (p. 290).

Gouldner's second criterion, commitment to specialized or professional skills postulated that individuals who have "relatively complex, seemingly mysterious skills, derived from long formal training, lead them to a more basic commitment to their job than to the organization where they work" (p. 288). Experts have intensive technical 
training in their area; this training provides them with greater job opportunities in other organizations, or "horizontal job mobility" (p. 288).

Gouldner's third criterion, reference group orientation, varies from one organization type to another (Gouldner, 1957). Gouldner (1957) noted that experts have to continually update their skills and may collaborate with other experts or professionals outside of the organization (p. 288). The expert's skills may not be understood or validated by members of the organization, so "the expert is more likely than others to esteem the good opinion of professional peers elsewhere; he is disposed to seek recognition and acceptance from "outsiders" (p. 288).

Gouldner's $(1957,1958)$ research involved faculty members at a small college. Other researchers have continued to expand and refine Gouldner's cosmopolitan and local latent social role distinctions on many professions in a variety of settings. These included faculty (Berger \& Grimes, 1973; Flango \& Brumbaugh, 1974; Goldberg, 1976; Gouldner, 1957, 1958; Tuma \& Grimes, 1981); scientists (Abrahamson, 1965; Friedlander, 1971); engineers (Goldberg et al., 1965; Rotundi, 1977); police chiefs (Pursley, 1974); military personnel (Stahl, Manley \& McNicols, 1978) and business professionals and managers (Larwood, Wright, Desrochers \& Dahir, 1998; Wright \& Larwood, 1997). Gouldner's $(1957,1958)$ theory has not been applied to college administrators; perhaps because the assumption has been that they are managers who were committed to the institution and were, therefore, oriented to the organization, or were locals in latent social role orientation. Additional research on the impact of latent social roles on community college administrators will extend this research. 
Researchers identified differences between cosmopolitans and locals in terms of influence, participation, acceptance of organizational rules, and informal relations to others. Community college administrators identify with and are committed to the institution where they work; Gouldner (1957) described this as a local latent social role orientation. However, the community college administrator career path, particularly for those who aspire to be CAOs and presidents, is one of mobility between institutions. CAOs advance their career by accepting another CAO position at a larger institution or by seeking a presidency; community college presidents have frequently sought three or more presidencies during their career (Weisman \& Vaughan, 2007). This mobility and commitment to a professional career path that encompasses multiple institutions might be described as cosmopolitan latent social role orientation. Cosmopolitans were committed to maintaining the skills and values of their profession (Gouldner, 1957).

Faculty were the primary source of community college administrators, and subsequently served as CAOs and presidents (Amey et al., 2002; Cejda, McKenney, \& Burley, 2001; Cejda, McKenney, \& Fuller, 2001; McKenney \& Cejda, 2000; Moore \& Twombly, 1985; Moore, Twombly, \& Martorana, 1985; Murray, Murray, \& Summar, 2000; Twombly, 1986, 1988; Vaughan, 1990). The cosmopolitan latent social role is developed and encouraged in faculty members during their academic education and in their early careers, as they seek positions at institutions other than those where they were educated (Rhoades, Kiyama, McCormick, \& Quiroz, 2008). Expertise, professional development, and commitment to research by faculty were valued and rewarded. Even community colleges, traditionally focused on teaching, have a relatively recent focus on professional development and research as a means of enhancing "both our performance 
and our image as professionals" (Vaughan, 1986, p. 14). Faculty were often highly mobile, placed a high value on their affiliation with professional organizations and were loyal to their field of study. Emphasis on expertise and loyalty to a profession rather than an organization, and an outer reference group orientation, were linked with Gouldner's (1958) cosmopolitan social role.

The importance of latent social roles to higher education institutions has been noted by other researchers. Chester Barnard and Herbert Simon indicated that technical expertise was not the only factor that was important for organizational survival, and noted the importance of loyalty to the organization and its mission (Gouldner, 1958, p. 465). Gouldner (1958) noted that loyalty was important to an organization, particularly if the organization operated in a "threatening environment" (p. 466). Loyalty was linked with Gouldner's (1958) local social role.

The Community College Chief Academic Officer. The Chief Academic Officer (CAO) position has been identified of crucial importance to the success of the community college, and of equal importance to that of the president's position, in terms of academic affairs (Birnbaum \& Umbach, 2001; Mech, 1997; Vaughan, 1990). The potential shortage of community college leaders, particularly presidents, has been widely reported (Boggs, 2003; Campbell, 2002; Carroll, 2004). In addition, many CAOs in community colleges were nearing retirement age. The average age of community college presidents was 58; the average age of CAOs was 57 (Duree, 2007). The pending retirement of many presidents and CAOs may leave a large gap in the community college leadership pool. 
Community college leadership research has also focused on community college labor markets. Moore and Twombly (1985) stated that research was needed to identify the increasing professionalization and career consciousness of administrators. Moore and Twombly (1985) discussed the perceived need among institutions for better prepared academic leaders who were looking outside their own institution. This was a cosmopolitan viewpoint in terms of latent social roles and also involves issues of career mobility (Gouldner, 1958). Administrators no longer build temporary careers on top of their permanent careers as faculty members. Academic administration was a full-fledged career with its own labor market (Twombly, 1986). College administrators have education and work experiences at several institutions, and build "occupational careers or a series of successively more important experiences within an occupation" (Moore, 1983, p. 15).

Twombly (1988) studied the career paths of administrative leadership positions (such as the $\mathrm{CAO}$ ) at community colleges; faculty positions were the single most prominent entry point in the pipeline for community college leaders. Amey et al. (2002) identified community college CAOs as coming from the faculty and other academic administrative positions, such as student affairs, business affairs, and continuing education. The researchers reported that $52 \%$ of community college CAOs were promoted from within, $23 \%$ came from other community colleges, and $25 \%$ of CAOs came from four-year institutions (p. 579). This would indicate that many community colleges were growing their own leaders to serve as the CAO. Latent social roles may impact the selection of an internal or external candidate for the CAO position. 
The CAO position has been identified as one of the most important steps in a career pathway to the presidency of higher education institutions (Vaughan, 1990). Recent research suggested evidence that many CAOs were not interested in the presidency. CAOs believed they could make a more significant contribution as the CAO or they were not interested in the fundraising duties of the presidency (Cejda, 2007). The retirement of presidents and CAOs along with limited interest by sitting CAOs in pursuing a community college presidency may compound the community college leadership crisis. The impact of latent social roles on CAO job satisfaction, intent to turnover, and intent to pursue a community college presidency will provide additional insight into this career pathway.

\section{Definitions}

An understanding and consistent use of terminology in relation to community colleges and latent social roles was vital to this study. The following key terms provided a common understanding of important concepts.

Associate's Colleges Classification-A classification scheme developed by Katsina, Lacey and Hardy at the University of Alabama based on five criteria: 1) rural, suburban, or urban (Carnegie Foundation, 2010). Rural institutions are not in a Primary Metropolitan Statistical Area (PMSA) or Metropolitan Statistical Area (MSA) as defined by the US Census and have a population less than 500,000. Suburban institutions are in a MSA with a population exceeding 500,000. Urban institutions are in a PMSA with a population exceeding 500,000. 2) Size is defined by full-year unduplicated credit headcount as reported to the Integrated Postsecondary Education Data System (IPEDS). Unduplicated credit headcount is the sum of students enrolled for credit with each student 
counted only once (NCES, 2010). Small is defined as a credit headcount of less than 2,500; medium as 2,500 through 7,500; and large is greater than 7,500. 3) Single or multiple campus, based on number of physical campuses, where courses are offered that are required to complete a degree, and control over the campus(es) by a single governance structure or body. 4) Special use colleges are identified by their narrow curricular focus and are not part of another institution. 5) Other considerations included 2-year institutions under the governance of a 4-year institution; these are included in the Public 2-year Colleges under Universities.

American Association of Community Colleges-The American Association of Community Colleges (AACC) was (and continues to be) one of the primary advocacy organization for United States community colleges. The AACC represents almost 1,200 two-year, associate degree-granting institutions and more than 11 million enrolled students (AACC, 2008).

Career Lines_- "Sequences of related positions that are common to a portion of the labor force and for which there was a high probability of movement from one position to another" (Twombly, 1988, p. 672).

Career Mobility - "Movement from one job to another through a sequence of jobs" (Twombly, 1986, p. 5). Promotion in an organization was a primary means of mobility for some individuals, but career mobility goes beyond that to job change, but not a random movement through a series of unrelated jobs. Twombly (1986) further defined career mobility as "the context of career lines, or through sequences of related positions" (p. 5). 
Carnegie Classification-Time specific snapshots of institutional attributes and behaviors. The Basic Classification identified six types: doctorate-granting universities; master's colleges and universities; baccalaureate colleges, associate's colleges, special focus institutions, and tribal colleges (Carnegie Foundation, 2010).

Chief Academic Officer (CAO) — "The administrative head of academic programs with responsibility for all academic affairs at the institution. At most community colleges, the chief academic officer was the second highest-ranking administrative officer and reported to the president" (Murray et al., 2000, p. 22). Other names for this position included provost, vice president for academic affairs, vice president for instruction, dean of instruction, and/or academic dean.

Comprehensive Community College-Two-year higher education public or private institutions that offer open access to all students. Community colleges award associate degrees, provide general and occupational education, provide the first two years of college for transfer students, and work with local communities to offer continuing education opportunities (AACC, 2008).

Cosmopolitan-A latent social identity low in organizational loyalty, high in commitment to specialized role skills, and most likely to use outer reference group orientations (Gouldner, 1957, 1958).

Entry Positions - “A job in a sequence held by a significant proportion of persons without prior employment in another position in the trajectory" (Spilerman, 1977, p. $560)$. 
Grow Your Own Leadership Programs (GYOL) - Those efforts developed by community colleges and states to prepare future leaders in the community college system (Kirby, 2004).

Higher Education Directory or HED — Provides information on accredited colleges and universities in the U.S. The HED is the successor to the U.S. Department of Education's Education Directory, Colleges and Universities that ceased publication in 1984 (HEP, 2010).

Higher Education General Information Survey or HEGIS-The predecessor to the Integrated Postsecondary Education Data System or IPEDS (NCES, 2010).

Internal Labor Market-Any cluster of jobs, regardless of occupational titles or employing organizations that have three basic structural features, including 1) job ladder or career line, 2) entry or entry ports only at the bottom, and 3) movement up the ladder that was associated with progressive development of knowledge and skill (Twombly, 1986). Note that labor markets can be firm specific, or firm internal labor markets (FILMS), or occupation specific, occupational internal labor markets (OILMS). Integrated Postsecondary Education Data System (IPEDS) — Higher Education institutions that participate in student aid programs are required to report data annually on enrollments, program completions, graduation rates, faculty and staff, finances, institution prices, and student financial aid. This data is made available to students, parents, researchers and others through the National Center for Education Statistics (NCES) IPEDS Data Center (NCES, 2010).

Labor Market—-“Arenas in which workers exchange their labor power in return for wages, status, and other job rewards" (Twombly, 1986, p. 11). 
Latent Social Roles-The internalized shared expectations that, although not always seen as relevant on face value, are predicted to affect an individual's attitudes and behavior. The two most widely recognized latent roles are cosmopolitan and local (Gouldner, 1957).

Local -A latent social identity high in organizational loyalty, low in commitment to specialized role skills, and most likely to use inner reference group orientations (Gouldner, 1957, 1958).

Manifest Social Roles-The expectations of a group which were universally shared and relevant to a given context (Grimes \& Berger, 1970). Examples cited by Gouldner (1957) include teachers and students (p. 283).

Occupational Internal Labor Market or OILM-Occupations that have become their own pool of potential candidates for open positions (Cejda, McKenney, \& Burley; 2001).

President-The highest ranking administrative officer or chief executive officer (CEO) in the educational institution, in this case, the community college (Vaughan, 1989).

Professional-A person with academic qualifications, expert and specialized knowledge in their field, excellent skills and knowledge, high quality work, and a high standard of occupational ethics. Professional was defined as "two important components: the development of expertise based on systemized knowledge, and the performance of a service to a client" (Goldberg, 1976, p. 334). 
Public_-“An educational institution whose programs and activities are operated by publicly elected or appointed school officials and which is supported primarily by public funds" (NCES, 2010).

Reference group-Organization members may have an inner or outer reference group. Organization members with an inner reference group value the opinion of organization members. Organization members with an outer reference group were "more likely to be oriented to a reference group composed of others not a part of his employing organization" (Gouldner, 1957, p. 288).

Social Roles - Set of expectations oriented toward people who occupy a certain position in a social system or group (Gouldner, 1957, 1958).

Turnover-Employees leaving their current position for another position (Larwood et al., 1998).

\section{Research Questions and Hypotheses}

There were seven research questions and hypotheses that were examined and reported on from this research. McMillan and Schumacher (2006) state that hypothesis should be concise and lucid; they recommend that a general hypothesis be rephrased into more specific hypothesis for clarity (p. 60). Using this approach, each of the seven research hypothesis presented below is further subdivided in specific alternative and null hypotheses. 
R1. Was there a correlation between the public community college CAO's job satisfaction and their latent social role and does the correlation vary according to the nature of the latent social role?

RH1a. There was a correlation between job satisfaction and the CAO's cosmopolitan latent social role.

NH1a. There was no correlation between the public community college CAO's cosmopolitan latent social role orientation and job satisfaction.

RH1b. There was a correlation between job satisfaction and the CAO's local latent social role.

NH1b. There was no correlation between the public community college CAO's local latent social role orientation and job satisfaction.

R2. Was there a correlation between the public community college CAO's aspirations to pursue a community college presidency and the CAO's latent social role and does the correlation vary according to the nature of the latent social role? RH2a.There was a correlation between the public community college CAO's aspirations to pursue a community college presidency and their cosmopolitan latent social role.

NH2a. There was no correlation between the public community college CAO's intent to pursue a community college presidency and the cosmopolitan latent social role of the CAO.

RH2b.There was a correlation between the public community college CAO's aspirations to pursue a community college presidency and their local latent social role. 
NH2b. There was no correlation between the public community college CAO's intent to pursue a community college presidency and the local latent social role of the CAO.

R3. Was there a correlation between the public community college CAO's intent to turnover and the CAO's latent social role and does the correlation vary according to the nature of the latent social role?

RH3a. There was a correlation between the CAO's intent to turnover and the CAO’s cosmopolitan latent social role.

NH3a. There was no correlation between the public community college CAO's intent to turnover and the cosmopolitan latent social role of the CAO.

RH3b.There was a correlation between the CAO's intent to turnover and the CAO's local latent social role.

NH3b. There was no correlation between the public community college CAO's intent to turnover and the local latent social role of the CAO.

R4. Was there a correlation between the selection of an internal or external candidate for the public community college CAO position and the CAO's latent social role and does the correlation vary according to the nature of the latent social role?

RH4a. There was a correlation between the CAO's cosmopolitan latent social role orientation and the selection of an internal or external CAO job candidate

NH4a. There was no correlation between the CAO's cosmopolitan latent social role orientation and the selection of an internal or external CAO job candidate. 
RH4b. There was a correlation between the CAO's local latent social role orientation and the selection of an internal or external CAO job candidate.

$\mathrm{NH} 4 \mathrm{~b}$. There was no correlation between the CAO's local latent social role orientation and the selection of an internal or external CAO job candidate.

R5. Was there a difference in intent to pursue a community college presidency and latent social role?

RH5a. There was a difference between the CAO's intent to pursue a community college presidency and the cosmopolitan latent social role of the CAO.

NH5a. There was no difference between the CAO's intent to pursue a community college presidency and the cosmopolitan latent social role of the CAO.

RH5b. There was a difference between the CAO's intent to pursue a community college presidency and the local latent social role of the CAO.

NH5b. There was no difference between the CAO's intent to pursue a community college presidency and the local latent social role of the CAO.

R6. Was there a difference between the environmental factors of public community college size, number of employees, location (rural, suburban, urban), number of locations (part of a system), or state of operation in relation to the latent social roles for public community college CAOs in the United States?

RH6a. There was a difference between community college size and the cosmopolitan latent social role of the CAO. Small was defined as under 2,500 unduplicated student headcount, medium was defined as 2,500 to 5,000 unduplicated student headcount, and large as greater than 5,000 unduplicated student headcount. 
NH6a. There was no difference between community college size and the cosmopolitan latent social role of the CAO.

RH6b. There was a difference between community college size and the local latent social role of the CAO. Small was defined as under 2,500 unduplicated student headcount, medium was defined as 2,500 to 5,000 unduplicated student headcount, and large as greater than 5,000 unduplicated student headcount.

NH6b. There was no difference between the community college size and the local latent social role of the CAO.

RH6c. There was a difference between the number of employees at the community college and the cosmopolitan latent social role of the CAO. A small number of employees was defined as less than 1,000 employees at the institution; a large number of employees was defined as greater than 1,000 .

NH6c. There was no difference between the number of employees at the community college and the cosmopolitan latent social role of the CAO.

RH6d: There was a difference between the number of employees at the community college and the local latent social role of the CAO. A small number of employees was defined as less than 1,000 employees at the institution; a large number of employees was defined as greater than 1,000.

NH6d. There was no difference between the number of employees at the community college and the local latent social role of the CAO.

RH6e. There was a difference between the rural, suburban, or urban community college location and the cosmopolitan latent social role of the CAO. Rural was defined as not a MSA or PMSA and with a population of less than 500,000. Suburban and urban 
was defined as a MSA or PMSA, respectively, with a population equal to or greater than $500,000$.

NH6e. There was no difference between the rural, suburban, or urban community college location and the cosmopolitan latent social role of the CAO.

RH6f. There was a difference between the rural, suburban, or urban community college location and the local latent social role of the CAO. Rural was defined as not a MSA or PMSA and with a population of less than 500,000. Suburban and urban was defined as a MSA or PMSA, respectively, with a population equal to or greater than $500,000$.

NH6f. There was no difference between the rural, suburban, or urban college location and the local latent social role of the CAO.

RH6g. There was a difference between the number of locations for the community college and the cosmopolitan latent social role of the CAO. Location was defined as either a single location or multiple locations.

NH6g. There was no difference between the number of locations for the community college and the cosmopolitan latent social role of the CAO.

RH6h. There was a difference between the number of locations for the community college and the local latent social role of the CAO. Location was defined as either a single location or multiple locations.

NH6h. There was no difference between the number of locations for the community college and the local latent social role of the CAO.

RH6i. There was a difference between the population of the state where the community college was located and the cosmopolitan latent social role of the CAO. A 
state with a small population was defined as less than 5 million. A state with a large population was defined as greater than 5 million.

NH6i. There was no difference between the population of the state where the community college was located and the cosmopolitan latent social role of the CAO.

RH6j. There was a difference between the population of the state where the community college was located and the local latent social role of the CAO. A state with a small population was defined as less than 5 million. A state with a large population was defined as greater than 5 million.

NH6j. There was no difference between population of the state where the community college was located and the local latent social role of the CAO.

R7. Was there a difference between the public community college CAO's personal or demographic characteristics (age, birth month, gender, marital status, education, tenure in office, research and publication history) and the CAO's latent social role?

RH7a. There was a difference between the CAO age and the cosmopolitan latent social role of the CAO. CAO age was summarized for analysis into the following categories: under age 30, $30-39,40-49,50-59,60-69$, and over 70 .

NH7a. There was no difference between the CAO age and the cosmopolitan latent social role of the CAO.

RH7b. There was a difference between the CAO age and the local latent social role of the $\mathrm{CAO}$. CAO age was summarized for analysis into the following categories: under age 30, $30-39,40-49,50-59,60-69$, and over 70 . 
NH7b. There was no difference between the CAO age and the local latent social role of the CAO.

RH7c. There was a difference between the CAO's birth month and the cosmopolitan latent social role of the CAO. The survey data was summarized into two categories; CAOs born January - April, and May - December.

NH7c. There was no difference between the CAO's birth month and the cosmopolitan latent social role of the CAO.

RH7d. There was a difference between the CAO's birth month and the local latent social role of the CAO. The survey data was summarized into two categories; CAOs born January - April, and May - December.

NH7d. There was no difference between the CAO's birth month and the local latent social role of the $\mathrm{CAO}$.

RH7e. There was a difference between the CAO's gender and the cosmopolitan latent social role of the $\mathrm{CAO}$.

NH7e. There was no difference between the CAO's gender and the cosmopolitan latent social role of the $\mathrm{CAO}$.

RH7f. There was a difference between the CAO's gender and the local latent social role of the CAO.

NH7f. There was no difference between the CAO's gender and the local latent social role of the CAO.

RH7g. There was a difference between the CAO's marital status and the cosmopolitan latent social role of the CAO. Marital status was defined as single, married, divorced and widowed. 
NH7g. There was no difference between the CAO's marital status and the cosmopolitan latent social role of the CAO.

RH7h There was a difference between the CAO's marital status and the local latent social role of the CAO. Marital status was defined as single, married, divorced and widowed.

NH7h. There was no difference between the CAO's marital status and the local latent social role of the CAO.

RH7i. There was no difference between the CAO's highest level of education and the cosmopolitan latent social role of the CAO. The CAO's highest level of education was reported as $\mathrm{PhD}$, EdD or other.

NH7i. There was no difference between the CAO's highest level of education and the cosmopolitan latent social role of the CAO.

RH7j. There was a difference between the CAO's highest level of education and the local latent social role of the CAO. The CAO's highest level of education was reported as $\mathrm{PhD}$, EdD or other.

$\mathrm{NH7j}$. There was no difference between the CAO's highest level of education and the local latent social role of the CAO.

RH7k. There was a difference between the CAO's tenure in office and the cosmopolitan latent social role of the CAO. Tenure as a CAO was categorized as less than 5 years, or more than 5 years.

NH7k. There was no difference between the CAO's tenure in office and the cosmopolitan latent social role of the CAO. 
RH71. There was a difference between the CAO's tenure in office and the local latent social role of the $\mathrm{CAO}$. Tenure as a $\mathrm{CAO}$ was categorized as less than 5 years, or more than 5 years.

NH71. There was no difference between the CAO's tenure in office and the local latent social role of the CAO.

$\mathrm{RH} 7 \mathrm{~m}$. There was a difference between the CAO's publication history and the cosmopolitan latent social role of the CAO. The data was categorized as CAOs who had published 2006 - 2010, and prior to 2006.

$\mathrm{NH} 7 \mathrm{~m}$. There was no difference between the CAO's publication history and the cosmopolitan latent social role of the CAO.

RH7n. There was a difference between the CAO's publication history and the local latent social role of the CAO. The data was categorized as CAOs who had published 2006 - 2010, and prior to 2006.

NH7n. There was no difference between the CAO's publication history and the local latent social role of the CAO.

\section{Summary}

Identifying community college leaders is vital for the continued success of community colleges. This research was conducted to determine if there was a relationship between latent social roles and self identification and selection of community college leaders. Previous research on community college leaders has focused on the presidential role; the CAO manifest role has not been studied extensively. The researcher used quantitative research to study chief academic officers from public community colleges in the United States. 
Previous research on latent social roles has focused on development of the theory, as well as the application of the theory to different professional groups, including faculty, scientists and engineers. Research on management or administration of organizations has been limited to police chiefs and business managers; this study extends the research to community college administrators, specifically CAOs. 


\section{Chapter 2}

\section{Literature Review}

The purpose of this quantitative study was to determine if there was a relationship between Gouldner's $(1957,1958)$ theory of cosmopolitan and local latent social roles and the selection of the public community college chief academic officer, as well as the chief academic officer's subsequent job satisfaction, intent to turnover, and intent to pursue a community college presidency. Gouldner (1958) noted that it was "too easy to focus on more evident manifest identities and roles" (p. 258). The latent social roles of cosmopolitan and local are based on three key variables: (a) loyalty to the organization, (b) commitment to specialized or professional skills, and (c) reference group orientation.

This literature review explored three areas in considering the relationship between latent social roles and the community college chief academic officer. First, research appraising the community college environment and the reported community college leadership crisis was reviewed. Second, the existing research concerning the chief academic officer (CAO) position, reportedly a key training ground for future community college presidents is reviewed. The CAO position was examined in terms of demographics, career paths, latent social roles, job satisfaction, and intent to turnover. Finally, the literature on latent social roles, in terms of cosmopolitan and local latent social role orientations, was examined both in theory and in how the research has been applied to the study of different groups.

\section{Community Colleges}

Community College History. The first private two-year colleges were established in the 1800's, including Monticello College in 1835 and Susquehanna 
University in 1858 (Blocker, Plummer, \& Richardson, 1965). Joliet Junior College was the first public community college in the United States. Joliet was founded in 1901 by J. Stanley Brow, superintendent of Joliet Township High School, and William Rainey Harper. The term "junior college" was attributed to William Rainey Harper, who was the president of the University of Chicago. He was also generally credited with the spread of the concept of junior colleges. Joliet was an experiential postgraduate high school program and academically paralleled the first two years of a four-year institution for students who wanted to remain within their own community to pursue a college education (Joliet Junior College, 2009).

Tillery and Deegan (1985) referred to five generations of community colleges. The first generation was from 1900 - 1930 and was characterized as the extension of high school. There were 259 public community colleges at the end of this era (p. 8). The American Association of Junior Colleges (AAJC), or what became the American Association of Community Colleges (AACC), was formed in 1920 (p. 237). The second generation of community colleges, from $1930-1950$, was characterized as the junior college generation (p. 8). The number of community colleges (299) and enrollments grew, fueled by the Serviceman's Readjustment Act of 1944, better known as the GI Bill (Witt, Wattenbarger, Collattscheck, \& Suppiger, 1994). The third generation was from $1950-1970$ and was referred to as the community college generation (p. 12). Community colleges more than doubled in number, with 847 in 1970 (Cohen \& Brawer, 1996). This was fueled by several events, including the National Defense Education Act, the Higher Education Facilities Act, the Vocational Education Act of 1963 and the establishment of the League for Innovation in the Community College in 1968 (Witt et 
al., 1994). The fourth generation was from 1970 - 1985 and was called the comprehensive community college generation (p. 16). Community colleges entered a period of stability with 1,030 public community colleges in 1976 and 1,082 in 1994. Enrollments leveled off as well. Tillery and Deegan (1985) did not name the fifth generation (mid 1980s to mid 1990s) (p. 25).

Community College Demographics. The exact number of community colleges depends on the source used and the institutions included in the definition (public, private, two-year branch campuses, and special purpose). The American Association of Community Colleges (AACC), a nonprofit association of community colleges, reported member schools totaling 1,195 community colleges in the United States (AACC, 2008). Of these, 987 were public, 177 were independent, and 31 were tribal community colleges (p. 1). Every state in the United States has at least one community college (p. 1). Community colleges enrolled 6.5 million students (full and part-time) in credit programs in 2005 (AACC, 2008). This was $40 \%$ of the total number of undergraduates in the United States (p. 1). The average age of community college students was 29. Approximately $35 \%$ of community college students planned to relocate to a four-year school (p. 1). Community colleges played a key role in the education of students in the United States as half of all students graduating with a bachelor's degree went to a community college first (Shaffer, 2008).

Community colleges provided non credit courses for another 5 million students annually (AACC, 2008). This workforce development function has become an important service for the community and an important source of revenue for community colleges. 
The Carnegie basic classification scheme was followed in identifying and classifying community colleges in this research project. The Carnegie Foundation Associate's Colleges classification is based on a classification scheme developed by Katsinas, Lacey and Hardy at the University of Alabama. The classification scheme is based on five criteria: (a) rural, suburban, or urban serving colleges; (b) size, based on full unduplicated headcount; (c) single or multi-campus colleges; (d) special use colleges, and (e) other considerations, such as public universities under the control of a 4-year university or system. Rural serving institutions are not in a Primary Metropolitan Statistical Area (PMSA) or Metropolitan Statistical Area (MSA) according to the US Census and have fewer than 500,000 people (Carnegie Foundation, 2010). Suburban serving institutions are located in a MSA with a population exceeding 500,000 people (p.1). Urban serving institutions are located in a PMSA with a population exceeding 500,000 people (p. 1). Institutional size is based on unduplicated headcount reported in the Integrated Postsecondary Education Data System (IPEDS), where small is less than 2,500; medium is 2,500 through 7,500; and large is greater than 7,500 (p. 1). Single campus institutions have one primary campus under the institution's exclusive control and governance that provides all of the courses to complete the degree (p. 1). Multiple campus institutions have more than one primary physical campus or are part of a district or system comprising multiple institutions that are organized under one governance structure or body (p. 1). Special use colleges have a narrow curricular focus and are not part of a more comprehensive institution (p. 1).

Community College Leadership. Community college leadership usually consists of a president, chief academic officer (CAO), chief student affairs officer, and chief 
business officer (Amey et al., 2002). Robillard (2000) noted that university presidents and professors have been extensively studied but deans have not. The CAO administrative position may also be referred to as provost, vice president for academic affairs, vice president for instruction, dean of instruction, and/or academic dean (Vaughan, 1990). Five book length studies on the deanship were published: Morris (1981), Tucker and Bryan (1988), Vaughan (1990), Martin et al. (1997) and Buller (2007). Vaughan's (1990) book was the only one that specifically addressed community college leadership. Robillard (2000) noted that the community college CAO was responsible for a greater variety and perhaps volume of activities than deans, chief academic officers, provosts, or academic vice presidents at four-year colleges and universities (p. 4). The CAO position is not as visible as the presidential position but is vital to the efficient and effective operation of the community college today (Vaughan, 1990).

Community College Leadership Crisis. One of the pressing issues facing community colleges today is a potential leadership crisis. Many of the community college professional organizations have identified this emerging issue as the leadership gap created by the impending retirement of many community college campus presidents and administrative leaders (AACC, 2008). The research by Shults (2001), Kelly (2002), Piland and Wolf (2003), Romero (2004), Duree (2007), and Weisman and Vaughan (2007) all indicated that a large percentage of community college presidents will retire, and that the primary source of replacements will come from the CAO position.

In 1992, 12\% of community college presidents left office (Mooney, 1993, p. 3). Shults (2001) reported that $45 \%$ of presidents planned to retire by 2007 (p. 1). Shults's 
data were gathered from an online survey of community college CEO's conducted by the AACC in 2001. The AACC's unpublished survey on leadership was designed to examine community college leadership issues. Vaughan (2001) calculated that there would be 129 presidential vacancies at community colleges each year and that $30 \%$ of these would be filled by individuals moving from one presidency to another (p. 2). Vaughan (2001) was very pragmatic and noted that there has been a need for presidents since the early 1960's, and stated "there is and will be room at the top. Room at the top does not need to translate into a leadership vacuum at the top and certainly does not need to constitute a crisis" (p. 1). Kelly (2002) reported that $80 \%$ of community college presidents plan to retire by 2017 (p. 1). This information was based on a report issued by the American Association of Community Colleges. She also noted that fewer applications were received for community college presidential openings; applications were down to 50 from 100 applications ten years ago (p. 1). Kelly reported this data based on an interview with Jeff Hockaday, a consultant who assists institutions with leadership searches (p. 1). Duree (2007) completed a study of community college presidents $(\mathrm{N}=415)$, or $38 \%$ of twoyear college presidents, and found that $79 \%$ plan to retire by 2012 and $84 \%$ by 2016 (p. 63). Duree developed a 40-item web-based survey "The Community College Presidency Demographics and Leadership Preparation Survey"; this was designed to study areas of the community college presidency including outstanding traits, educational preparation, lifestyles, and career pathways (p. 51). Weisman and Vaughan (2007) reported that 84\% of presidents plan to retire within the next 10 years; this was an increase from those reporting plans to retire in 2001 (79\%) and in 1996 (68\%) (p. 6). The population for Vaughan's study was the presidents of public U.S. community colleges $(\mathrm{N}=545)$ listed 
in the AACC membership database (p. 2). The survey used was the Career and Lifestyle Survey; the survey was administered in 1984, 1991, 1996, 2001, and 2006 (p. 2). The survey was not a longitudinal study, but represented a snapshot in time of the community college presidency in general. More recent data from the American Council on Education (ACE) survey indicated that $49 \%$ of sitting presidents were 61 or older (ACE, 2007) (p. 1). The ACE study was conducted in 2006 and included information from 2,148 college and university presidents. This data represented information on presidents' education, career paths, length of service, as well as personal characteristics. The ACE study (2007) noted that $60 \%$ of current community college presidents were previously in another presidency $(26 \%)$ or were a CAO $(34 \%)(\mathrm{p} .1)$. The research also reported that retirement was on the minds of the presidents; $24 \%$ plan to retire in $1-3$ years; $32 \%$ within $4-6$ years, and $28 \%$ within $7-10$ years.

The research suggested that $84 \%$ of presidents plan to retire within the next 10 years, an increase from those reporting plans to retire in 2001 (79\%) and in 1996 (68\%) (ACE, 2007; Weisman \& Vaughan, 2007). There is a rising tide of community college administrators who plan to retire and the need for competent replacements. Piland and Wolf (2003) noted the lack of leadership development for future community college leaders and stated that "properly prepared leaders are one of the major problems - some would say the major problem - facing community colleges” (p. 98). Romero (2004) reinforced this issue and added that the senior administrators who provided a pool for presidency candidates were approximately the same age as the presidents who were preparing to retire. A large percentage, 50\%, of community college faculty also planned 
to retire. Romero's conclusions were based on studies by the AACC (2001) and Weisman and Vaughan (2002).

\section{The Chief Academic Officer}

Pathway to the Community College Presidency. Several studies reported that the chief academic officer (CAO) position is the primary pathway to the community college presidency (ACE, 2007; McKenney \& Cejda, 2000; Twombly, 1990; Vaughan, 1990). Between $27 \%$ and $50 \%$ of community college presidents have been CAOs (Twombly, 1990; Vaughan, 1990; McKenney \& Cejda, 2000; ACE, 2007) . Twombly (1990) noted that CAOs were often a good fit for the president's job because: (a) They were viewed as more effective in working with faculty, a key human resource; (b) The academic center of any higher education institution had the most influence over the organization and over searches for senior administrators; and, (c) A president's academic credentials gave him or her significant status within the community college and within the greater community (p. 10).

Community College Chief Academic Officer Demographics. One of the first studies of the community college CAO was Eells' (1931) report. He completed a textbook documenting the Junior College. Two chapters of that work focused on administrative functions. Eell's research was based on a survey of deans in $1929(\mathrm{~N}=95)$ (p. 368). The junior college administrative function of 1929 is not directly comparable to today as the reporting structure and titles differ considerably. The junior college chief administrative officer was referred to as the president (15\%), dean (61\%) and in the remaining cases referred to as the principal or director (p. 369). The chief administrative officer reported to the city superintendent or high school principal (p. 356). The title 
CAO was not used; typically there was a dean of men and a dean of women (p. 356). Eells reported that only a few of the institutions reported a separate dean of instruction (p. 379). The data reported were based on the chief administrative officer information. All but six of the deans were men (p. 369). Eells reported the dean's educational attainment as follows: $7 \%$ had a doctoral degree; $75 \%$ had a master's degree, and $18 \%$ had a bachelor's degree. Tenure in their current positions was an average of 4.5 years; three quarters indicated they planned to remain in their present work, $7 \%$ planned to transfer to college work, 2\% to research, and 5\% to public school superintendents (p. 370). Age and retirement plans were not reported.

Additional research conducted by Anderson (1973) investigated the characteristics, preparation, and attitudes of community college CAOs. National studies on community college CAO demographics were completed by Moore, Twombly, and Martorana (1985); Vaughan (1990); Hawthorne (1994); McKenney and Cejda (2000); Amey et al. (2002); and Keim and Murray (2008). This research is summarized in Table 1 and reported on in the following paragraphs.

Moore, Twombly and Martorana (1985) completed research on the educational and employment backgrounds, career goals and aspirations, career paths, and concerns of two-year college administrators. They studied eight administrative positions at 1,219 public and private two-year colleges $(\mathrm{N}=2049)$ using a standardized 31 item questionnaire. Included in this sample were CAO's $(\mathrm{N}=271)$. They noted five trends: (a) an increasing percentage of two-year college presidents hold doctorates; (b) an increasing percentage of presidents hold degrees in education; (c) a trend toward the 
Table 1

\section{National Research on CAO Demographics}

\begin{tabular}{|c|c|c|c|c|c|c|}
\hline Demographic & $\begin{array}{c}\text { Moore, Twombly, } \\
\text { \& Martorana } \\
(1985) \\
\text { N-271 }\end{array}$ & $\begin{array}{c}\text { Vaughan (1990) } \\
\quad \mathrm{N}=619\end{array}$ & $\begin{array}{l}\text { Hawthorne } \\
\begin{array}{c}(1994) \\
\mathrm{N}=712\end{array}\end{array}$ & $\begin{array}{c}\text { McKenney \& } \\
\text { Cejda (2000) } \\
\mathrm{N}=369\end{array}$ & $\begin{array}{c}\text { Amey, } \\
\text { VanDerLinden, \& } \\
\text { Brown (2002) } \\
\mathrm{N}=918\end{array}$ & $\begin{array}{c}\text { Keim \& Murray } \\
(2008) \\
N=300\end{array}$ \\
\hline Average Age & 49 years & 48 years & 50 years & 52 years & 54 years & N/A \\
\hline \multicolumn{7}{|l|}{ Gender } \\
\hline Male & $84 \%$ & $79 \%$ & $74 \%$ & $61 \%$ & $58 \%$ & $56 \%$ \\
\hline Female & $16 \%$ & $21 \%$ & $26 \%$ & $39 \%$ & $42 \%$ & $44 \%$ \\
\hline Married & $89 \%$ & $87 \%$ & N/A & $81 \%$ & N/A & N/A \\
\hline Average Tenure & 6.2 years & 5.4 years & 6.1 years & 6 years & N/A & N/A \\
\hline Doctorate Total & $74 \%{ }^{1}$ & $70 \%$ & $67 \%$ & $76 \%$ & $74 \%$ & $70 \%{ }^{1}$ \\
\hline Ph.D. & $49 \%$ & $33 \%$ & $34 \%$ & $41 \%$ & $40 \%$ & $59 \%$ \\
\hline Ed.D. & $40 \%$ & $36 \%$ & $33 \%$ & $35 \%$ & $34 \%$ & $39 \%$ \\
\hline Other & $11 \%$ & & & & & \\
\hline $\begin{array}{l}\text { Research } \\
\text { Performed in the } \\
\text { last } 5 \text { years }\end{array}$ & $30 \%$ & $38 \%$ & $68 \%$ & N/A & N/A & N/A \\
\hline
\end{tabular}

${ }^{1}$ The percentage reported with a doctorate was then reported within that total by degree. 
appointment of older presidents; (d) the decreasing tenure of two-year college presidents; and, (e) a trend toward appointing presidents from within the two-year college market (p. 1). They reported that the average age of CAOs was $49.1 ; 84.1 \%$ were male and $15.9 \%$ were female (p. 9). CAOs surveyed indicated their race/nationality as follows: $86.2 \%$ were white, $2.6 \%$ were black, .7\% were Hispanic, $1.1 \%$ were Native American; . $4 \%$ were Asian, and $.4 \%$ were other (p. 9). Most of the CAOs were married (88.6\%) and their spouse's occupation was a homemaker $(26.9 \%)$, an educator $(27.3 \%)$ or a manager (7.9\%) (p. 9). The CAO's father most frequently had a managerial background (24.9\%) or a blue collar background (27.9\%) and may not have finished high school, as $21 \%$ reported their father held a high school diploma, with another $15 \%$ holding advanced degrees beyond high school (p. 9). The CAO's mother was often a homemaker $(64.2 \%)$ and had a higher rate of high school completion (34.5\%) and post secondary education (21\%) than the CAO's father (p. 9). They reported that the educational background of CAO's was generally a doctoral degree (73.8\%), with the $\mathrm{PhD}(48.5 \%)$ more common than the EdD (40.3\%) (p. 13). The primary field for the doctoral degree was higher education (34.5\%), education (32.1\%); other professional fields (3.0\%) and other $(33.5 \%)$ (p. 13). Mean tenure in office was 6.2 years, with $57 \%$ serving less than five years (p. 19). Faculty rank was held by $25 \%$ of CAOs; the research suggested that this might be unusually low and may be explained by the fact that administrators were not eligible for rank at their institution (p. 22). Regardless, $29.9 \%$ of CAOs taught at their own campus or another institution (p. 22).

Vaughan's (1990) study used the Career and Lifestyles Survey (CLS) to survey public community college CAOs $(\mathrm{N}=619)$. The researcher reported that the majority of 
CAOs came from families with a working class background (77\%) and they may have been the first to graduate from college in their family (p. 21). He reported on CAO mobility, and noted that $50 \%$ of CAOs work in the same state where they finished high school (p. 28). The average tenure of CAOs was 5.4 years (p. 28). Of the CAOs surveyed, $70 \%$ held a doctorate, $33 \%$ held a $\mathrm{PhD}$, and 36\% held an EdD (p. 29). Vaughan (1990) reported on membership in professional associations and found that $80 \%$ of the CAOs belonged to one or more professional organizations, including $34 \%$ that were members of the American Association of Higher Education (AAHE), and 28\% to Phi Delta Kappa (PDK) (p. 30). The researcher noted with surprise "deans (19\%) who listed no professional memberships would seem to be high for members of a profession that depended upon the distribution, interpretation, and advancement of knowledge-key roles played by professional organizations" (p. 30). The researcher indicated that CAOs work 51 hours per week and rarely used all of their vacation time (p. 32). CAOs used the president or another dean on campus as an on the job confidant (p. 32). He reported that $49 \%$ of CAOs have completed research in the last five years and $38 \%$ have published in the last five years (p. 31). Overall, the author reported that community college CAOs were a mirror image of the presidents that they will likely succeed, as at the time of the study, one out every two CAOs were likely to become a community college president (p. 41).

Hawthorne (1994) completed a study of CAO s $(\mathrm{N}=712)$ at 1,243 public and private community colleges. Hawthorne (1994) reported on the average age (50.3 years), gender (74\% male, $26 \%$ female), degree attainment (30\% master's degree, $34 \% \mathrm{PhD}$ and $33 \%$ EdD), tenure in office (average 6.1 years), discipline (humanities - 21\%, social 
sciences $-20 \%$, and physical/natural sciences/math - 23\%, with their most recent degree in education for $53 \%$ of respondents), and community college teaching experience (8.8 years) (pp. 272-274). She noted that the large percentage of CAOs (67\%) who held a doctoral degree pointed to the increasing professionalization of community college educators (p. 274). The researcher further examined the professional intentions of CAOs by asking questions about their presentations and publications. Sixty-eight percent of the CAOs reported having made a presentation or having been published in the last five years (p. 275).

McKenney and Cejda (2000) completed a national study of CAOs ( $\mathrm{N}=369)$ to discover: (a) the differences or changes between the profile of CAOs at public community colleges compared with previous findings; (b) differences or changes in the representation of women serving as CAOs at public community colleges compared with previous findings; and, (c) differences or changes in the representation of members of minority groups serving as CAOs at public community colleges compared with previous findings. Their findings revealed the average age of CAOs was 52 years and female CAOs represented $39 \%$ of all community college CAO's, an increase of $13 \%$ from what was reported in Hawthorne's study (p. 749). They reported that $81 \%$ of CAOs were married (p. 750). Professional characteristics studied included that $41 \%$ of CAOs had attained the $\mathrm{PhD}$ and $35 \%$ the $\mathrm{EdD}$ (p. 750). The average tenure of CAOs was 6 years (p. 751).

Shults (2001) found that the average age of presidents was 56 and CAOs was 54 (p. 1). Details of the study were provided on page 31 in this chapter. Anderson, Murray and Olivarez (2002) gathered demographic statistics that supported the conclusion that 
community college CAOs will be retiring in large numbers in the next 10 years. The researchers used a managerial role survey $(\mathrm{N}=184)$ of randomly selected CAOs at nationally accredited community colleges. The researchers reported the average age of the $\mathrm{CAO}$ was 52 , and the median was 53 and modal age was 55 (p. 4).

Amey et al. (2002) conducted a national study of community college administrators $(\mathrm{N}=918)$ using a 34-item questionnaire that was adapted from the 1984 Moore et al. study. They found that women represented $42 \%$ of CAOs, compared to $15.9 \%$ in the 1984 study by Moore et al. The racial and ethnic diversity of CAOs remained essentially the same between the two studies (p. 578). The mean age of CAOs had increased to 54 years from 49.1 years in 1985 (p. 579). The researchers indicated this may be due to women who entered the workforce later and progressed at a slower pace. This may also be reflective of presidents pursuing multiple presidencies and as a result slowing or blocking CAO advancement (p. 579). A doctorate was held by $74 \%$ of the CAOs, and this was consistent with the 1985 research (p. 579). Interestingly, the percent of CAOs with doctorates that hold the PhD dropped to 40\% in 2000 from $49 \%$ in 1985 (p. 579).

Keim and Murray (2008) surveyed public community college CAOs $(\mathrm{N}=300)$ selected from the American Association of Community Colleges (AACC) membership directory. The researchers did not use a survey, but gathered information regarding each community college's CAO via the institutional web site, and telephone and e-mail inquiries. This study reported an increase in the percentage of female CAO's (44\%) (p. 6). The study found that $70 \%$ of the CAO's had an earned doctorate ( $\mathrm{PhD}$ or EdD) (p. 6). This was a decrease from 74\% in 1985 (Moore et al., 1985) and 76\% in 2000 (McKenney 
$\&$ Cejda, 2000). The researchers noted a possible reason for this was the difficulty of finding qualified CAOs with earned doctorates, as well as citing complaints of failed searches and shallow candidate pools (p. 6). The number of doctoral degrees awarded in community college leadership had declined 78\% from 1982 to 1997 (Kelly, 2002, as quoted on $\mathrm{p}$. 7). The doctoral degrees earned by CAO's were still primarily in education $(66 \%)$ with other popular disciplines being literature, chemistry, psychology, sociology, and history (p. 7). The PhD was the most common doctorate, with $59 \%$ of the CAO's surveyed holding this degree, followed by the EdD with $39 \%$ of CAO's earning this degree (p. 7). The percentage of CAOs holding the EdD rather than a PhD had held steady at between 33 and 36\% over the last 15 years (Hawthorne, 1994; McKenney \& Cejda, 2000; Vaughan, 1990). The CAOs in the sample study who had earned their doctorate prior to 1990 was 70\% (p. 7). Keim and Murray’s (2008) research indicated that many CAOs were approaching retirement and that "turnover rates may be much greater in the coming years than in previous decades" (p. 8). The CAOs surveyed had earned their doctorates at over 100 different universities. The authors concluded from this information that an earned doctorate was more important than where the doctorate was earned (p. 8).

Summary Chief Academic Officer Demographics. The research on CAO demographics over the last 20 years has shown that CAOs have gradually increased in age (from an average of 48 years to an average of 54 years), have served an average tenure of 5 to 6 years; were likely to have been on the job 5 years or less; were increasingly likely to be female (from $16 \%$ to $44 \%$ ), and were less likely to be married. Several possible explanations for the increasing age and changes in job tenure exist: 
(a) The increasing age of CAOs has been attributed to more females entering the CAO pipeline later in life than their male counterparts (Amey et al., 2002, p. 579); (b) Female CAOs may have started their academic career later in life or stopped out of their academic career to take care of family (Amey et al., 2002, p. 579); (c) The increasing age and tenure of CAOs may reflect their inability to move on to the community college presidency, as the careers of current community college presidents extend when they serve as president at two, three, four, or even five community colleges (Amey, VanDerLinden \& Brown, 2002, p. 579); (d) Another possible explanation for the increasing age and tenure of community college CAO was that they were happy with their positions and do not intend to pursue a community college presidency (McKenney \& Cejda, 2000, p. 751); and, (e) The retirement of CAOs and the fluidity of the community college CAO job market were creating a decreasing supply of qualified candidates and an increasing demand (Keim \& Murray, 2008, p. 6). This may explain the shorter tenure and decreasing number of CAOs with PhDs.

The research on community college CAO education attainment reported relatively high but fluctuating levels of educational attainment over the last 25 years. The percentage of CAOs with an earned doctorate has fluctuated up and down (from 67 to $76 \%$ ) instead of consistently increasing. This could be a reflection of the high demand for CAOs and the willingness of community colleges to accept candidates without a doctorate when fewer candidates were available (Keim \& Murray, 2008, p. 6). This was also supported by the decreasing number of doctorates awarded in higher education as this was a field of study that many community college administrators pursued. The 
research also indicated greater $\mathrm{CAO}$ professionalization with increasing amounts of published research on topics of interest, such as student learning (p. 274).

Chief Academic Officer Career Paths. Colleges and universities are higher education professional organizations with goals of teaching, research and service carried out by the faculty (Twombly, 1986). Administrators perform support activities for the organization (p. 21). Higher education institutions are often flat organizations with few clearly defined steps to the presidency (p. 21). Mobility in higher education is accomplished by increased responsibilities, changes in title to reflect increased responsibilities, and by leaving an institution for a higher position with another institution, or a lower position at a higher status institution (p. 22). Job change rates declined with the increasing age of academics, and institutional size and resources may be a barrier to mobility (p. 23).

The typical CAO career path was suggested by Cohen and March (1974) to be through a series of positions, including faculty member, department chair, academic dean, and CAO. The career path for public community college CAOs was not always this clear cut. When the community college movement was at its peak in the 1960s, administrators were pulled from many areas, including public school administration (Vaughan, 1990). Community colleges have matured in many ways over the last 50 years; in age, in organization structure, and in the development of more defined careers for administrators.

Carroll (1991) investigated the normative career line of academic administrators by studying department chairs' career movements and those of their predecessors. Carroll surveyed department chairs $(\mathrm{N}=808)$ of 101 higher education institutions. He noted that 
the career path of faculty, department chair, dean, provost and presidency was thought to be normative (p. 670). However, Moore (1983) reported that $76 \%$ of presidents $(\mathrm{N}=310)$ had never been department chairs. This was part of the Leaders in Transition project; the project was designed to provide a more systematic analysis of higher education administrative careers. Several researchers have researched community college CAO career lines or career paths including Moore et al. (1985), Moore and Twombly (1985), Twombly (1986, 1987, 1988), Vaughan (1990), McKenney and Cejda (2000), Cejda, McKenney, and Burley (2001), Cejda, McKenney, and Fuller (2001), and Amey et al. (2002).

Moore et al. (1985) reported on the professional background of community college CAOs $(\mathrm{N}=271)$ and indicated that the mean number of academic positions held by CAOs was 6.4 positions. CAOs serving as the initial CAO for their institution represented $22 \%$ of the population (p. 18). CAOs reported 89 different previous positions (also referred to as "first previous"), the most common being CAO (18.7\%), department chairperson (11.9\%) and faculty member (8.6\%) (p. 27). The CAO's first previous position was often at their current institutions (52.4\%) (p. 30). CAOs often made lateral moves from one $\mathrm{CAO}$ position to another $\mathrm{CAO}$ position at another institution $(18.7 \%)$ (p. 30). External professional activities were analyzed, and many CAOs had participated in activities that were important to their careers, including serving as external consultants (34.8\%); participating in a fellowship or internship (24.5\%); serving on the board of directors for a professional organization (42.7\%) and publishing books, articles or technical materials (30.3\%) (p. 32). CAOs participated in an average of four internal professional activities that they deemed to be important, including formal written 
performance reviews, in-service staff development, special institutional task forces, and additional responsibilities over and above the job description (p. 36). Community activities were important for community colleges; CAOs were most likely to be involved in (in order of participation): local schools; civic and fraternal organizations; economic development and business; church and religious activities and philanthropic/cultural events (p. 39). The authors noted that CAOs were less likely to participate in philanthropic/cultural events than presidents (p. 40). CAOs reported having at least one mentor $(55.6 \%)$ who was most often another administrator; this mentoring relationship lasted an average 8.5 years (p. 45).

Career Paths - Administrator Mobility. Moore and Twombly (1985) studied administrator mobility, and particularly administrators who crossed the boundary from two-year to four-year colleges and universities $(\mathrm{N}=170)$. Caplow and McGee (1958) coined the higher education prestige system of the major league (research universities), minor league (comprehensive colleges and universities), the bush league (liberal arts colleges) and academic Siberia (two-year colleges). They argued that most faculty were trained in the major league but were hired by the minor league and bush league (p. 8). Thus, most faculty moves were downward. Research on faculty moves has been limited as it was thought that there was not much movement between institution types. The movement between institution types was termed "crossover." Moore and Twombly (1985) quoted a study by Birnbaum (1971) "Exchange value equals prestige of the institution multiplied by the status of the position" (p. 6). Exchange theory would allow a faculty member who wanted to be an administrator to trade down in the leagues for a more prestigious job title. Moore and Twombly's (1985) research purpose was to 
discover what characteristics, if any, differentiated administrators with two-year college experience from those who do not have experience (p. 4). The researchers studied the professional backgrounds of two-year crossovers and noted that certain positions (head librarian, registrar, and student affairs administrator) and types of institutions (liberal arts) were more open to crossing institution boundaries (p. 8). They noted that the twoyear crossover administrators identified had attained a higher educational and degree level; had earned degrees at major doctoral universities, and a high percentage had earned doctorates in education, most notably, higher education administration (p. 9). The researchers concluded that administrators were not generally mobile across institution type boundaries (p. 19). A large percentage of administrators, 60.2\%, did not change institution type for their entire careers, although they did change jobs and institutions within their home institution type an average of six times (p. 18). The researchers argued that "homogeneity of mission and function may be more compelling as an explanation than any notion of prestige" as an explanation why individuals did not cross institutional boundaries (p. 22).

\section{Career Paths - Community College Labor Markets. Twombly’s (1986)} research regarding administrative career paths concluded that community colleges were primarily an occupational internal labor market (OILM). According to the researcher, if an OILM exists within community colleges, the OILM would have these features: (a) employees would begin in lower level positions, termed entry ports; (b) job ladders or career lines would develop to minimize the cost of training employees; and, (c) mobility or movement up the career line would be based on development of skill or knowledge ( $\mathrm{p}$. 20). She extensively reviewed labor market segmentation and the internal labor market 
theory, including firm internal labor markets (FILMS) and occupational internal labor markets (OILMS) (p. 15). She summarized theoretical approaches to career lines as those that: (a) focused on the individual and individual career plan (supply side of the labor market); or, (b) were concerned with organizational careers or careers as structures of organizations (demand side of the labor market) (p. 5).

Career Paths - Career Lines and Entry Ports. Twombly (1986) researched the career history of two-year college administrators to address the following components of internal labor markets: (a) To what extent were administrators selected from within the postsecondary labor market rather than external markets?; (b) What career lines were identified?; (c) What were the entry ports?; and, (d) What level of education and additional degrees were obtained by administrators? CAO data $(\mathrm{N}=271)$ from the Today's Academic Leaders: A National Study of Administrators in Community and Junior Colleges study was used. Career lines were traced using an extensive questionnaire that asked participants to list up to 10 previously held professional positions, institutions of employment, and years of employment (p. 28). She found that the ordering of positions through which individuals moved was important, and that relatively few long career lines existed (p. 31). Two-year college presidents came from only two previous positions - a top executive or CAO position (p. 32). CAOs were likely to move to their current position from one of five previous positions but with little commonality in their earlier positions (p. 32). She noted that a large proportion of each administrative group came to their current position from a position of similar title (p. 33). Rank or level of earlier positions was more important than specific positions held (p. 34). There was a predominance of administrative positions in all career lines (p. 34). Faculty 
positions did not appear prominent in the immediate previous positions, but were prominent at earlier points in careers (p. 34). The researcher noted that a doctorate was not a requirement for entry into the career lines leading to the CAO position, but the doctorate appeared to be a requirement for acquiring a presidency (p. 38). She reported that three quarters of all CAOs in this study held doctorates and one fourth of the CAOs were working on a doctorate (p. 38).

Twombly (1987) continued to research the importance of the types of entry positions through which two-year college presidents began their college work careers and the rate they subsequently obtained the presidency. The researcher collected data in a national study of two-year college administrators; the focus of this research was first time two-year college presidents $(\mathrm{N}=155)$. This analysis identified two types of entry positions: administrative and faculty (p. 17). Other factors studied included the relationship of age, level of education at entry, and number of positions between entry and the presidency. The number of positions explained the greatest amount of variance of the four factors (20\%); age accounted for $16 \%$ of the variance; and entry position only explained 5.8\% of the variance (p.18). The level of education and interaction of the variables did not explain a significant amount of the variance; only $50 \%$ of those surveyed earned their doctorates prior to beginning their college careers, even though $80 \%$ of two-year college presidents held doctorates (p. 19). She noted that the number of positions held emerged as the most important factor was not surprising, as some of the respondents moved directly into a presidency (p. 18). Further, those that began in administrative positions in two-year colleges held fewer positions and reached the presidency faster than younger individuals who started in a faculty position and worked 
their way through the organization (p. 20). Finally, regardless of whether individuals began as administrators or faculty members they both arrived at presidencies at approximately the same age (p. 20).

Twombly (1988) continued to study career lines and internal labor markets of two-year colleges from the demand side of the labor market. "Careers serve as streams on which personnel flow through the organization from positions of low prestige to positions of high prestige" (p. 10). Career lines were defined "as sequences of related positions that are common to a portion of the labor force and for which there is a high probability of movement from one position to another" (p. 672). CAO data $(\mathrm{N}=268)$ from the Today's Academic Leaders: A National Study of Administrators in Community and Junior Colleges study was used, along with data on community college presidents and chief business officers. The survey respondents were asked to list up to 10 professional full and part-time positions they had held. Higher Education General Information Survey (HEGIS) administrative codes were used to identify and classify each administrative type. There are two strategies for analyzing career lines: from entry point forward and from the current position back. Twombly (1988) used the second strategy and reported that the careers of two-year college administrators were not highly structured and identified career lines that were relatively short (p. 682). The only exception was the path to the presidency where $61 \%$ came from only two sources: other top executive leadership positions, and from the CAO position (p. 683). She suggested that "presidents from academic backgrounds may serve as symbols of academic credibility to trustees, funding agencies, faculties, and other segments of postsecondary education” (p. 683). There appeared to be a high rate of lateral movement among administrative positions (president, 
CAO, chief student affairs officer, and chief business officer) to other institutions, particularly larger institutions (p. 684). The author noted that this supports a definition of career lines that does not assume a hierarchy of positions, and career line analysis should not end with the first presidency achieved (p. 684). Faculty positions were the most frequent and prominent type of entry position; $42.3 \%$ of respondents who were CAOs began their careers as faculty members (p. 678). Similar to presidents, $20 \%$ of CAOs were most likely to have previously been CAOs in the previous position (p. 677). Administrative positions such as dean or department head occurred most frequently after that (p. 677). The researcher noted that four-year institution positions and positions outside of the academy were an important source of current top-level administration. Faculty from four-year institutions may be seeking two-year college administrative positions to gain administrative experience: $40 \%$ of community college CAOs had held at least one position at a four-year institution (p. 679). She concluded this study by noting that the two-year college administrative labor market was not the traditional OILM, as there were not highly structured career lines or low-level, fixed entry positions (p. 685). However, the author believed that a two-year labor market did exist and labeled the market a "portfolio model of careers" (p. 685). The portfolio model placed more importance on the types of experiences and the positions held rather than the order in which they were held (p. 685).

Vaughan (1990) surveyed community college leaders to review the pathway to the deanship. He reported that one of every two CAOs would likely become a community college president (p. 41). His research on community college presidents $(\mathrm{N}=590)$ indicated that over $50 \%$ had been CAOs immediately prior to assuming their first 
presidency (p. 42). CAOs immediate past position had been the division chair (29\%), associate or assistant dean (11\%), faculty member (12\%) and various other administrative positions (p. 42). The researcher reported that the traditional route to the CAO position (faculty, division chair or assistant CAO, CAO) was followed by $40 \%$ of the CAOs surveyed (p. 42). He noted that "the roadway that deans of instruction travel is relatively broad but becomes a narrow pathway once one assumes the deanship and aspires to the presidency" (p. 43). The researcher further noted that the CAO was often the "more equal" administrator among senior staff, and was often in charge when the president was off campus (p. 43). Vaughan (1990) noted that $6 \%$ of CAOs came from positions at fouryear institutions (p. 45).

McKenney and Cejda's (2000) research looked at community college CAOs previous work and administrative experiences. A survey was used to collect data from public community college CAOs $(\mathrm{N}=369)$. The majority of respondents indicated that they became administrators in their third previous position. The terms of mode of movement (internal, within state, out of state) was reported by McKenney and Cejda (2000) to be similar to Vaughan (1990). The percentage of respondents who moved out of state to secure a CAO position was $26 \%$ for women and $22 \%$ for men (p. 753 ).

Cejda, McKenney, and Burley (2001) studied the career lines of CAOs in public community colleges. As noted previously, studies of administrative careers can look at individual or structural perspectives. Most of the studies have been individually focused and studied demographics and background characteristics. The structural perspective focuses on organizational careers along career lines, career paths, or career ladders. Cejda, McKenney, and Burley (2001) emphasized career lines and used labor market 
theory in their examination of community college CAO careers. They noted that two-year institutions have become their own labor pool, or occupational internal labor market (OILM), of potential candidates for administrative positions (p. 32). Over time, the positions that lead to the top of the organization became institutionalized in an internal labor market. They used a survey instrument to gather data including institutional type, mode of movement, number of years in the position, type of contract, and title for up to five positions prior to serving as community college CAO $(\mathrm{N}=368)$. The researchers classified the information gathered regarding previous positions according to the Higher Education General Information Survey (HEGIS) classifications (p. 35). The researchers noted that $\mathrm{CAO}$ career lines have become more institutionalized, as they identified six different three position career lines as opposed to only one three position career line identified by Twombly in 1988 (p. 38). The researchers noted two common characteristics shared by a majority of CAOs. The first was a history of community college employment (p. 42). Prior to becoming CAO, 64.9\% had held one of four positions at a community college, working an average of 11.9 years in the community college sector (p. 42). The second characteristic was the number of internal candidates moving to the $\mathrm{CAO}$ position in their institution; $59 \%$ were internal candidates and $8 \%$ had moved within a system or district (p. 42). The most common entry point was faculty (51.1\%) (p. 39). CAOs had held an average of three community college positions (p. 42). They did not identify a normative career line, but suggested this was an internal labor market, supporting this with two survey results; 1) $77 \%$ of the CAOs immediate previous position was administrative, and 2) only $7.6 \%$ of the CAOs entered that role from outside the community college system (p. 41). 
Cejda, McKenney and Fuller (2001) researched why CAOs left office. The researchers outlined two methods for examining careers.

One is to start with a critical position in the organization and trace individuals careers backward from that position. This approach is the most common in career studies of higher education administrators, as evidenced by the overwhelming number focusing on the presidency. The second method is to trace individual's careers forward from the entry point. (p. 144)

They noted that many studies had studied career paths of CAOs and presidents but found only four studies that asked the question: Where did they go? The researchers' purpose was to study where CAOs went after leaving their position. This survey was conducted in 1998-1999 from a sample of two-year public comprehensive community colleges CAOs $(\mathrm{N}=628)$ from the AACC membership list. The researchers reported that $30 \%$ of CAOs had moved on to the presidency, as compared to Vaughan (1990) who cited 50\%, Twombly (1988) who cited 27\%, and Ross and Green (1988), who cited 33\% (p. 142). A large percentage, 28\%, of CAOs had changed jobs but remained in higher education administration as a vice president (11\%), other administrative position (9\%), or CAO at a different institution (8\%) (p. 143). This was consistent with McKenney and Cejda's (2000) study of current CAOs who indicated that $30 \%$ of CAOs had made lateral career moves (p. 143). They suggested that lateral moves may provide greater status through additional responsibilities, institution size, etc. (p. 143). CAO advancement to the community college presidency may be slowed by community college presidents who serve multiple terms was also noted as an explanation. Other studies have suggested that “many perceive the CAO as the so called 'better' academic job because the president engages mostly in fundraising, public relations, and student recruitment” (p. 143). Only $7 \%$ of CAOs had returned to faculty positions (p. 143). The researchers noted that the 
CAO position was no longer a short term duty of faculty, to be endured temporarily before returning to the faculty ranks, but was a career path (p. 138).

Amey et al. (2002) examined the assumption that changes in community college organization, mission, and function could shift internal labor market forces. This would provide leadership opportunities for administrators in tangential community college units. They used a national survey of community college administrators $(\mathrm{N}=918)$ with data from the AACC designed to replicate, in part, a survey completed by Moore et al. (1985) (p. 575). Amey and VanDerLinden (2002) also presented the results of this study as an AACC Research Brief. This study examined the career trajectories of administrators at community colleges to determine if the leadership succession patterns to the leadership roles were remaining traditional in light of the additional complexity of the community college organization and the increasing turnover of community college faculty, staff and administrative work force. A majority of the CAOs (52\%) were promoted from within their current institution; 28\% were hired from another community college (p. 579). Slightly more than half of the CAOs had been at their current institution for 10 years or more in some capacity; $40 \%$ of the remaining half had been at their current institution less than five years (p. 579). As for the CAO position, $74 \%$ had held this position for less than 5 years, and 54\% less than three years (p. 579). The immediate past position for CAOs had been held for an average of 4 to 5 years or less (p. 579). The traditional academic administrative positions such as associate or assistant CAO, dean, and department chair represented $51 \%$ of the immediate past positions, as compared to $65 \%$ in the Moore et al. (1985) study (p. 579). These positions included associate, assistant, or interim CAO (8\%); assistant, associate, academic dean or dean of instruction (31\%) or 
department chair (4\%) (p. 579). Career paths for CAOs were more diverse than in 1985. This study reported $28 \%$ had achieved the CAO position from areas other than academic, as compared to $12 \%$ in the 1985 study (p. 579). These other areas included dean, assistant dean, or director of: (a) continuing/vocational education (10\%), (b) student affairs or institutional planning or development (18\%) (p. 579). The researcher's findings documented evolving career paths to the community college $\mathrm{CAO}$ position, including prior presidential experience, more movement between four-year and two-year colleges, and a dominant internal labor market for leader succession in community college administrative positions, except for the president and CAO positions, whose pathways indicated a mixed internal/external labor market (p. 585). The researchers found that one third of community college presidents had worked in the four-year institution sector and then switched to the community college sector somewhere in their career; this was a slightly higher percentage than reported in Moore et al. (1985) study (p. 577). The researchers noted that the trend of community college presidents who had completed two, three and four presidencies highlighted a trend for search committees and governing boards to hire presidents with previous experience (p. 578).

Career Paths to the Presidency. Birnbaum and Umbach (2001) researched career paths leading to the presidency. The study used data collected by the American Council on Education (ACE) in 1986, 1990, and 1995 ( $\mathrm{N}=2,297)$. This study did not specifically address the community college presidency, but did provide a framework to study presidential career paths. They collapsed eight career trajectories into four career paths within two major trajectories: (a) Traditional - Scholar, (b) Steward, (c) Nontraditional - Spanner (covers five paths), and (d) Stranger. Scholar presidents 
(66.3\%) had full-time teaching experience and their previous two positions were in higher education (p. 207). Steward presidents had never taught, but their two previous positions were in higher education (p. 205). Stewards (20\%) became presidents after an administrative career (p. 207). They reported that $89 \%$ of all presidents followed one of these two traditional academic career paths (p. 206). The nontraditional career paths included Spanners (7.4\% of presidents surveyed), who had been in higher education and had been outside of the academy at some recent point prior to assuming the presidency (p. 207). Strangers (3.9\%) were presidents who had never taught and whose two previous positions were outside of higher education (p. 206). Strangers were more often presidents of specialized institutions (46.7\%) such as schools of medicine, law, or art and design (p. 208).

Garza Mitchell and Eddy (2008) conducted qualitative research via semistructured interviews $(\mathrm{N}=9)$ at a rural community college to examine the career trajectories of midlevel community college administrators. Several themes emerged from the interviews: (a) midlevel administrators were still active in the classroom; (b) administrative positions were obtained more by accident or another's request, than by initiation; and (c) there was no formal structure in place to mentor leaders. The authors noted

institutions need to rethink what it means to be a senior level administrator and redesign positions that may prove to be attractive to those currently in the middle. The ability to link to students, to allow for job-sharing, and to obtain life-balance may ultimately create a larger pipeline to the top. (p. 809).

The career path to administrative careers in community colleges was identified as an OILM without a clear hierarchy of positions to reach the top administrative positions of $\mathrm{CAO}$ and president. Changes in the $\mathrm{CAO}$ career path have been occurring in the last 
20 years as the $\mathrm{CAO}$ position has become more professionalized and CAOs have sought jobs at multiple institutions to advance their careers. The motivation for the community college CAO to seek another administrative position, either as a CAO at another institution or to seek a community college presidency, is examined next.

Chief Academic Officer Job Satisfaction. Research on CAOs has revealed the importance of job satisfaction and its connection to turnover. This also has implications for CAO mobility between institutions. Community college CAO job satisfaction has been studied by Moore et al. (1985) and by Murray et al. (2000).

Moore et al. (1985) looked at job satisfaction indirectly as part of their review of career mobility issues. CAOs $(\mathrm{N}=271)$ reported that they became a candidate for their current job via direct application (46.9\%) or appointment $(22.3 \%)$ (p. 50). CAOs ranked the duties/responsibilities of the position as the most attractive reason for seeking a CAO position (p. 57). The lack of other opportunities and the financial costs of moving were important factors in a CAO's decision to remain at their present institution (p. 64). CAOs reported that they were actively seeking or considering a job change $(40.5 \%)$ with the primary consideration being a new position at a higher level in the current area $(47.3 \%)$; the authors note that this was "undoubtedly referring to a presidency" (p. 68). They concluded that "two year colleges are generally able to supply campus executives and CAOs from within their own labor market" (p. 130). They pointed to a career ladder where the president's successor came from within the two-year institution labor market from such positions as campus executive, CAO, or chief student affairs officer (p. 23).

Murray et al. (2000) researched community college CAOs levels of job satisfaction, explored their plans for leaving their present positions, and explained their 
perceptions of the roles they fulfilled at their institutions. The survey instruments were sent to randomly selected community college CAOs $(\mathrm{N}=120)$ from a list provided by the AACC (p. 2). Important results of this research included the findings that responding CAOs had a high level of satisfaction and a low propensity to leave their institutions (p. 3). However, $37.7 \%$ of CAOs indicated they would likely leave within three to five years to seek a new position (p. 3). They suggested that this may be due to CAOs understanding that the opportunity to seek the presidency at their own institution was not likely due to an entrenched president or a history at their institution of selection of succeeding presidents from outside the organization (p. 3). The study of CAO career aspirations indicated that $34.2 \%$ were interested in the presidency of their own institution and an additional $28.2 \%$ were interested in the presidency at another college (p. 3). Another important finding by Murray et al. (2000) was that CAO tenure was relatively short and the authors noted this may lead to high turnover. Problems that may result from high turnover include greater expenses, morale problems with faculty, instability and missed opportunities, and the thwarting of ongoing initiatives (p. 3).

Chief Academic Officer Turnover. Turnover in key academic positions occurs frequently at most community colleges. Research on turnover of community college presidents was included in a study by Bernardin-Demougeot (2008) for 11 community colleges in a Mid-Atlantic state. All of these colleges had experienced at least one turnover in the 10 year time period.

Cejda and Leist (2006) studied issues facing community colleges, as perceived by chief academic officers $(\mathrm{N}=114)$ in a nine-state area $(A R, A Z, C O, L A, N M, O K, T X$, UT, WY) (p. 262). The survey used was an adaptation of Amey and VanDerLinden's 
(2002) CAO career path survey instrument. They noted several implications related to community college leadership. High turnover rates were reported by respondents for administrators (65.2\%) and faculty (72.8\%) (p.267). Department heads, division directors, and CEOs/presidents were identified as positions likely to experience large turnover in the next decade (p. 267). The faculty turnover was larger than reported by other research, while administrative turnover was slightly lower than other research had reported (p. 267).

Weisman and Vaughan (2007) reported an average presidential tenure of 7 years; this remained the same as previously reported in 2001 and 1996. This was based on the results of the 2006 Career and Lifestyle Survey (CLS) of public community college presidents $(\mathrm{N}=545)$ who were listed in the AACC membership database (p. 2). More than half of the 2006 respondents had been on the job five years or less, with $16 \%$ serving one year or less (p. 4). The number of years in the current position was reported to be an average of 7 years (p. 4). The average number of years as a community college president, including all of their presidencies, was 9.6 years in 2006, slightly less than the 9.7 years in 2001 and the 9.8 years in 1996 (p. 5). This suggested community college presidents were mobile and were serving as career presidents at multiple institutions. Presidents reporting a second presidential appointment in 2006 were 33\%; this was an increase from $25 \%$ in 1984 (p. 5). Indeed, 7\% of presidents surveyed had held three presidencies and 3\% had held four or more presidencies in the 2006 survey (p. 5). Weisman and Vaughan (2007) reported the most common path to the presidency was the academic pathway, and this was consistent in all of the surveys from 1984 to 2006 . In 2006, 55\% of respondents were in academic positions prior to the community college presidency (p. 5). 
Interestingly, $35 \%$ of the presidents were internal candidates, an increase from $33 \%$ in 2001 and 1996 (p. 5). The authors attributed this increase to board preference for internal candidates (p. 6).

The Chief Academic Officer - Summary. The community college CAO position has been examined in terms of demographics, career path, job satisfaction, and intent to turnover. Recent research indicated that community college CAOs are following a career path that includes work as a faculty member, department chair, and may include work experience in a four-year institution. The majority of CAOs are selected internally from the community college environment and are highly satisfied with their current position. Even though they are satisfied with their current role, CAOs may seek additional responsibility by pursuing a community college presidency. CAOs seek membership in professional organizations (Vaughan, 1990) and may seek different positions to advance their careers in community college leadership (Cejda, McKenney, \& Fuller, 2001). This professional orientation may seem to be in conflict with their role as key administrators in the community organization. How social roles impact the community college $\mathrm{CAO}$ is examined next.

\section{Social Roles}

Manifest Social Roles of Chief Academic Officers. Manifest social roles are the universally shared expectations that are relevant in a given situation (Grimes \& Berger, 1970). Defining the manifest social role of a community college chief academic officer was not always straightforward. George Vaughan (1990) completed a study and landmark book Pathways to the Presidency. He used this anecdote to describe the lack of definition regarding the term "dean of instruction" or CAO. A newly appointed 
community college president asked Vaughan to serve as dean of instruction. "What is a dean of instruction?" Vaughan asked (p. ix). The president replied "I'll be damned if I know, but if you want the position, we'll find out together." (p. ix). He defined the CAO roles using several different researchers' definitions, including Shawl's (1974) major roles of: (a) interpreter/mediator of policies and procedures; (b) advocate for the instructional needs of the college; and, (c) the instructional leader of the institution (p. 9). He noted that the "effective dean of instruction serves as an "internal auditor" responsible for maintaining the college's academic integrity" (p. 11).

Underwood and Hammons (1999) reported on the most common organizational functions that report to the $\mathrm{CAO}$ at a community college. The researchers surveyed public community college presidents $(\mathrm{N}=118)$ based on the 1991 AACC membership directory (p. 40). The research data provided a summary of the organization functions that report to the community college CAO. The functions included, in addition to the primary duties related to the academic mission of the institution: business and industry training, community services and continuing education, learning assistance center, library, career and occupational education, remedial and developmental education, staff development, telecommunications courses, transfer education, co-op education, instructional development, and off campus credit (p. 51).

Mech (1997) completed a study analyzing the managerial nature of the CAO's work. The researcher surveyed the Carnegie Classification of Comprehensive Colleges and Universities I institutions $(\mathrm{N}=349)$. Mech (1997) theorized that academic management was similar to corporate management, using Mintzberg's (1973) framework. Mintzberg defined roles as “a set of behaviors that manager's display based on their 
position in the organization" (p. 284). The ten managerial roles were figurehead, leader, liaison, monitor, disseminator, spokesperson, entrepreneur, disturbance handler, resource allocator, and negotiator (p. 284). These 10 roles were grouped into two categories of internal or external activities. The manager's performance of these roles was influenced by four variables; the environment, the job, the person, and the situation (p. 284). He also included environmental variables regarding the institution (age, affluence, size, complexity, sponsorship, collective bargaining presence, CAO's span of control) as well as the CAO's demographic information (age, gender, years in position, years within the organization, and years of managerial experience) (pp. 286-288). The internal roles were ranked as most important by the CAOs, indicating that they spent a significant portion of their time dealing with relationships within academic affairs (p. 288). The researcher also noted that the emphasis on internal and interpersonal roles were consistent with those who were second in command in an organization (p. 289). The president or CEO concentrated on external roles (p. 288).

Mech (1997) further emphasized the CAO's internal focus by using Alexander's managerial topology (pp. 290-291). Alexander classified Mintzberg's (1973) roles into three groups: strategic, operational, and interface. Mech (1997) found that CAOs emphasized the operational roles more than strategic or interface roles. The organization variables of size, affluence, and span of control impacted the role groups that CAOs emphasized more than the CAOs demographic factors (age). He concluded that with a good understanding of CAOs managerial roles and the influence of organizational and personal characteristics on role performance, CAOs would understand job requirements 
better and be able to meet the needs of the job, reduce stress, and serve the needs of the organization (p. 296).

Anderson et al. (2002) conducted a study to benchmark managerial roles of CAOs at community colleges. They used a survey based on Mintzberg's (1973) taxonomy and modified by Anderson et al. (2002). The sample for this survey was a stratified, random sample of CAOs $(\mathrm{N}=250)$ from each of the six national accrediting regions. Anderson et al. (2002) noted all ten managerial roles in the CAO's work; the roles of leader, liaison and disseminator were the roles identified as most frequently used (p. 8).

The American Association of Community Colleges (AACC) analyzed the community college administrator duties from a leadership viewpoint. They were prompted to do so based on the published research predicting a shortage of future leaders in the community college labor market. The AACC was awarded a grant entitled "Leading Forward" by the W.K. Kellogg Foundation in 2003 (AACC, 2008). The Leading Forward grant was based on building consensus on the key knowledge, values, and skills needed by community college leaders, as well as how to develop and sustain these leaders (p. 2). The AACC surveyed participants in the Leadership Summit and members of the Leading Forward National Advisory Panel $(\mathrm{N}=95)$. Key competencies developed by the survey respondents were based on these assumptions: (a) leadership can be learned; (b) many members of the community college community can lead; (c) effective leadership is a combination of management and vision; and, (d) learning leadership is a lifelong process (p. 3). The six core competencies developed included: (a) organizational strategy, (b) resource management, (c) communication, (d) collaboration, (e) community college advocacy, and (f) professionalism (pp. 4-6). 
Keim and Murray (2008) reviewed dissertations completed by CAOs surveyed $(\mathrm{N}=300)$; results indicated the dissertations were heavily weighted to the field of education $(66 \%)$. The authors noted that this may be an important change in mindset by CAO search committees and others who have "recognized that community college leadership roles have become more complex, demanding legal, fiscal, and human resource management skill sets that are not included in traditional academic programs" (p. 7).

Understanding the demands of the work is crucial for potential leaders. BassoppoMoyo and Townsend (1997) noted that:

Individuals seeking positions in academic affairs can better understand what knowledge, skills, and attitudes they should develop as part of their efforts to strengthen their candidacy and to project to the seasoned administrators who will interview them. With academic affairs administrators who are better prepared and who are chosen for those characteristics that seem to contribute to administrator effectiveness, community colleges will be better able to deal with the problems facing them and their leaders now and into the twenty-first century. (p. 55)

George Vaughan (2001) noted that:

higher education administration is a professional field and those who enter it are no longer historians, mathematicians, scientists or whatever. That is, they must understand what they are getting into. They must realize they are professionals in a highly specialized field and take the necessary steps to become proficient in that field. (p. 12)

Latent Social Roles Theory Development. Understanding the community college environment, CAO demographics and career paths is significant because not all candidates may be given serious consideration at all types of institutions. The search process by which candidates for community college administrative positions are interviewed and selected is one of assessment of the candidate's degree of social match with the institution (Birnbaum, 1988; Cohen \& March, 1974). 
Chappell (2008) reported on new community college presidents that were younger than average and from a diversified background. Four of the presidents interviewed had a background in student services and/or institutional research and were all under the age of 42. What was more significant than their relatively young age and backgrounds were that they had held a number of different positions in community colleges in a relatively short period of time before being named president (p. 4). This diversity in background as well as diversity of experiences provided a more "cosmopolitan" job candidate for the community college president's position.

Jencks and Riesman (1968) put forth a theory that the strength and quality of the American academic profession was the orientation of professor to "universalistic" values that are national in scope and override the "particularistic" and non-meritocratic values of local groups and individuations. Roe and Baker (1989) quoted Keyser's 1985 holistic leadership as "a two hemisphere integration in which management was a left brain science, defining order out of ambiguity, while leadership was a right brain art, creating and anticipating new directions while influencing others" (p. 6). Roe and Baker (1989) advocated that leadership attributes can be cultivated and refined, and that followers were developed by leaders through a series of stages. They noted that readiness for leadership was manifested by self confidence, positive self regard, a drive to serve and have a positive impact, and the ability to impact the behavior of others (p. 13). The authors noted that more opportunities for self-assessment and personal development were needed for those in leadership roles (p. 14). The study of latent social roles may provide the opportunity needed for self assessment by potential leadership candidates. Awareness of latent social roles may also provide the opportunity for others to consider the impact of 
latent social roles on the selection of potential job candidates for leadership positions. Latent social roles are the internalized shared expectations that are predicted to affect an individual's attitudes and behavior. The two most widely recognized latent social roles are cosmopolitan and local.

Gouldner (1957, 1958) hypothesized that organizations were impacted by latent social identities, as well as manifest identities. The initial study included faculty and administrators at one college (Co-op College, $\mathrm{N}=125)$. The survey instrument included 114 questions; these were designed using Guttmann scales (p. 293; no other source noted) to measure each of the three key variables. His hypothesis was that two latent social identities, cosmopolitans and locals, were found in organizations and were impacted by three variables: (a) loyalty to the employing organization, (b) commitment to specialized or professional skills, and (c) reference group orientations (p. 293). Cosmopolitans were hypothesized to be low on loyalty to the employing organization, high on commitment to specialized role skills, and likely to use an outer reference group orientation (p. 293). Locals were hypothesized to be high on loyalty to the organization, low on commitment to specialized role skills, and likely to use an inner reference group (p. 293). Gouldner typed individuals based on these three variables as cosmopolitans or locals.

Gouldner (1958) refined his theory using factor analysis, the centroid method of extraction, and the Quartimax system of rotation, and produced six orthogonal and unidimensional factors (p. 445; no other source noted). He developed labels for four types of locals and two types of cosmopolitans as a result of his research. The locals included the dedicated, the true bureaucrat, the home guard, and the elders; the cosmopolitans included the outsiders and the empire builders (pp. 446-450). These 
refinements of the roles of cosmopolitans and locals indicated that these latent social roles may be on a continuum and may overlap based on the three variables (loyalty, specialized skills, and reference group orientation).

Several researchers tested and expanded Gouldner's (1957 and 1958) cosmopolitan-local construct (Abrahamson, 1965; Berger \& Grimes, 1973; Brumbaugh \& Flango, 1973; Friedlander, 1971; Goldberg et al., 1965; Goldberg, 1976; Grimes \& Berger, 1970; Rotundi, 1977; Tuma \& Grimes, 1981). Several of these research studies were reviewed to explain their contributions to the latent social roles construct.

Research conducted by Abrahamson (1965) suggested that individuals seek different career paths based on their latent social roles. Abrahamson (1965) explored geographical mobility, dependence identification and the relation of these factors to the cosmopolitan-local construct. He studied scientists who worked as faculty $(\mathrm{N}=67)$ at a Midwestern university (p. 102). Questionnaires were used, including some of Gouldner's (1957) items. He explored whether attitudes and personality needs will explain variations in geographical mobility (p. 100). Abrahamson's hypotheses were: (a) Mobility was directly related to cosmopolitanism. Cosmopolitans were professionally oriented and loyal to outside reference groups; they were more likely to be geographically mobile; (b) Mobility and cosmopolitanism were not part of the same dimension; (c) Mobility was inversely related to the strength of the dependence identification (dependence identification was the individual's orientation to the family that raised them and the individual's subsequent ties to geographic areas as a result); and, (d) Mobility was most strongly (and positively) related to cosmopolitanism for scientists with low dependenceidentification. Cosmopolitanism may be integrated into an individual's personality and 
was supported by an underlying personality need, such as dependence on family ties. The research supported all hypotheses (p. 106). Specifically, cosmopolitanism and geographical mobility were not part of the same dimension; mobility was related to both cosmopolitanism and dependence identification in approximately equal intensity (p. 106). Cosmopolitans were more likely to manifest overt, behavioral mobility when they have an underlying low psychological dependence identification need, or few ties to family and a geographic region (p. 106). "It follows, too, that different career patterns are best followed by scientists with different (cosmopolitan and local) orientations, especially when their orientations are supported by underlying psychological needs" (Abrahamson, 1965, p. 106).

Gouldner's initial research classified individual latent social roles as either cosmopolitan or local. Subsequent research suggested that cosmopolitans and locals latent social roles were on a multidimensional construct related to orientation and values (Friedlander, 1971; Grimes \& Berger, 1970) and that individuals could utilize both social roles. Goldberg et al.'s (1965) study of 81 engineers $(\mathrm{N}=81)$ with a 36 item questionnaire evaluated two criteria deemed important in evaluating research ideas and projects: (a) professional and (b) organization criteria. Gouldner's and Goldberg's study were not directly comparable, but Grimes and Berger noted that an organizational or local orientation was compatible with a strong professional orientation, contrary to Gouldner's cosmopolitan orientation (p. 410). Grimes and Berger's (1970) research included three major findings to modify Gouldner's (1957) concept: (a) the cosmopolitan - local construct was not unidimensional or bipolar but was multidimensional; (b) Gouldner's formulation should be modified; the internal-external reference dichotomy was complex 
and depends on organization variables; and, (c) prior research lacked homogeneity in research samples (pp. 412-413). "It would be more rigorous to differentiate among organizational members in the same manifest role and with similar opportunities to obtain professional training" (Grimes \& Berger, 1970, p. 413).

Friedlander (1971) explored the professional orientations of research scientists in a study of scientists $(\mathrm{N}=178)$ engaged in Navy research and development. His purpose was to explore the usefulness of a conceptual framework in accounting for a variety of potential criteria that might be used to measure research success. A secondary purpose was to understand the effects of using this conceptual framework in exploring (a) the kinds of scientific disciplines that the criteria would favor, and (b) the impact the criteria have on the scientist remaining with or leaving the organization over a three-year period. The study was completed from personnel files and was based on tenure, age, education, membership in professional organizations, publications, and various aspects of research. The data were analyzed to determine interrelationship among the 14 variables. Friedlander's (1971) research indicated that there was not a single cosmopolitan-local continuum; the cosmopolitan-local continuum was a multidimensional construct related to orientation and values.

Researchers further expanded Gouldner's constructs by refining and testing new surveys to measure the cosmopolitan and local latent social roles of participants. They also used more recently developed and accepted statistical methods in the analysis of survey results. Berger and Grimes (1973) expanded and tested Gouldner's theory. Their purpose was to: (a) validate Gouldner's (1958) construct, using a similar sample and methodology; and, (b) replicate Goldberg et al. (1965) construct of the cosmopolitan 
local factor structure (p. 223). Berger and Grimes (1973) used a revised 58 item questionnaire with faculty $(\mathrm{N}=796)$ from the American Association of Collegiate Schools of Business (AACSB) business schools (p. 224). Faculty members were selected as the sample to minimize differences in manifest roles among participants and to approximate the professional roles and organizational context of Gouldner's (1957) study (p. 224). The 58 item survey included five categories: (a) attitudinal, (b) professional, (c) interpersonal, (d) environmental, and (e) biographical (pp. 224-225). The data were analyzed using principal axis factor solution with Varimax rotation, component analysis, coefficient of congruence, $\mathrm{Z}$ scores, $\mathrm{t}$ statistics, and one-way ANOVA (pp. 226-231). Their research results supported Gouldner's (1957) original cosmopolitan/local theory, specifically loyalty to organization and reference group orientation.

Brumbaugh and Flango (1973) used a questionnaire with 73 items, taken from Gouldner's (1957) questionnaire, to further test and refine Gouldner's theory. The intent of this study was to determine to what degree Gouldner's (1958) typology, from his work in a small, private, liberal arts college could be reproduced in a study of Pennsylvania's 14 public, state colleges, and to determine if the resulting topology would be useful in predicting the attitudes of faculty and administrators in regards to a common issue (p. 1). Surveys were sent to faculty members at Pennsylvania's 14 state owned college and universities prior to their vote to unionize $(\mathrm{N}=813)$. The data were analyzed using Gouldner's original methods; then reanalyzed using newer more accepted methods, including z-scores and principal components analysis with varimax rotation (p. 11). Results included six factors, including Factor 1 - rule tropism (true bureaucrat); Factor 2 - the dedicated - locals; Factor 3 - elder - locals who may have aspirations to be 
administrators; Factor 4 - cosmopolitan - outsider; Factor 5 - the dedicated - locals; and Factor 6 - home guard - locals. Gouldner's “Dedicated-Locals" was separated into two social role types in this analysis - Factor 2 and 5, with factor 5 faculty believing that more decision making power should be concentrated in the hands of the teaching faculty (p.15). Gouldner's (1958) empire builder-cosmopolitan factor was not reproduced in this study. The researchers noted that factors 4 and 6 "seem to measure best the concept that Gouldner originally called local-cosmopolitanism" (p. 16).

Rotundi (1977) examined the inner reference group dichotomy proposed by Gouldner (1957). The researcher tested three hypotheses: (a) cosmopolitans were more closely oriented toward outer reference groups than locals; (b) locals were more closely oriented toward inner reference groups than cosmopolitans; and, (c) local/cosmopolitans were more closely oriented toward reference groups than uncommitted individuals (p. 258). Reference groups included inner reference groups (included the employing company, company division, company department, and/or company work group) and outer reference groups (included the scientific community, the professional group, and/or a professional specialty group) (p. 258). A sample $(\mathrm{N}=179)$ of non managerial personnel, engineers and scientists, at an electronics company was used (p. 258). The data were analyzed by examining inter correlations among the variables, divided the scales at their respective median values to obtain high-low distinctions, completed an analysis of variance among the mean scores, and located differences using Scheffe's test (Ostle, 1963, as quoted on p. 260). His results included five major points: (a) local/cosmopolitans reference group orientation were similar to those of cosmopolitans; (b) the orientation of cosmopolitan engineers to internal work groups contradicted 
Gouldner (1957) but supported Bennis et al. (1958) findings; (c) the first two hypotheses were supported; (d) the study highlighted the importance of distinguishing among specific reference groups, in more detail than inner and outer groups; and, (e) Gouldner's (1957) reference group orientation was too generalized, and may differ depending on the organization (pp. 260-261).

Wright and Larwood (1997) further refined the cosmopolitan and local construct by developing and testing two new scales. This research involved participants from a random grouping of diverse industries $(\mathrm{N}=260)$ from metropolitan areas in the western United States. Raelin's (1989) eight item professional or cosmopolitan scale was used and analyzed using Cronbach and principal components factor analysis of the inter correlations of the scores with Kaiser varimax rotation. This did not support a unidimensional scale, but did lead to a revised cosmopolitan scale. Wright and Larwood (1997) also developed and tested a second four-item scale that emphasized the local dimensions and used research previously completed by Goldberg (1976) and Grimes and Berger (1970). Wright and Larwood (1997) addressed concerns that previous researchers (Cornwall \& Grimes, 1987; Tuma \& Grimes, 1981) had identified with Gouldner's (1957, 1958) cosmopolitan-local latent social roles construct. Wright and Larwood's (1997) study addressed the dimensionality of the construct as either uni-dimensionality (Raelin, 1989) or as many as six independent orientations (Grimes \& Berger, 1970; Tuma \& Grimes, 1981). Wright and Larwood (1997) also addressed measurability concerns with the development of two new scales using Raelin's (1989) eight item inventory for the cosmopolitan dimension, and a four item scale to measure the local dimension using research by Goldberg (1976) and Grimes and Berger (1970). 
An individual's orientation to a cosmopolitan or local latent social role may change over the course of an individual's career. Goldberg's research suggested that career stage influenced behavior and latent social roles. Goldberg (1976) further developed Gouldner's construct by refining the difference between cosmopolitanism and professionalism. He argued that an orientation that combined both cosmopolitan and local reference groups was more reasonable than the assumption that only cosmopolitans were professionals and oriented to an outer reference group (pp. 331-332). Goldberg (1976) defined professionalism as the development of expertise based on systematized knowledge, and the performance of a service to a client (p. 334). The research to this point noted that a cosmopolitan orientation was directed toward the discipline and the local orientation was directed to a concern for a client. Goldberg (1976) hypothesized that contradictions in the relationship between cosmopolitan/local orientation and professional behavior may be influenced by situational factors, including: (a) career stage; (b) primary occupational role (managerial or technical); and, (c) the quality of the work environment (poor or good) (p. 332). Goldberg (1976) surveyed professional engineers $(\mathrm{N}=192)$ and concluded that the career stage of the professional and his primary occupational role were shown to have an influence on the relationship between orientation and behavior. Goldberg (1976) concluded that a combination orientation, termed cosmo-local, was optimal for professionals (p. 353).

Latent Social Roles - Professional Groups and Problems Studied. The cosmopolitan and local latent social role constructs have been applied in researching various professional groups, including faculty (Brumbaugh \& Flango, 1973; Cornwall \& Grimes, 1987; Goldberg, 1976; Gouldner, 1957 \& 1958); scientists (Abrahamson, 1965; 
Friedlander, 1971); engineers (Goldberg et al., 1965; Rotundi, 1977); police chiefs (Pursley, 1974); military personnel (Stahl et al., 1978); business professionals and managers (Larwood et al., 1998; Wright \& Larwood, 1997). The constructs have been applied to a variety of problems, including politics (Dye, 1966); religious commitment (Petersen \& Takayama, 1983, 1984; Roof, 1972, 1976); leadership (Pursley, 1974); and organization change (Lutz \& Arney, 1987). Several of these studies are reviewed below.

Cornwall and Grimes (1987) completed research to further study the five dimensions of the cosmopolitan/local construct in relation to professional role orientations. Their research question was to determine if professional role orientations influenced professional behavior, or if professional behaviors influenced professional role orientations (p. 285). The study involved faculty $(\mathrm{N}=219)$ at a large prestigious research oriented university (p. 285). The participants responded to two surveys over a three year time span. They used a questionnaire designed by Berger and Grimes (1973). The researchers used cross lagged correlation analysis of the five scales of professional role orientation to examine the results of the survey. The cross lagged correlation analysis resulted in 20 separate cross lagged correlation analyses that were examined to evaluate the directionality of the relationship between professional role orientations and professional behaviors (p. 287). The research indicated that the professional behaviors influenced four of the five professional role orientation scales (pp. 287-289). The scale item professional commitment was influenced by the number of publications (p. 287). They reported some support for the conclusion that professional behaviors, at one point in time, influence professional attitudes at a future point in time by the number of offices held in national professional organizations (p. 287). Specifically, offices held influences 
professional commitment; recognition by professional peers may heighten commitment to the profession (p. 293). The number of offices held in national professional organizations varies negatively with commitment to organizational goals; those who did not hold office, were more satisfied with teaching and more committed to organizational goals (p. 293). Professional association varies positively with organizational immobility; this may indicate that external contacts and recognition may provide more knowledge of the job market and improve one's ability to find another position (p. 293). This may lead to the realization that the "grass was not greener" in another position. Professional association varied negatively with concern for advancement; the researchers noted that older, higher ranked faculty were more likely to hold office and less likely to be concerned about their organizational advancement (p. 294). Publications varied positively with professional commitment; this correlated with age, as older faculty had more publications and professional commitment, and research (p. 294). Cornwall and Grimes (1987) concluded their analysis by stating that the results do not specify a casual relationship between professional behaviors and role orientations in the theoretical model of the cosmopolitan-local construct (p. 295). "Both the organization and the profession influence both role orientations and behaviors, and previous attitudes and behaviors shape future attitudes and behaviors" (p. 295).

The research had never focused on management personnel, as administrators or managers were assumed to be committed to a specific organization, and they would utilize a local latent social role. Larwood et al. (1998) tested the cosmopolitan/local construct on business organizations and management personnel, and to examine if cosmopolitan/local social roles were reliability related to employee perception and 
activities such as job satisfaction, intent to turnover, job market fluidity, and fit to psychological contract. Employees from 17 business organizations participated in the survey $(\mathrm{N}=260)$. The survey was updated using other researchers previously tested survey instruments to measure cosmopolitan-local role orientation, organization politics, intent to turnover, job market fluidity, job satisfaction, and fit to psychological contract. A variety of statistical procedures were used, including factor analysis, calculation of mean and standard deviation, and correlation analysis. The researchers noted that the intention to turnover was more strongly identified with cosmopolitans, and was also related to perceived fluidity of the job market and to lower job satisfaction (p. 116). Job satisfaction was higher among those research subjects identified as locals, and locals were more likely to focus on political behavior (p. 116).

Dowd and Kaplan (2005) utilized a grounded theory approach to examine how academic careers related to the concept of boundaried careers. Boundaried academic careers were tenure and tenure track faculty whose job security reduced job mobility. They defined interaction as the primary factor distinguishing a boundary-less career, and whether a person behaved as a local or a cosmopolitan. Faculty who developed their primary identification and relationships within their university would be classified as locals with boundaried careers. Faculty whose identification was with their academic discipline and who built relationships mainly outside of their institution were cosmopolitans with primarily boundary-less careers (p. 701). The researchers referred to boundary-less careers as protean careers, where the individual, not the organization, was responsible for managing their careers. They interviewed faculty $(\mathrm{N}=34)$ and classified faculty into a one of four career types: probationer (initial boundaried), conservationist 
(subsequent boundaried), maverick (initial boundary-less) and connector (subsequent boundary-less) (p. 710). The faculty were classified into these career types based on five factors: role/identify, motivation factors, tenure concerns, other concerns, and career management. They noted that the typology provided structure for individual faculty members to conduct self-analysis and career planning.

Some of the most recent work has challenged the accepted wisdom of the emphasis on the cosmopolitan latent social role in academe. Rhoades et al. (2008) qualitative study challenged the academic norms that structure the academic profession. The academic profession had a central norm that mobility in a national market was expected, and that nationally oriented universities were of a higher quality than local institutions. The United States nationally oriented system of research universities trained a large percentage of all faculty members, but subsequently would not employ its own graduates (Rhoades et al., 2008). The system rewarded those who were mobile and circulated nationally. Rhoades et al. (2008) challenged the assumption without rejecting the value of a cosmopolitan outlook. They called for a more balanced alternative that values "cosmopolitan sensibilities with local sensitivities" (p. 233). They indicated that local connections to the local communities promoted a broader professional ethic of service to society, which were often not valued by the academy as highly as research and mobility.

Rhoades (2009) makes a further plea for a review of the current academy model that prioritizes cosmopolitan faculty and administration, and that doesn't reward or even punishes those in the academy who were locally engaged in the community. "We can imagine a more balanced professoriate in which academics are 'local cosmopolitans' or 
'cosmopolitan locals' who are connected professionally not only to (inter)national networks but also to local networks outside of academe" (p. 14).

\section{Summary of Literature Review}

Kelly (2002) reported that we need a new generation of community college leaders who have a much wider range of skills and attributes than before. Experts differ on who are best prepared to serve as future community college leaders. Dr. George Vaughan noted that "in the metaphorical sense, we're becoming a little too inbred" (as reported in Kelly, 2002, p. 2). However, another expert, Libby Roeger, thought that "homegrown community college leaders may be just as effective as experienced entrepreneurs" (as reported in Kelly, 2002, p. 3).

The development and selection of community college leaders usually focuses on the manifest social roles of the CAO. Latent social roles also help explain human behavior in organizations and may provide insight into the development and selection of community college leaders. The latent social roles of cosmopolitan and local may impact an individual's decision to seek a CAO leadership role. Latent social roles may influence the attraction to and selection of potential leaders to a particular community college environment. The community college CAOs job satisfaction and decision to leave their current position may be related to their latent social role. The community college CAOs interest in the community college presidency may also be influenced by latent social roles.

Gouldner (1958) noted it was "too easy to focus on more evident manifest identities and roles" (p. 285). Identification and selection of future community college leaders is an important task; the examination of latent social roles in relation to this 
process is the focus of this research project. The research on the importance of latent social roles has addressed many different occupations and types of work, but has not been applied consistently to a homogenous population with the same management work role, such as the community college chief academic officer.

The methodology used to explore the relationship between latent social roles and their impact on the community college chief academic officer will be explained in the next chapter. Quantitative research was used to address questions pertaining to the relationship between these two concepts. 


\section{Chapter 3}

\section{Methodology}

The purpose of this quantitative study was to determine if there was a correlation between Gouldner's $(1957,1958)$ theory of cosmopolitan and local latent social roles and identification of, interest in, and selection of the public community college chief academic officer. The review of the literature highlighted the importance of latent social roles in relation to individual job satisfaction and intent to turnover. This research investigated the correlation of latent social roles of community college chief academic officers to their selection, job satisfaction, intent to turnover, and intent to pursue a community college presidency.

\section{Research Questions and Hypotheses}

Based on the purpose of this study, the following research questions will be addressed:

R1. Was there a correlation between the public community college CAO's job satisfaction and their latent social role and does the correlation vary according to the nature of the latent social role?

RH1a. There was a correlation between job satisfaction and the CAO's cosmopolitan latent social role.

NH1a. There was no correlation between the public community college CAO's cosmopolitan latent social role orientation and job satisfaction.

RH1b. There was a correlation between job satisfaction and the CAO's local latent social role. 
NH1b. There was no correlation between the public community college CAO's local latent social role orientation and job satisfaction.

R2. Was there a correlation between the public community college CAO's aspirations to pursue a community college presidency and the CAO's latent social role and does the correlation vary according to the nature of the latent social role?

RH2a.There was a correlation between the public community college CAO's aspirations to pursue a community college presidency and their cosmopolitan latent social role.

NH2a. There was no correlation between the public community college CAO's intent to pursue a community college presidency and the cosmopolitan latent social role of the CAO.

RH2b.There was a correlation between the public community college CAO's aspirations to pursue a community college presidency and their local latent social role.

NH2b. There was no correlation between the public community college CAO's intent to pursue a community college presidency and the local latent social role of the CAO.

R3. Was there a correlation between the public community college CAO's intent to turnover and the CAO's latent social role and does the correlation vary according to the nature of the latent social role?

RH3a. There was a correlation between the CAO's intent to turnover and the CAO's cosmopolitan latent social role.

NH3a. There was no correlation between the public community college CAO's intent to turnover and the cosmopolitan latent social role of the CAO. 
RH3b.There was a correlation between the CAO's intent to turnover and the CAO's local latent social role.

NH3b. There was no correlation between the public community college CAO's intent to turnover and the local latent social role of the CAO.

\section{R4. Was there a correlation between the selection of an internal or external candidate for the public community college CAO position and the CAO's latent social role and does the correlation vary according to the nature of the latent social role?}

RH4a. There was a correlation between the CAO's cosmopolitan latent social role orientation and the selection of an internal or external CAO job candidate

NH4a. There was no correlation between the CAO's cosmopolitan latent social role orientation and the selection of an internal or external CAO job candidate.

RH4b. There was a correlation between the CAO's local latent social role orientation and the selection of an internal or external CAO job candidate.

NH4b. There was no correlation between the CAO's local latent social role orientation and the selection of an internal or external CAO job candidate.

\section{R5. Was there a difference in intent to pursue a community college} presidency and latent social role?

RH5a. There was a difference between the CAO's intent to pursue a community college presidency and the cosmopolitan latent social role of the CAO.

NH5a. There was no difference between the CAO's intent to pursue a community college presidency and the cosmopolitan latent social role of the CAO. 
RH5b. There was a difference between the CAO's intent to pursue a community college presidency and the local latent social role of the CAO.

NH5b. There was no difference between the CAO's intent to pursue a community college presidency and the local latent social role of the CAO.

R6. Was there a difference between the environmental factors of public community college size, number of employees, location (rural, suburban, urban), number of locations (part of a system), or state of operation in relation to the latent social roles for public community college CAOs in the United States?

RH6a. There was a difference between community college size and the cosmopolitan latent social role of the CAO. Small was defined as under 2,500 unduplicated student headcount, medium was defined as 2,500 to 5,000 unduplicated student headcount, and large as greater than 5,000 unduplicated student headcount.

NH6a. There was no difference between community college size and the cosmopolitan latent social role of the CAO.

RH6b. There was a difference between community college size and the local latent social role of the CAO. Small was defined as under 2,500 unduplicated student headcount, medium was defined as 2,500 to 5,000 unduplicated student headcount, and large as greater than 5,000 unduplicated student headcount.

NH6b. There was no difference between the community college size and the local latent social role of the $\mathrm{CAO}$.

RH6c. There was a difference between the number of employees at the community college and the cosmopolitan latent social role of the CAO. A small number 
of employees was defined as less than 1,000 employees at the institution; a large number of employees was defined as greater than 1,000.

NH6c. There was no difference between the number of employees at the community college and the cosmopolitan latent social role of the CAO.

RH6d: There was a difference between the number of employees at the community college and the local latent social role of the CAO. A small number of employees was defined as less than 1,000 employees at the institution; a large number of employees was defined as greater than 1,000.

NH6d. There was no difference between the number of employees at the community college and the local latent social role of the CAO.

RH6e. There was a difference between the rural, suburban, or urban community college location and the cosmopolitan latent social role of the CAO. Rural was defined as not a MSA or PMSA and with a population of less than 500,000. Suburban and urban was defined as a MSA or PMSA, respectively, with a population equal to or greater than 500,000 .

NH6e. There was no difference between the rural, suburban, or urban community college location and the cosmopolitan latent social role of the CAO.

RH6f. There was a difference between the rural, suburban, or urban community college location and the local latent social role of the CAO. Rural was defined as not a MSA or PMSA and with a population of less than 500,000. Suburban and urban was defined as a MSA or PMSA, respectively, with a population equal to or greater than 500,000 . 
NH6f. There was no difference between the rural, suburban, or urban college location and the local latent social role of the CAO.

RH6g. There was a difference between the number of locations for the community college and the cosmopolitan latent social role of the CAO. Location was defined as either a single location or multiple locations.

NH6g. There was no difference between the number of locations for the community college and the cosmopolitan latent social role of the CAO.

RH6h. There was a difference between the number of locations for the community college and the local latent social role of the CAO. Location was defined as either a single location or multiple locations.

NH6h. There was no difference between the number of locations for the community college and the local latent social role of the CAO.

RH6i. There was a difference between the population of the state where the community college was located and the cosmopolitan latent social role of the CAO. A state with a small population was defined as less than 5 million. A state with a large population was defined as greater than 5 million.

NH6i. There was no difference between the population of the state where the community college was located and the cosmopolitan latent social role of the CAO.

RH6j. There was a difference between the population of the state where the community college was located and the local latent social role of the CAO. A state with a small population was defined as less than 5 million. A state with a large population was defined as greater than 5 million. 
NH6j. There was no difference between population of the state where the community college was located and the local latent social role of the CAO.

R7. Was there a difference between the public community college CAO's personal or demographic characteristics (age, birth month, gender, marital status, education, tenure in office, research and publication history) and the CAO's latent social role?

RH7a. There was a difference between the CAO age and the cosmopolitan latent social role of the CAO. CAO age was summarized for analysis into the following categories: under age 30, $30-39,40-49,50-59,60-69$, and over 70 .

NH7a. There was no difference between the CAO age and the cosmopolitan latent social role of the CAO.

$\mathrm{RH} 7 \mathrm{~b}$. There was a difference between the CAO age and the local latent social role of the $\mathrm{CAO}$. CAO age was summarized for analysis into the following categories: under age $30,30-39,40-49,50-59,60-69$, and over 70 .

NH7b. There was no difference between the CAO age and the local latent social role of the CAO.

RH7c. There was a difference between the CAO's birth month and the cosmopolitan latent social role of the CAO. The survey data was summarized into two categories; CAOs born January - April, and May - December.

NH7c. There was no difference between the CAO's birth month and the cosmopolitan latent social role of the CAO. 
RH7d. There was a difference between the CAO's birth month and the local latent social role of the CAO. The survey data was summarized into two categories; CAOs born January - April, and May - December.

NH7d. There was no difference between the CAO's birth month and the local latent social role of the CAO.

RH7e. There was a difference between the CAO's gender and the cosmopolitan latent social role of the $\mathrm{CAO}$.

NH7e. There was no difference between the CAO's gender and the cosmopolitan latent social role of the CAO.

RH7f. There was a difference between the CAO's gender and the local latent social role of the CAO.

NH7f. There was no difference between the CAO's gender and the local latent social role of the CAO.

RH7g. There was a difference between the CAO's marital status and the cosmopolitan latent social role of the CAO. Marital status was defined as single, married, divorced and widowed.

NH7g. There was no difference between the CAO's marital status and the cosmopolitan latent social role of the CAO.

RH7h There was a difference between the CAO's marital status and the local latent social role of the CAO. Marital status was defined as single, married, divorced and widowed.

NH7h. There was no difference between the CAO's marital status and the local latent social role of the $\mathrm{CAO}$. 
RH7i. There was no difference between the CAO's highest level of education and the cosmopolitan latent social role of the CAO. The CAO's highest level of education was reported as $\mathrm{PhD}, \mathrm{EdD}$ or other.

NH7i. There was no difference between the CAO's highest level of education and the cosmopolitan latent social role of the CAO.

RH7j. There was a difference between the CAO's highest level of education and the local latent social role of the CAO. The CAO's highest level of education was reported as $\mathrm{PhD}, \mathrm{EdD}$ or other.

NH7j. There was no difference between the CAO's highest level of education and the local latent social role of the CAO.

RH7k. There was a difference between the CAO's tenure in office and the cosmopolitan latent social role of the CAO. Tenure as a CAO was categorized as less than 5 years, or more than 5 years.

NH7k. There was no difference between the CAO's tenure in office and the cosmopolitan latent social role of the CAO.

RH71. There was a difference between the CAO's tenure in office and the local latent social role of the $\mathrm{CAO}$. Tenure as a $\mathrm{CAO}$ was categorized as less than 5 years, or more than 5 years.

NH71. There was no difference between the CAO's tenure in office and the local latent social role of the CAO.

RH7m. There was a difference between the CAO's publication history and the cosmopolitan latent social role of the CAO. The data was categorized as CAOs who had published 2006 - 2010, and prior to 2006. 
NH7m. There was no difference between the CAO's publication history and the cosmopolitan latent social role of the CAO.

RH7n. There was a difference between the CAO's publication history and the local latent social role of the CAO. The data was categorized as CAOs who had published $2006-2010$, and prior to 2006.

NH7n. There was no difference between the CAO's publication history and the local latent social role of the CAO.

\section{Research Design}

Creswell (2008) indicated that the researcher should match the approach to the research problem. Quantitative research addresses research problems that require a description of trends or an explanation of the relationships among variables. Quantitative research should be measurable and the hypotheses specific and narrow (Creswell, 2008). The rationale for using a quantitative approach for this research study was threefold:

(a) The nature of the research questions lead the researcher to a quantitative method;

(b) The research questions were designed to determine if a relationship exists; these questions were best answered using a quantitative research method; and, (c) The research questions could form hypotheses. The quantitative research method will provide data to support or reject the hypotheses (Creswell, 2008). The research design was descriptive and not experimental; the research did not attempt to change behavior or conditions. Participants were surveyed once prior to relationships being determined.

\section{Population of the Study}

The population for the study included the entire dataset of 932 chief academic officers at public community colleges in the United States who reported data to the 
Higher Education Directory (HED). The researcher made the following selections in purchasing data from the HED: (a) manpower code of 05 - chief academic officer; (b) public institutions; and, (c) two-year institutions. The resulting data file included 364 different job titles within the 05-chief academic officer category, with Vice President Academic Affairs representing the most common job title with 106 occurrences, or $11 \%$ of the population. All institutions in the population were public, two-year, coed institutions. The institutions were located in 54 states and territories, with the largest number located in California (105 institutions, or 11.27\%). Figure 1 displays the number of institutions in each state represented in the population.

The HED provided the data in an Excel format and included 37 different fields for each record, including: Federal Interagency Committee on Education (FICE) number, unit identification, manpower code (MPC), title, prefix, first name, middle initial, last name, institution name, institution address (including street address, city, state, and zip code), institution telephone number, individual work telephone number and extension, fax number, e-mail address, two-year, public institution, up to five different program codes, emphasis, co-ed or all male/female students, institution type, offering code, affiliations, Carnegie classification code, date institution established, web site, enrollment, and tuition.

The Carnegie Classification of the institutions in the population is reported in Table 2. More than one half of the total population was classified as rural, with the largest category being rural, medium size institutions. 


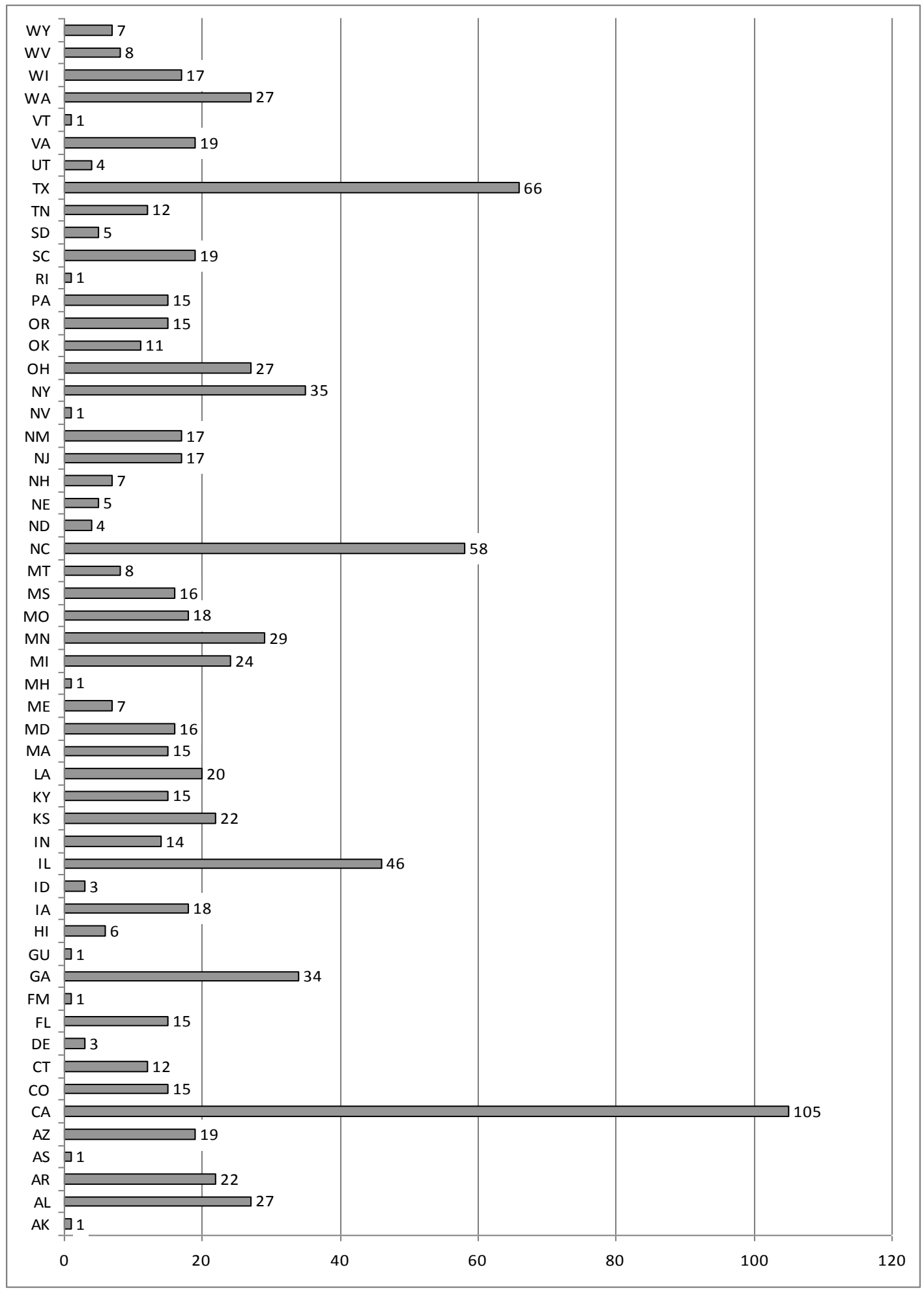

Figure 1. Number of institutions by state. 
Table 2

Carnegie Classification of Institutions in Population

\begin{tabular}{lcc}
\hline Type of Institution & $\mathrm{N}$ & $\%$ \\
\hline Associate/Public/Rural/Small & 100 & 10.73 \\
Associate/Public/Rural/Medium & 277 & 29.72 \\
Associate/Public/Rural/Large & 127 & 13.63 \\
Associate/Public/Suburban/Single campus & 102 & 10.94 \\
Associate/Public/Suburban/Multiple Campus & 88 & 9.44 \\
Associate/Public/Urban/Single Campus & 31 & 3.33 \\
Associate/Public/Urban/Multiple Campus & 128 & 13.73 \\
Other & 79 & 8.48 \\
Total & 932 & 100.00 \\
\hline
\end{tabular}

The researcher received 275 usable complete responses representing a response rate of $30 \%$. The number of people who started the survey was 315; two respondents selected "No" to the informed consent document and 38 respondents started but did not complete the entire survey. Demographic characteristics of the responding participants are reported in Chapter 4.

Dillman (2007) recommended a survey protocol of multiple contacts and multiple channels of contact be followed to increase the response rate. The protocol used was an adapted protocol for on-line delivery; three e-mail contacts and a telephone follow-up were included in the protocol. The initial e-mail invitation invited the chief academic 
officer to participate; the e-mail included a web hyperlink to the informed consent document, and then linked the participant to the survey. A second e-mail reminder and a third e-mail reminder were sent to those members of the population who had not completed the survey. The use of multiple channels of contact was recommended by Dillman to improve response rates; telephone follow-up was included in the protocol (p. 150). The response rate was sufficient after the third e-mail reminder as to not require this additional telephone follow-up protocol step.

\section{Variables}

The dependent or criterion variable was the latent social role of cosmopolitan or local. These variables were assessed using a 7 question cosmopolitan scale and 4 question local scale. See Appendix B for the entire questionnaire. Independent variables included in the study were: public community college size in number of students (small - under 2,500; medium - 2,500 to 5,000; and large - greater than 5,000); total number of employees (less than 1,000 or greater than 1,000); organization type (single location or multiple locations under a common governance); state of operation (54 possibilities including an other category); age (select from age 21 to 95 with an other category); birth month (12 possible categories included January through December); gender (male or female); marital status (4 possible categories including single, married, divorced, widowed); highest level of education completed ( 8 possible categories included $\mathrm{PhD}$, EdD, JD, MD, DO, DMD, Masters, and an other category); education discipline (respondent typed in the discipline); tenure in office (12 categories included from less than a year to 10 years and an other category); research and publication history (7 categories available to report last publication in 2006 - 2010, $2001-2005$; 1996 - 2000; 
1991 - 1995, 1986 - 1990, 1981 - 1985 and an other category); selection as an internal or external candidate for the $\mathrm{CAO}$ position; job satisfaction of the $\mathrm{CAO}$ ( 5 questions were directed to measuring this); CAO intent to pursue a community college presidency (1 questions considered this); CAO intent to turnover (7 questions were directed to measuring this); three most recent previous positions (respondents selected from a list of 17 possible previous community college positions that ranged from president to faculty member; an other category was also available); and, CAO future plans (4 questions probed future plans including the time frame for seeking another position in the community college labor market, seeking a position in higher education, returning to the faculty, or retiring).

\section{Instrumentation}

A survey was used to measure the dependent and independent variables, with additional questions to gather demographic information. The basis of the survey instrument was a 39-item survey questionnaire that was previously used and validated by Larwood et al. (1998). These researchers tested the local and cosmopolitan latent social roles construct with employees of business organizations, and examined cosmopolitan/local latent social roles and the relationship to employee perception and activities such as job satisfaction, intent to turnover, job market fluidity, and fit to psychological contract.

The Larwood et al. (1998) survey instrument was based on Raelin's (1991) single scale to measure both cosmopolitan and local latent social roles. Larwood et al. (1998) indicated that the instrument reliability $(\alpha=.43)$ was not sufficient to use the scale as a uni-dimensional construct. However, principal components factor analysis with 
orthogonal rotation demonstrated three statistically independent dimensions (Eigen values > 1.0). Larwood et al. (1998) used the factor scores from the primary scale to create a revised cosmopolitan scale. Low scores indicated a stronger cosmopolitan orientation.

A second scale, which emphasized the local dimension, was independently developed and tested by Larwood et al. (1998) ( $\alpha=.72)$. Low scores indicated a stronger local latent social role orientation.

The intent to turnover scale used by the Larwood et al. (1998) survey and this study included six items adapted from two respected and validated scales $(\alpha=.85)$ : (a) the Intention to Turnover scale (Camman, Fichman, Jenkins, \& Klesh, 1979; Seashore, Lawler, Mirvis, \& Camman, 1982), and (b) Lyons' Propensity to Leave scale (as cited in Cook, Hepworth, Wall, \& Warr, 1981). Higher scale values indicated a greater intent to turnover.

The Larwood et al. (1998) survey used five widely recognized dimensions of the satisfaction construct to measure job satisfaction. These items were summed to form a composite or global measure of satisfaction for each individual $(\alpha=.67)$. Low values indicated a greater degree of job satisfaction.

The job market fluidity and the fit to psychological contract scales from the Larwood et al. survey was not included in the present study.

All four researchers involved in the Larwood et al. (1998) study were contacted, but the original survey document could not be located. The researcher reconstructed the survey based on the research article and a review of the original source documents. Survey questions utilized measured responses using dichotomous responses (yes and no), 
numerical scales, and a Likert-type rating scales (e.g., "not important" to "very important"). See Appendix A for a complete copy of the survey instrument. The 44-item survey was organized into seven sections: (a) questions related to cosmopolitan social role orientation -7 questions; (b) questions related to local social role orientation -4 questions; (c) questions related to job satisfaction - 5 questions; (d) questions related to turnover - 7 questions; (e) question related to intent to pursue a community college presidency - 1 question; (f) question related to selection as an internal or external job candidate - 1 question; (g) questions related to the institutional environment; and, (h) questions related to CAO demographics - 19 questions total for sections 6 and 7 .

The researcher contacted Larwood, Wright, Desrochers, and Dahir via e-mail, and requested that they review the survey as an expert panel. This contact was undertaken as the original complete survey was no longer available. Larwood and Dahir agreed to do so; Wright and Desrochers did not participate. Larwood and Dahir suggested minor changes to the survey, including: (a) rewording of the question regarding tenure, to clarify between tenure in the position versus tenure in faculty rank; (b) review and clarification of the questions on intent to turnover; and (c) balancing the Likert scales on three of the questions. The researcher reviewed and implemented the suggested changes.

\section{Pilot Study}

A pilot study was conducted to assess the reliability of the survey instrument and the survey instructions. The pilot study was conducted in May 2010 with 15 community college CAOs using the data collection methods described previously. The research subjects were selected to proportionately represent the Carnegie classifications in the population: two CAOs from an Associate/Public/Rural/Small institutions; four CAOs 
from Associate/Public/Rural/Medium institutions; two CAOs from Associate/Public/ Rural/Large institutions; two CAOs from Associate/Public/Suburban/Single campus institutions; one CAO from an Associate/Public/Suburban/Multiple Campus institution; one CAO from an Associate/Public/Urban/Single Campus institution; two CAOs from Associate/Public/Urban/Multiple Campus institutions; and one CAO from an institution in the Other category.

The pilot study was started by four CAOs; three CAOs completed the entire survey. Two additional questions were included in the pilot study: (a) As a community college CAO, what would be the best month (June, July or August) for you to complete this survey, considering availability, workload, etc?; and (b) Please provide feedback regarding the length of time to complete the survey, questions that needed clarification, or any other comments. July was the preferred month by the CAOs responding to the pilot survey. The CAOs participating in the pilot did not provide any feedback regarding the length of time to complete, or questions that needed clarification. As a result of the pilot study, no revisions were made to the survey and data collection method.

\section{Data Collection}

The researcher proceeded with the data collection process in July 2010. The research population of public community college chief academic officers had access to organization based e-mail as part of their work routine. The first contact with participants, an e-mail notification on UNL letterhead, helped legitimatize the study and: (a) introduced the participants to the study of chief academic officers; (b) highlighted the importance of learning more about CAO career paths and their future career aspirations; (c) emphasized the importance of the research to community colleges; (d) noted that the 
researcher was a UNL student who had received IRB approval; and, (e) addressed participants confidentiality concerns. The e-mail, as depicted in Appendix A, invited the public community college $\mathrm{CAO}$ to participate in the survey by clicking on the embedded web link. When participants clicked on the web link, they were directed to the Survey Monkey ${ }^{\mathrm{TM}}$ web site, as this was the service used to deliver the survey. The first screen of the survey was an informed consent document on UNL letterhead that included the IRB approval information (20100410696 EX). After reviewing the informed consent form (Appendix B), participants clicked on "Yes, I agree to participate in the survey" or "No, I do not agree to participate." Those that clicked on "Yes" were directed to the first survey question; those participants who clicked on "No" were directed to the final survey

“Thank You” screen. There were eight pages in the survey (Appendix B); all were based on a common design and screen layout. After the participants completed the survey, a "thank you" message was displayed.

Dillman (2007) recommended a system of five varied contacts with potential participants. The survey procedures, as recommended by Dillman (2007), are outlined below.

1. Survey letter notification Each CAO in the survey population was notified by e-mail on July 14, 2010 of the request to participate in the survey; they were provided an internet link to the survey. Dillman (2007) recommended that the participants receive a post card delivered through the US mail; discussion with the staff at the University of Nebraska-Lincoln Evaluation and Research (NEAR) Center revealed that e-mail was as effective as or more effective than US mail. This 
request to participate in the survey noted the researcher's connection with the University of Nebraska.

2. Survey Questionnaire Survey Monkey ${ }^{\mathrm{TM}}$, a web-based survey tool, was used to deliver the survey via the internet; this was a proven product with consistent results and reports available to the researcher. The first page of the web-based survey process displayed the informed consent document that advised the participants of the purpose of the research, the benefits and risks to them, and of their right to withdraw from the research at any time. Participants who agreed to the Informed Consent document were automatically transferred to the first page of the web-based survey. There were eight pages in total in the survey.

Completion of the 44-item questionnaire was accomplished in approximately 15 minutes.

\section{First Reminder}

Participants who did not complete the web-based survey within two weeks after their first notification were sent an e-mail reminder on July 28, 2010. The e-mail repeated the request for participation and provided the web site survey as an embedded e-mail link.

4. Second Reminder

Participants who did not complete the survey within four weeks after their initial notification were sent a second e-mail reminder on August 11, 2010. The reminder repeated the request for participation and the web site survey link. 
5. Telephone call (final contact)

The researcher planned on contacting participants who did not complete the web-based survey six weeks after their initial notification via telephone to request their participation. If the participant was willing to participate but did not want to use the web survey, a paper copy of the survey was to be offered and mailed to the participant (with a return, postage paid envelope). If the participant indicated they did not want to participate, this was to be noted and the participant would not be contacted again. The researcher did not complete this final telephone contact step in the protocol as the response rate was sufficient after the second e-mail reminder.

\section{Confidentiality}

The research protocol involved human subjects and was submitted to the University of Nebraska Institutional Review Board (UNL IRB) for review. The IRB office provided approval on May 18, 2010 and the approval number was 20100410696 EX. The research protocol was classified as exempt.

Data was stored on the researcher's secure computer and backed up on a flash drive, which was stored in a locked file cabinet. Printed reports were stored in a locked cabinet in the researcher's office. Results of this research were presented in aggregate form only with all identifying information removed. Results of the study will be maintained on file for 5 years after survey completion.

\section{Data Analysis}

The results of the survey were collected using the Survey Monkey ${ }^{\mathrm{TM}}$ web site and the researcher downloaded the data using Survey Monkey ${ }^{\mathrm{TM}}$ tools. The data were 
analyzed using spreadsheet and SPSS statistical software. The NEAR Center assisted with the analysis of the data. The researcher provided the NEAR Center with an Excel worksheet of the data without participants identifying information and a list of the statistical analysis work to be completed.

The researcher had identified six hypotheses to be examined. Data analysis involved three steps, as described below.

Step 1. The researcher confirmed the model fit of the cosmopolitan and local latent social roles scales for the data obtained from this study by using Confirmatory Factor Analysis. Factors are independent variables (Creswell, 2008). Factor analysis is a common statistical method used for two purposes: (a) to find a small set of unobserved variables, or latent factors, which can account for the covariance among a larger set of observed variables, or manifest factors; and (b) to assess the reliability and validity of measurement scales (Stat/Math Center, 2006). There are two types of factor analysis, exploratory and confirmatory factor analysis. Exploratory factor analysis is a theory generating procedure while confirmatory factor analysis is a theory testing procedure (Stapleton, 1997). Larwood et al. (1998), who originally designed and used the survey, had used a type of exploratory factor analysis labeled principal component factor analysis to validate the latent social role scales and analyze the data. In this study, the researcher completed confirmatory factor analysis to confirm the model fit of the cosmopolitan and local latent social role scales.

Step 2. The researcher used descriptive statistics to obtain a cosmopolitan and local social role score for each participant. 
Step 3. The researcher used a variety of statistical techniques to examine each of the six research hypothesis using the cosmopolitan and latent social role scores developed in step 2. These statistical methods included descriptive statistics, $t$ tests, ANOVA with Tukey HSD Post Hoc tests, and Pearson product-moment correlation analysis. Each of these methods will be explained during the analysis of the data. $T$ tests were used to identify significant differences between environmental, demographic, and situational characteristics of CAOs and latent social roles. ANOVA with Tukey HSD Post Hoc tests were used to determine if significant differences existed in latent social roles and CAO environmental, demographic, and situational characteristics. The Pearson correlation measures the degree and direction of linear relationship between two variables (Gravetter \& Wallnau, 2007, p. 511).

\section{Research Validity}

Validity is achieved when the "researchers can draw meaningful and justifiable inferences from scores about a sample or population" (Creswell, 2008). There are four types of design validity in quantitative research, according to McMillan and Schumacher (2006): (a) Statistical conclusion validity, or is there a relationship among the variables; (b) Internal validity, or is there a causal relationship between the intervention and the dependent variable; (c) Construct validity, or what is the nature of the constructs; and, (d) External validity, or what is the generalizability of the results. The survey instrument had been previously used and validated by other researchers (Larwood et al., 1998). Validity of the research data was addressed by using statistical conclusion validity to report on relationships among the variables for each hypothesis. Validity was also addressed by only using complete responses for each research hypothesis in analyzing the data. 
Validity was also established, as recommended by McMillan and Schumacher (2006), by evidence based on internal structure; factor analysis was used to examine the internal structure of the survey and will be reported in Chapter 4 .

\section{Ethical Issues}

This research did not involve any experimentation with human subjects; there were very few ethical dilemmas to manage. The researcher sought review and approval of this research project by the University of Nebraska Institutional Review Board (IRB). All participants in this survey were provided with an Informed Consent document and asked to review the document, and agree to their participation. The data collected from participants was kept confidential with participant names maintained separately from their responses.

\section{Summary}

This quantitative study was conducted to determine the impact of latent social roles on the community college chief academic officer. The population of 932 public community college CAOs were surveyed, with 275 complete responses. The survey results were analyzed using descriptive and inferential statistics. Analyses of the results of this study are reviewed in Chapter 4. Each of the six hypotheses developed were evaluated using the data collected and a variety of statistical methods, including confirmatory factor analysis, descriptive statistics, $t$ tests, ANOVA, and correlation analysis. 


\section{Chapter 4}

\section{Results}

The purpose of this quantitative study was to determine if there was a relationship between Gouldner's $(1957,1958)$ theory of cosmopolitan and local latent social roles and the selection of the public community college chief academic officer (CAO) as well as certain organization behaviors of chief academic officers, including subsequent job satisfaction, intent to turnover, and intent to pursue a community college presidency. This relationship was determined by testing for a correlation between cosmopolitan and local latent social role scores and the other factors using the results of a survey of CAOs. The differences between the community college CAO's latent social roles and their demographic and environmental factors were also studied.

Seven research questions and corresponding hypotheses examined the cosmopolitan and local latent social roles of community college CAOs. The latent social role names will be shortened to "cosmo" for cosmopolitan and "local" for local for ease of reading and clarity as data are presented in subsequent tables. The survey population was composed of the CAOs working at public community colleges in the United States; information on 932 CAOs in the population was obtained from the Higher Education Directory (HED). The survey instrument used was previously used by Larwood et al. (1998) and included a demographic and environmental questionnaire that was specific to higher education. Participant responses to the survey were gathered using a survey delivered electronically using Survey Monkey ${ }^{\mathrm{TM}}$, a commercially available internet software tool. 
The UNL Nebraska Evaluation and Research (NEAR) Center assisted with the statistical analysis. Data were analyzed at the $95 \%$ confidence level. Notations were made when the level of significance was higher. Responses were received from 293 participants for the questions related to the major research hypotheses 1 through 5, or $31 \%$ of the population. Responses for the environmental and demographic research questions 6 and 7 were completed by 275 of the participants. Participants who answered other for the environmental and demographic research questions 6 and 7 were not included in the analysis for that question if their response could not be properly categorized.

Data analysis involved three steps:

1. The researcher confirmed the model fit of the cosmopolitan and local latent social roles scales for the data obtained from this study by using Confirmatory Factor Analysis.

2. The researcher used descriptive statistics to obtain a cosmopolitan and local latent social role score for each participant.

3. The researcher used a variety of statistical techniques to examine each of the seven research hypotheses using the cosmopolitan and local latent social role scores developed in step 2.

These statistical methods included descriptive statistics, $t$ tests, ANOVA with Tukey HSD post hoc tests, and Pearson product-moment correlation analysis. Each of these methods will be explained during the analysis of the data. 


\section{Latent Social Role Scale Confirmation}

The researcher examined the validity of the cosmopolitan and local latent social role scales by completing Confirmatory Factor Analysis (CFA). Factor analysis is a common statistical method used for two purposes: (a) to find a small set of unobserved variables, or latent factors, which can account for the covariance among a larger set of observed variables, or manifest factors; and, (b) to assess the reliability and validity of measurement scales (Stat/Math Center, 2006). There are two types of factor analysis, exploratory and confirmatory factor analysis. Exploratory factor analysis is a theory generating procedure while confirmatory factor analysis is a theory testing procedure (Stapleton, 1997).

The seven items related to the cosmopolitan scale were originally developed by Raelin (1989); and subsequently used by Wright and Larwood (1997). These researchers used a type of exploratory factor analysis, specifically principal components (factor) analysis (PCA), to verify the reliability of the scales. PCA is a statistical method used to identify patterns in data and then compress the data to reduce the number of dimensions without losing too much information (Smith, 2002). Larwood et al. (1998) used 7 questions related to the cosmopolitan role and 4 related to the local role; PCA was used to examine the importance of each question in regards to the prediction of the cosmopolitan or local latent social roles.

Confirmatory Factor Analysis (CFA) is used when prior exploratory factor analysis techniques such as PCA have been applied. As Larwood et al. (1998) had already validated the cosmopolitan and local scales using PCA, the researcher used CFA to confirm the model fit of these scales. CFA was performed using the MPlus statistical 
software package. The chi-square test of model fit along with the Root Mean Square Error of Approximation were the primary statistics used to evaluate the results of the CFA. The chi-square value, or $X^{2}$ value, was evaluated using a table to determine a $p$ value, based on the $X^{2}$ factor and the degrees of freedom $(d f)$ for the analysis. The $p$ value must be above .05 to not reject the null hypothesis. Another indicator of the model fit was the Root Mean Square Error of Approximation or RMSEA value; RMSEA was evaluated based on an acceptable value below the .05 cutoff to indicate a good model fit (Stapleton, 1997).

Cosmopolitan Latent Social Role Scale. The overall model fit was acceptable for the cosmopolitan related questions 1 to 7 . The chi-square test of model fit value was $X^{2}(14, \mathrm{~N}=293)=22.960, d f=14, p=.06$. The $p$ value was sufficiently high, or above .05 , and did not reject the null hypothesis of a good fit. The RMSEA value was .047, or below .05, and indicated acceptable model fit. Both the chi-square test of model fit and the RMSEA evaluations indicated that the cosmopolitan scale was an acceptable scale and model. Table 3 presents a summary of CFA results.

\section{Table 3}

Confirmatory Factor Analysis - Goodness of Fit Indicators for Cosmopolitan and Local Scales

\begin{tabular}{lccccc}
\hline Model & $\chi^{2}$ & $\mathrm{df}$ & $\mathrm{p}$ value & $\mathrm{CFI}$ & RMSEA \\
\hline Cosmopolitan $(\mathrm{N}=293)$ & 22.96 & 14 & .06 & .76 & .047 \\
Local $(\mathrm{N}=292)$ & 3.78 & 2 & .15 & .98 & .055 \\
\hline
\end{tabular}


Examination of the model results indicated that cosmopolitan latent social role questions 3, 4, and 7 were the most important to the model fit. Survey questions related to the cosmopolitan latent social role orientation measured responses on a 5-point scale ranging from 1 (strongly disagree) to 5 (strongly agree). The questions on the cosmopolitan scale included: (a) You agree that it is the right of a professional to make his or her own decisions about what is to be done on the job; (b) You have no interest in moving up to the top community college administrative post; (c) You believe that professionals are better evaluated by professional categories rather than by management; (d) You would feel better making a contribution to society than to your organization; (e) You would stay in this profession/administrative post even if your income were reduced; (f) Your best friends tend to be others who work as community college administrators; and, (g) You believe it is more important to advance your professional reputation than the organization reputation. Table 4 presents the results of the confirmatory factor analysis for each question.

Local Latent Social Role Scale. The four questions related to the local latent social role scale were originally developed by Wright and Larwood (1997) and verified using principal components factor analysis. The four item scale was analyzed in the present research study using Confirmatory Factor Analysis (CFA). The overall model fit for the four questions related to the local latent social role scale was acceptable. The chisquare test of model fit value was $X^{2}(2, \mathrm{~N}=293)=3.784, d f=2, p=.1507$; this confirmed the model fit. The $p$ value was sufficiently high, or above .05 , to not reject the null hypothesis of a good fit. The RMSEA was .055, or near enough to the cutoff of .05 
Table 4

Confirmatory Factor Analysis - Model Results for Cosmopolitan Questions

\begin{tabular}{lccc}
\hline Model & Estimates & Std. Error & Est/Std. Error \\
\hline Cosmopolitan Questions & & & \\
Q1 & 1.000 & 0 & 0 \\
Q2 & -.105 & .332 & -.318 \\
Q3 & .773 & .293 & $2.636^{*}$ \\
Q4 & 1.531 & .642 & $2.387^{*}$ \\
Q5 & -.303 & .260 & -1.165 \\
Q6 & .162 & .257 & .629 \\
Q7 & .492 & .217 & $2.267^{*}$ \\
\hline
\end{tabular}

*Significant if greater than 2.0

to indicate acceptable model fit. Both the chi-square test of model fit and the RMSEA evaluations indicated that the local scale was an acceptable scale and model. Table 3 presents a summary of the CFA results.

Examination of the model results indicated that local latent social role questions 22 and 23 were the most important to the model fit. Survey questions related to the local latent social role orientation measured responses on a 5-point scale ranging from 1 (not very important) to 5 (very important). The questions on the local scale were: (a) What is the importance of on-the-job training to what you are doing now?; (b) What is the extent of your personal psychological investment in your present organization?; (c) How important is it that you succeed in your present organization?; and, (d) How important is it to you to move up in your present organization? Table 5 presents the results of the confirmatory factor analysis for each question. 
Table 5

Confirmatory Factor Analysis - Model Results for Local Questions

\begin{tabular}{lccc}
\hline Model & Estimates & Std. Error & Est/Std. Error \\
\hline Local Questions & & & \\
Q21 & 1.000 & 0 & 0 \\
Q22 & 1.818 & .508 & $3.578^{*}$ \\
Q23 & 1.180 & .317 & $3.721^{*}$ \\
Q24 & .0483 & .341 & 1.416 \\
\hline
\end{tabular}

*Significant if greater than 2.0

Summary - Latent Social Role Scale Confirmation. CFA indicated that the cosmopolitan and local scales used were acceptable scales and a good model fit. The research data were used to determine the latent social role of the participants based on research questions 1 through 7 for the cosmopolitan latent social role and questions 21 through 24 for the local latent social role. The results of these scales will be used to evaluate the research hypotheses $1-7$.

\section{Cosmopolitan and Local Latent Social Roles}

After verifying the validity of the latent social role scales, the researcher used the following statistical methods to analyze the latent social roles of the survey participants: descriptive statistics, including the mean, standard deviation, and percentage score in relation to the entire sample.

The latent social role scores were developed using cosmopolitan latent social role related questions 1 through 7 and local latent social role related questions 21 through 24 . The questions included a Likert type scale. A 1 indicated the participant "strongly 
disagrees" and a 5 indicated the participant "strongly agrees" for cosmo related questions 1 through 7. A 1 indicated the item is "not very important" and a 5 indicated the item is "very important" for local related questions 21 through 24. See Appendix B for the survey instrument.

Table 6 presents the descriptive statistics on the cosmopolitan latent social role for CAOs. The responses to the seven questions related to the cosmopolitan latent social role were averaged for each participant to obtain a cosmopolitan latent social role rating. The four questions related to the local latent social role were averaged for each participant to obtain a local latent social role rating. These cosmopolitan and local average values were used in evaluating the research hypotheses in relation to the cosmopolitan and local latent social roles of the public community college CAOs. High average scores indicated a dominate cosmopolitan or local latent social role respectively.

Table 6

Descriptive Statistics - Cosmopolitan Scale Questions

\begin{tabular}{lccc}
\hline Scale & $\mathrm{N}$ & Mean & Std Dev \\
\hline Cosmopolitan - Average of Questions 1 - & 293 & 2.72 & .44 \\
Question 1 & 3.30 & 1.02 \\
Question 2 & 2.60 & 1.41 \\
Question 3 & 2.98 & .90 \\
Question 4 & 2.63 & .95 \\
Question 5 & 3.25 & 1.06 \\
Question 6 & 2.44 & 1.08 \\
Question 7 & 1.83 & .75 \\
\hline
\end{tabular}


An average score of a 4 to 5 on the cosmopolitan latent social role scale would indicate that the $\mathrm{CAO}$ had a strong cosmopolitan latent social role, as evidenced by a lower level of loyalty to the organization, a strong orientation to external reference groups, and a commitment to professional skills and/or organizations. An average score of 4 to 5 on the local latent social role scale would indicate that the CAO had a strong local latent social role orientation, as evidenced by a high level of loyalty to the organization, an orientation to internal (to the organization) reference groups, and a weaker commitment to professional skills and/or organizations.

Cosmopolitan - Social Roles. Participant responses to questions 1 through 7 ranged from an average score of 1.83 for question 7 to an overall average of 3.30 for question 1. Question 7 was related to the participants input on their belief that advancing their professional reputation was more important than the organization's reputation; most participants ranked that question very low, indicating they were more local in orientation than cosmopolitan. Table 6 indicates that the average cosmo overall score for all participants was 2.72. This was lower than the median scale score of a 3.0 (on a scale of 1 to 5). This would indicate that the public community college CAOs surveyed were not exhibiting cosmopolitan latent social roles, as a whole.

Further analysis of the data was performed by ranking how each participant scored on questions 1 through 7 to determine how many participants were cosmopolitan in latent social role. The cosmopolitan scores of participants were ranked in Table 7. Of the entire population, 58 participants or $20 \%$ of the sample scored an average of 3 or higher on the cosmopolitan scale; 230 participants, or $80 \%$ of the sample, reported a 
Table 7

Descriptive Statistics - Cosmopolitan Scale

\begin{tabular}{lccc}
\hline Scale & Overall Mean & Number of Participants & $\%$ of total \\
\hline Cosmopolitan Questions 1 - & 2.72 & & \\
Average less than 3 & & 57 & 80 \\
Average greater than 3, less than 4 & 1 & 20 \\
Average greater than 4 & & -- \\
\hline
\end{tabular}

cosmopolitan score of less than a 3. This indicated that the majority of the CAOs surveyed were not classified as cosmopolitan in their latent social role.

Local Social Roles. Questions 21 through 24 ranged from an average score of 2.63 for question 24 to an overall average of 4.81 for question 23 . Table 8 presents the results of this analysis. Question 24 was "How important is it to you to move up in your present organization?"; most participants ranked that question very low. Table 8 indicates that the average local score for all participants was 4.06. This was higher than the median scale score of a 3.0 (on a scale of 1 to 5). The public community college CAOs surveyed were exhibiting local latent social roles as a whole in that they were loyal to their present organization, valued internal relationships more than external; and had a weaker commitment to professional groups and organizations.

Further analysis of the data by ranking how each participant scored on questions 21 through 24 was performed to determine how many participants were local in latent social roles. The local latent social role scores of participants were ranked in Table 9. Of the entire population, 272 participants or $94 \%$ of the sample scored an average of 3 or higher on the local scale; 16 participants, or $6 \%$ of the sample, reported a local score of 
Table 8

Descriptive Statistics - Local Scale Questions

\begin{tabular}{lccc}
\hline Scale & N & Mean & Std Dev \\
\hline Local - Average of Question 21 - 24 & 292 & 4.06 & .54 \\
Question 21 & & 4.27 & .98 \\
Question 22 & 4.54 & .70 \\
Question 23 & 4.81 & .48 \\
Question 24 & 2.63 & 1.31 \\
\hline
\end{tabular}

Table 9

Descriptive Statistics - Local Scale

\begin{tabular}{lccc}
\hline Scale & Overall Mean & Number of Participants & $\%$ of total \\
\hline Local Questions 21 - 24 & 4.06 & & \\
Average less than 3 & 16 & 6 \\
Average greater than 3, less than 4 & 131 & 49 \\
Average greater than 4 & 141 & 49 \\
\hline
\end{tabular}

less than a 3. This indicated that the majority of the CAOs surveyed were classified as local in their latent social role.

The cosmopolitan and local scales were inversely related; participants who scored high on the cosmopolitan latent social role scale were likely to have low scores on the local latent social role scale and vice versa. This relationship was confirmed by completing the Pearson product-moment correlation statistical analysis of the cosmopolitan factors versus the local factors; Pearson's $r(293)=-.126, p<.05$. The 
negative $r$ value indicated an inverse relationship between the cosmopolitan and local scales for the survey participants.

Summary - Cosmopolitan and Local Latent Social Roles. Public community college CAO's scores for the cosmopolitan and local latent social roles indicated that they were more "local" with an overall average score of 4.06 on the local scale, and an overall average of 2.72 on the cosmopolitan scale. The majority, or $94 \%$, of the CAOs reported a local latent social role of greater than 3; 6\% reported a local latent social role score of less than 3. The inverse was true of the cosmopolitan latent social role scores; only $20 \%$ reported a cosmopolitan latent social role of greater than 3 , and $80 \%$ reported a cosmopolitan score of less than 3. CAOs were measured on both cosmopolitan and local scales. Cosmopolitan and local latent social role scores were inversely related; survey participants with a high local latent social role score were likely to have a low cosmopolitan latent social role score. CAOs serve as managers and administrators; their loyalty to the organization and the use of inner reference groups is both expected and cultivated by the college community and administrators at the community college.

The relationship between the participants' cosmopolitan and local latent social role orientation and the research hypotheses regarding selection of an internal or external candidate, job satisfaction, intent to turnover, and intent to pursue a community college presidency were considered next. Statistical inference in general requires five steps: (a) formulating the null and research hypothesis (one-tailed or two-tailed), (b) choosing a (subjective) significance level $(\alpha)$ or forming rejection regions, (c) computing the (objective) test statistic or its $p$ value, (d) comparing the test statistic with the critical value or the $p$ value with the significance level, and (e) draw a conclusion (reject or do 
not reject the null hypothesis) (Stat/Math Center, 2006). This procedure was followed in considering each of the research questions.

\section{Research Questions and Hypotheses}

Research Hypotheses 1, 2, 3, and 4. The hypotheses developed were concerned with the correlation of the selection of an internal or external job candidate, job satisfaction, intent to pursue a community college presidency, and intent to turnover with the cosmopolitan and local scales for the community college CAOs surveyed. This required determining the level of interrelationships between each variable and the cosmopolitan and local scales. The Pearson product-moment correlation statistic was used to determine this interrelationship. The Pearson statistic reported the linear relationship between two variables and determined the following: (a) was there a relationship or correlation; (b) how strong was the relationship; and, (c) whether the relationship was positive or negative (inverse) (Statistics-help-for-students.com, 2008). Three statistics were reported with the Pearson product-moment correlation; the rho or $r$ value, the positive or negative value of the relationship, and the significance or sig. of the relationship. The Pearson correlation was reported as the Pearson rho or $\mathrm{r}$ value, and this $\mathrm{r}$ value was between -1 and +1 . A zero value indicated no correlation. Values closer to -1 or +1 indicated a strong correlation. A negative value indicated that as one variable increases, the other decreases. A positive relationship indicated that both variables increase (and decrease) simultaneously. The sig. indicated whether there was a statistically significant relationship between two variables; a sig. (2-tailed) that was less than .05 was significant, and may also be evaluated at the .01 level. 
Table 10 reports the results of the means and standard deviations for the study variables that were used to address research questions 1, 2, 3 and 4.

Table 10

Mean and Standard Deviation - Cosmo and Local Latent Social Roles and Study Variables

\begin{tabular}{lcc}
\hline Scale & Mean & Std Deviation \\
\hline 1. Cosmopolitan & 2.71 & .43 \\
2. Local & 4.06 & .54 \\
3. Internal/External Candidate & 1.52 & .50 \\
4. Job Satisfaction & 3.85 & .66 \\
5. Intent to Pursue a CC Presidency & 2.54 & 1.13 \\
6. Intent to Turnover & 2.33 & .43 \\
\hline
\end{tabular}

Table 11 reports the results of the Pearson product-moment correlation analysis including the intercorrelations among the study variables that were used to address research questions $1,2,3$ and 4 . The rho or $r$ value was reported in the table in a comparison to each of the numbered study variables, including: (a) cosmopolitan latent social role orientation; (b) local latent social role orientation; (c) internal/external candidate; (d) job satisfaction; (e) intent to pursue a community college presidency; and, (f) intent to turnover. Positive values were indicated without a symbol preceding the $r$ value; negative values have a “_"symbol preceding them. The significant $r$ values were indicated with an asterisk following the $r$ value; those items that were significant at the .05 level have a single asterisk, while correlations significant at the .01 level have two asterisks. 
Table 11

Pearson Correlation between Cosmopolitan and Local Latent Social Roles and Study

Variables

\begin{tabular}{lcccccc}
\hline Scale & & & 3 & 4 & 5 & 6 \\
& $\begin{array}{c}1 \\
\text { Cosmo }\end{array}$ & $\begin{array}{c}2 \\
\text { Local }\end{array}$ & $\begin{array}{c}\text { Internal } \\
\text { External }\end{array}$ & $\begin{array}{c}\text { Job } \\
\text { Satisfaction }\end{array}$ & $\begin{array}{c}\text { Intent to Pursue } \\
\text { CC Presidency }\end{array}$ & $\begin{array}{c}\text { Intent to } \\
\text { Turnover }\end{array}$ \\
\hline 1. Cosmopolitan & -- & $-.12^{*}$ & .01 & -.08 & $-.29^{* *}$ & .07 \\
2. Local & & -- & -.02 & $.16^{* *}$ & $.31^{* *}$ & .06 \\
$\begin{array}{l}\text { 3. Internal/External } \\
\text { Candidate }\end{array}$ & & -- & -.09 & $.28^{* *}$ & .11 \\
4. Job Satisfaction & & & & -.07 & $-.37^{* *}$ \\
5. Intent to Pursue a & & & & & -- & $.36^{* *}$ \\
$\quad$ CC Presidency & & & & & & -- \\
6. Intent to Turnover & & & & & & \\
\hline
\end{tabular}

Note: All scales were scored from 1 to 5 .

Note: All scale items were perfectly correlated with themselves (1); this correlation was not reported and represented with a --.

Degrees of Freedom range from 292 to 293.

* Correlation significant at $p<.05$.

$* *$ Correlation significant at $p<.01$

\section{Research Question 1. Was there a correlation between the public community} college CAO's job satisfaction and their latent social role and does the correlation vary according to the nature of the latent social role? The Pearson product-moment correlation was used to determine correlations between the cosmopolitan and local latent social role scores and $\mathrm{CAO}$ job satisfaction scores. The correlation analysis is presented in Table 11, item 4 (p. 122). These data were used to test hypotheses NH1a-NH1b.

NH1a. There was no correlation between the public community college CAO's cosmopolitan latent social role orientation scores and job satisfaction scores. 
The hypothesis was not rejected. There was no significant correlation indicated between the cosmopolitan latent social role scores and job satisfaction scores, based on $r$ $(293)=-.082, p>.05$.

NH1b. There was no correlation between the public community college CAO's local latent social role orientation score and job satisfaction score.

The hypothesis was rejected. A Pearson product-moment correlation coefficient was computed to access the correlation between the CAO's local latent social role score and job satisfaction score. There was a positive correlation between the two variables, the CAO's local latent social role score and job satisfaction score, at the .01 level of significance, based on $r(292)=.161, p<.01$. Overall, there was a significant correlation between CAOs with a local latent social role and a higher level of job satisfaction. CAOs with stronger local latent social role scores were correlated with higher levels of job satisfaction.

Summary. A significant positive correlation was identified between CAO's with local latent social roles and higher levels of job satisfaction; there was no significant correlation indicated between CAO's with a cosmopolitan latent social role and job satisfaction.

Research Question 2. Was there a correlation between the public community college CAO's aspirations to pursue a community college presidency and the CAO's latent social role and does the correlation vary according to the nature of the latent social role? The Pearson product-moment correlation was used to determine if there was a correlation between the cosmopolitan and local latent social role scores and CAO aspirations to pursue a community college presidency. The correlation analysis is 
presented in Table 11, item 5 (p. 122). These data were used to test hypothesis NH2a and $\mathrm{NH} 2 \mathrm{~b}$.

NH2a. There was no correlation between the public community college CAO's intent to pursue a community college presidency and the cosmopolitan latent social role score of the CAO.

The hypothesis was rejected. There was a negative correlation between the CAO's cosmopolitan latent social role score and the intent to pursue a community college presidency, based on $r(292)=-.287, p<.01$. CAOs who displayed a cosmopolitan latent social role did not indicate they intended to pursue a presidency. A cosmopolitan is theorized to have a lower level of loyalty to the organization and a stronger professional orientation to outer reference groups; this may explain their lack of interest in the community college presidency as the presidency requires an immersion in and dedication to one local organization.

NH2b. There was no correlation between the public community college CAO's intent to pursue a community college presidency and the local latent social role score of the CAO.

The hypothesis was rejected. There was a positive correlation between the CAO's local latent social role score and the intent to pursue a community college presidency, based on $r(292)=.314, p<.01$. CAOs who displayed a local latent social role more frequently reported an intent to pursue a community college presidency.

Summary. A correlation between the local and cosmopolitan latent social role and the CAO's intent to pursue a community college presidency was identified. The correlation between the cosmopolitan latent social role and the intent to pursue a 
community college presidency was an inverse relationship, indicating they do not intend to do so. CAOs with a local latent social role correlated positively and strongly with an intention to pursue a community college presidency.

Research Question 3. Was there a correlation between the public community college CAO's intent to turnover and the CAO's latent social role and does the correlation vary according to the nature of the latent social role? The Pearson product-moment correlation was used to determine correlations between the cosmopolitan and local latent social role scores and the CAO's intent to turnover. The correlation analysis is presented in Table 11, item 6 (p. 122). These data were used to test hypothesis $\mathrm{NH} 3 \mathrm{a}-\mathrm{Nh} 3 \mathrm{~b}$.

NH3a. There was no correlation between the public community college CAO's intent to turnover and the cosmopolitan latent social role score of the CAO.

The hypothesis was not rejected. There was no correlation indicated between the cosmopolitan latent social role score and the CAO's intent to turnover using the Pearson correlation, $\mathrm{r}(293)=.068, p>.05$.

NH3b. There was no correlation between the public community college CAO's intent to turnover and the local latent social role score of the CAO.

The hypothesis was not rejected. There was no correlation indicated between the local latent social role score and the CAO's intent to turnover using the Pearson correlation, $\mathrm{r}(292)=.058, p>.05$.

Summary. The analysis of the relationship between the CAO's intent to turnover and their cosmopolitan and local latent social role failed to demonstrate a correlation. 
Research Question 4. Was there a correlation between the selection of an internal or external candidate for the public community college CAO position and the CAO's latent social role and does the correlation vary according to the nature of the latent social role? The Pearson product-moment correlation was used to determine correlations between the cosmopolitan and local latent social role scores and the selection of an internal or external job candidate for the $\mathrm{CAO}$ position. The correlation analysis is presented in Table 11, item 3 (p. 122). These data were used to test hypothesis NH4a NH4b.

NH4a. There was no correlation between the public community college CAO's cosmopolitan latent social role score and the selection of an internal or external CAO job candidate.

The hypothesis was not rejected. There was no correlation indicated between the CAO's cosmopolitan latent social role score and the selection of an internal or external CAO, $r(292)=.010, p>.05$.

NH4b. There was no correlation between the public community college CAO's local latent social role score and the selection of an internal or external CAO job candidate.

The hypothesis was not rejected. No correlation was indicated as a result of the Pearson correlation test between the CAO's local latent social role score and the selection of an internal or external CAO, $r(290)=-.021, p>.05$.

While there was not a correlation indicated between the selection of an internal or external candidate for the CAO position and the CAO's latent social role, additional information in the form of descriptive statistics for the CAOs and their status as an 
internal or external candidate were examined and presented in Table 12. The majority of CAOs, or $52 \%$, were external candidates for their position. The cosmopolitan and local latent social role means for the CAOs selected externally to the organization indicated that the CAOs were more local in latent social role orientation, as indicated by the local mean of 4.05. CAOs selected from an internal candidate pool were $48 \%$ of the survey, and were more local in orientation on average, as indicated by the local mean of 4.07 .

Table 12

Descriptive Statistics - Internal/External CAO Candidates

\begin{tabular}{lcccccc}
\hline Scale & $\mathrm{N}$ & $\%$ & $\begin{array}{c}\text { Cosmo } \\
\text { Mean }\end{array}$ & $\begin{array}{c}\text { Cosmo } \\
\text { Std Dev }\end{array}$ & $\begin{array}{c}\text { Local } \\
\text { Mean }\end{array}$ & $\begin{array}{c}\text { Local } \\
\text { Std Dev }\end{array}$ \\
\hline Internal & 139 & $48 \%$ & 2.71 & .45 & 4.07 & .54 \\
External & 151 & $52 \%$ & 2.72 & .43 & 4.05 & .54 \\
\hline
\end{tabular}

Summary. The analysis did not indicate any correlation between the CAO's cosmopolitan or local latent social role and the selection of the CAO as an internal or external job candidate. Descriptive statistics indicated that $48 \%$ of the survey population were internal candidates for their CAO position and 52\% were external candidates.

\section{Research Question 5. Was there a difference between the CAO's intent to} pursue a community college presidency and the CAO's latent social role? Analysis of Variance, or ANOVA, is used to compare three or more groups of results. ANOVA analysis can be performed multiple ways; a one-way ANOVA is used to determine if the means for each group are significantly different from one another or if they are relatively the same (Statistics-help-for-students.com, 2008). For this research, a one-way between 
subjects ANOVA was conducted to compare the cosmopolitan and latent social role scores to each of the responses to the question regarding intent to pursue a community college presidency, including (a) not at all, (b) a small extent, (c) to some extent, and (d) to a very great extent.

NH6a. There was no difference between the CAO's intent to pursue a community college presidency and the cosmopolitan latent social role of the CAO.

The hypothesis was rejected. There was a significant difference for CAOs with cosmopolitan latent social roles and the intent to pursue a community college presidency, $F(3,288)=9.182, p<.05$.

NH6b. There was no difference between the CAO's intent to pursue a community college presidency and the local latent social role of the CAO.

The hypothesis was rejected. A significant difference was reported for CAOs with local latent social roles and their intent to pursue a community college presidency, $F$ $(3,288)=11.913, p<.05$. Table 13 presents results for the ANOVA analysis.

Table 13

ANOVA Results - Intent to Pursue a Community College Presidency and Latent Social Roles

\begin{tabular}{|c|c|c|c|c|c|c|}
\hline Scale & & SS & $d f$ & MS & $F$ & $p$ \\
\hline \multirow[t]{2}{*}{ Cosmopolitan } & Between Groups & 4.840 & 3 & 1.613 & 9.182 & $.000 *$ \\
\hline & Within Groups & 50.607 & 288 & .176 & & \\
\hline \multirow[t]{2}{*}{ Local } & Between Groups & 9.478 & 3 & 3.159 & 11.913 & $.000^{*}$ \\
\hline & Within Groups & 76.380 & 288 & .265 & & \\
\hline
\end{tabular}

$* p<.05 *$ 
ANOVA identified the existence of significant differences between the groups or conditions, but does not identify which means were different. Post hoc tests are statistical analysis methods that are performed to identify the groups or conditions with statistically significant differences after ANOVA has identified that significant differences exist (Statistics-help-for-students.com, 2008).

The ANOVA results of this research required further analysis using post hoc comparisons, specifically the Tukey Honestly Significant Difference (HSD) test, to determine which conditions were most significant. Post hoc comparisons using the Tukey HSD test indicated for CAOs with cosmopolitan latent social roles and the mean score for intent to pursue a community college presidency "not at all" $(\mathrm{M}=2.92, \mathrm{SD}=.40)$ was significantly different than the mean scores for "to some extent" $(\mathrm{M}=2.65, \mathrm{SD}=.43)$ and to a "very great extent" $(\mathrm{M}=2.58, \mathrm{SD}=.46)$. However, the mean score for intent to pursue a community college presidency "to a small extent" was not significantly different than the "not at all," "to some extent" or to a "very great extent" conditions; the mean score between "to some extent" was not significantly different than the "to a small extent" or to a "very great extent" conditions; and, the mean score between to a "very great extent" was not significantly different than the "to a small extent" or the "to some extent" conditions. Table 14 presents the results of the Tukey HSD analysis.

Post hoc comparisons using the Tukey HSD test indicated for CAOs with local latent social roles that the mean score for intent to pursue a community college presidency "not at all" $(\mathrm{M}=3.87, \mathrm{SD}=.39)$ and "a small extent" $(\mathrm{M}=3.85, \mathrm{SD}=.65)$ were significantly different than the mean scores for "to some extent" 
Table 14

Tukey HSD Post Hoc - Cosmopolitan Latent Social Role by Intent to Pursue a Presidency

\begin{tabular}{|c|c|c|c|c|c|}
\hline Scale & $\begin{array}{l}\text { (I) intent to pursue a } \\
\text { presidency }\end{array}$ & $\begin{array}{l}\text { (J) intent to pursue a } \\
\text { presidency }\end{array}$ & $\begin{array}{c}\text { Mean Difference } \\
(\mathrm{I}-\mathrm{J})\end{array}$ & SE & $p$ \\
\hline \multirow[t]{3}{*}{ Cosmopolitan } & Not at all & A Small Extent & .1916 & .07722 & .065 \\
\hline & & To Some Extent & $.2646 *$ & .06398 & .000 \\
\hline & & Very Great Extent & $.3336 *$ & .06830 & .000 \\
\hline \multirow[t]{3}{*}{ Cosmopolitan } & A Small Extent & Not At All & -.1916 & .07722 & .065 \\
\hline & & To Some Extent & .0729 & .07489 & .764 \\
\hline & & Very Great Extent & .1420 & .07861 & .272 \\
\hline \multirow[t]{3}{*}{ Cosmopolitan } & To Some Extent & Not At All & $-.2646 *$ & .06398 & .000 \\
\hline & & A Small Extent & -.0729 & .07489 & .764 \\
\hline & & Very Great Extent & .06911 & .06565 & .719 \\
\hline \multirow[t]{3}{*}{ Cosmopolitan } & Very Great Extent & Not At All & $.3336 *$ & .06830 & .000 \\
\hline & & A Small Extent & -.1420 & .07861 & .272 \\
\hline & & To Some Extent & -.0691 & .06565 & .719 \\
\hline
\end{tabular}

$* p<.05$

$(\mathrm{M}=4.16, \mathrm{SD}=.54)$ and to a "very great extent" $(\mathrm{M}=4.29, \mathrm{SD}=.51)$. However, the mean score for intent to pursue a community college presidency "to a small extent" was not significantly different than the "not at all," and the mean score for "to some extent" was not significantly different than the "very great extent" condition. Table 15 presents the results of the Tukey HSD analysis. 
Table 15

Tukey HSD Post Hoc Procedure - Local Latent Social Role by Intent to Pursue a Presidency

\begin{tabular}{|c|c|c|c|c|c|}
\hline Scale & $\begin{array}{l}\text { (I) intent to pursue a } \\
\text { presidency }\end{array}$ & $\begin{array}{l}\text { (J) intent to pursue a } \\
\text { presidency }\end{array}$ & $\begin{array}{l}\text { Mean Difference } \\
(\mathrm{I}-\mathrm{J})\end{array}$ & SE & $p$ \\
\hline \multirow[t]{3}{*}{ Local } & \multirow[t]{3}{*}{ Not at all } & A Small Extent & -.0223 & .09487 & .995 \\
\hline & & To Some Extent & $-.2861 *$ & .07860 & .002 \\
\hline & & Very Great Extent & $-.4147 *$ & .08391 & .000 \\
\hline \multirow[t]{3}{*}{ Local } & \multirow[t]{3}{*}{ A Small Extent } & Not At All & .0223 & .09487 & .995 \\
\hline & & To Some Extent & $-.3085 *$ & .09200 & .005 \\
\hline & & Very Great Extent & $-.4371 *$ & .09657 & .000 \\
\hline \multirow[t]{3}{*}{ Local } & \multirow[t]{3}{*}{ To Some Extent } & Not At All & $.2861 *$ & .07860 & .002 \\
\hline & & A Small Extent & $.3085 *$ & .09200 & .005 \\
\hline & & Very Great Extent & -.1286 & .08065 & .383 \\
\hline \multirow[t]{3}{*}{ Local } & \multirow[t]{3}{*}{ Very Great Extent } & Not At All & $.4147 *$ & .08391 & .000 \\
\hline & & A Small Extent & $.4371 *$ & .09657 & .000 \\
\hline & & To Some Extent & .1286 & .08065 & .383 \\
\hline
\end{tabular}

$* p<.05$

Further examination of the differences between the CAOs latent social role scores and their interest in pursuing a community college presidency was performed through the use of descriptive statistics. The descriptive statistics representing participants' interest in pursuing a community college presidency are displayed in Table 16 . A total of $57 \%$ of the CAOs were interested "to some extent" (32\%) and to "a very great extent" $(25 \%)$ in pursuing a community college presidency. The average local latent social role score for 
Table 16

Descriptive Statistics - Intent to Pursue a Community College Presidency

\begin{tabular}{lcccccc}
\hline $\begin{array}{l}\text { Intent to Pursue a CC } \\
\text { Presidency }\end{array}$ & $\mathrm{N}$ & $\begin{array}{c}\% \\
\text { of Total }\end{array}$ & $\begin{array}{c}\text { Cosmo } \\
\text { Mean }\end{array}$ & $\begin{array}{c}\text { Cosmo } \\
\text { Std Dev }\end{array}$ & $\begin{array}{c}\text { Local } \\
\text { Mean }\end{array}$ & $\begin{array}{c}\text { Local } \\
\text { Std Dev }\end{array}$ \\
\hline Not at All & 79 & 27 & 2.92 & .40 & 3.87 & .39 \\
A Small Extent & 47 & 16 & 2.72 & .37 & 3.85 & .65 \\
To Some Extent & 94 & 32 & 2.65 & .43 & 4.16 & .53 \\
Very Great Extent & 72 & 25 & 2.58 & .46 & 4.29 & .51 \\
Total & 292 & & 2.72 & .44 & 4.06 & .54 \\
\hline
\end{tabular}

those who were interested to "a very great extent" in pursuing a community college presidency was 4.29 ; the local score was 4.16 for those CAOs who were interested "to some extent" in pursuing a community college presidency. The local latent role score was very high for those interested in pursuing a community college presidency; this suggested a strong relationship between the CAO's local latent role score and their intent to pursue a community college presidency. The CAO's who reported that they were "not at all" interested in pursuing a community college presidency (27\%) had a lower local latent social role score (3.87) and a higher cosmopolitan latent social role score (2.92). This suggested that CAOs who were not interested in pursuing a community college presidency exhibited stronger cosmopolitan latent social roles.

Summary. CAOs with a cosmopolitan latent social role displayed a difference in intention to pursue a community college presidency, with the response "not at all" indicating the most significant mean difference. CAOs with a local latent social role presented significant differences in the responses "to some extent" and to a "very great extent" in relation to intention to pursue a community college presidency. 
Research Question 6. Was there a difference between the environmental factors of public community college size, number of employees, location (rural, suburban, urban), number of locations (single or multiple), or state of operation in relation to the latent social roles for public community college CAOs in the United

States? Institutional environmental factors studied included college size (small, medium, or large); number of employees (small or large); location (rural, suburban or urban); number of locations (single or multiple); and, the population of the state where the institution is located (small or large). The mean and standard deviation of the institutional environmental factors studied is presented in Table 17.

Statistical methods used to determine differences between the institution environmental factors and the CAO's latent social role included the ANOVA and $t$ test methods. ANOVA was used to test the hypotheses for community college size as there were three possibilities: small, medium and large institutions; and for location, as there were three possibilities: rural, suburban and urban. $T$ tests are used to compare the means from two different groups of data to help determine if the means are significantly different from one another or if they are the same (Statistics-help-for-students.com, 2008). The data in this research compared groups of participants that were not related but rather were independent; thus independent samples $t$ tests were used. $T$ tests were used to examine the difference between the latent social role of the CAO and each of the following environmental factors: (a) number of employees, (b) number of locations, (c) the size of the population of the state where the institution is located.

NH6a. There was no difference between community college size and the cosmopolitan latent social role of the CAO. 
Table 17

Means and Standard Deviations - Community College Environmental Variables

\begin{tabular}{|c|c|c|c|c|c|}
\hline Scale & $\mathrm{N}$ & Mean & Std. Deviation & Cosmo Mean & Local Mean \\
\hline College Size & 289 & 2.23 & .806 & & \\
\hline Small & 68 & & & 2.74 & 4.00 \\
\hline Medium & 87 & & & 2.76 & 4.04 \\
\hline Large & 134 & & & 2.67 & 4.11 \\
\hline Number of Employees & 289 & 1.21 & .406 & & \\
\hline Small (less than 1,000) & 229 & & & 2.71 & 4.04 \\
\hline Large (greater than 1,000 ) & 60 & & & 2.73 & 4.19 \\
\hline Location & 255 & & & & \\
\hline Rural & 155 & & & 2.73 & 4.10 \\
\hline Suburban & 62 & & & 2.71 & 4.04 \\
\hline Urban & 28 & & & 2.76 & 4.04 \\
\hline Number of Locations & 289 & 1.58 & .494 & & \\
\hline Single & 120 & & & 2.73 & 3.95 \\
\hline Multiple & 69 & & & 2.71 & 4.15 \\
\hline State Institution Located in & 266 & 25.1 & 14.95 & & \\
\hline Small Population & 90 & & & 2.84 & 4.10 \\
\hline Large Population & 176 & & & 2.68 & 4.04 \\
\hline
\end{tabular}

Small was defined as under 2,500 unduplicated student headcount; medium was defined as 2,500 to 5,000 unduplicated student headcount, and large as greater than 5,000 unduplicated student headcount. The hypothesis was not rejected. A one-way ANOVA analysis was conducted and the researcher determined there was not a significant difference in the cosmopolitan latent social role of CAOs and community college size at 
the $p<.05$ level, $F(2,286)=1.26, p>.05$. Table 18 presents the results of the ANOVA test.

NH6b. There was no difference between the community college size and the local latent social role of the CAO.

Small was defined as under 2,500 unduplicated student headcount; medium was defined as 2,500 to 5,000 unduplicated student headcount, and large as greater than 5,000 unduplicated student headcount. The hypothesis was not rejected. A one-way ANOVA analysis was conducted and the researcher determined there was not a significant difference in the local latent social role of CAOs and community college size, F $(2,286)=$ $1.172, p>.05$. Table 18 presents the results of the ANOVA test.

Table 18

ANOVA Results - Community College Size and Latent Social Role

\begin{tabular}{lccccc}
\hline Scale & $S S$ & $d f$ & $M S$ & $F$ & Sig. \\
\hline College Size (small, medium, large) & & & & & \\
Between Groups & & & & & \\
Cosmo & .48 & 2 & .24 & 1.26 & .29 \\
Local & .69 & 2 & .34 & 1.17 & .31 \\
Within Groups & & & & & \\
Cosmo & 54.48 & 286 & .19 & -- & -- \\
Local & 83.65 & 286 & .29 & -- & -- \\
\hline
\end{tabular}

NH6c. There was no difference between the number of employees at the community college and the cosmopolitan latent social role of the CAO. 
A small number of employees was defined as less than 1,000 employees at the institution; a large number of employees was defined as greater than 1,000. The hypothesis was not rejected for the cosmopolitan latent social role. The difference between CAO's cosmopolitan latent social role and the number of employees was not significant, $t(287)=-.188, p>.05$. Table 19 presents the results of the analysis.

Table 19

Descriptive Statistics and t tests Results - Number of Employees and Latent Social Role

\begin{tabular}{lccccccc}
\hline Scale & $N$ & $\begin{array}{c}\text { \% of } \\
\text { Total }\end{array}$ & Mean & $\begin{array}{c}\text { Std. } \\
\text { Deviation }\end{array}$ & $t$ test & $d f$ & $\begin{array}{c}\text { Sig. } \\
\text { (2-tailed) }\end{array}$ \\
\hline Number of Employees & & & & & & & \\
Small (less than 1,000) & 229 & 79 & & & & & \\
Cosmo & & & 2.71 & .42 & -.19 & 287 & .85 \\
Local & & & 4.04 & .54 & -1.93 & 287 & $.05^{*}$ \\
Large (greater than 1,000) & 60 & 21 & & & & & \\
Cosmo & & & 2.72 & .48 & -.19 & 287 & .85 \\
Local & & 4.19 & .52 & -1.93 & 287 & $.05^{*}$ \\
\hline$* p<.05$ & & & & & &
\end{tabular}

NH6d. There was no difference between the number of employees at the community college and the local latent social role of the CAO.

A small number of employees was defined as less than 1,000 employees at the institution; a large number of employees was defined as greater than 1,000 . The hypothesis was rejected. The researcher conducted a $t$ test and determined there was a 
significant difference between the local latent social role and the number of employees, $t$ $(287)=-1.925, p<.05$. Table 19 presents the results of the analysis.

The analysis of the data indicated that the difference between the number of employees and the CAO's local latent social role was significant. CAOs at small and large community colleges identify themselves as locals. A further analysis of the mean and standard deviation for the local latent social role determined the larger local latent social role mean (4.19) was for CAOs from institutions with a large number of employees.

Descriptive statistics indicated that 229 survey participants or $79 \%$ of the total population worked for institutions with less than 1,000 employees and that 60 survey participants or $21 \%$ of the total population worked for institutions with more than 1,000 employees.

NH6e. There was no difference between the rural, suburban, or urban community college location and the cosmopolitan latent social role of the CAO.

Rural was defined as not a MSA or PMSA and with a population of less than 500,000 . Suburban and urban were defined as a MSA or PMSA, respectively, with a population equal to or greater than 500,000. The hypothesis was not rejected. A one-way ANOVA analysis was conducted and the researcher determined there was not a significant difference in the cosmopolitan latent social role of CAOs and community college location at the .05 confidence level, $F(2,252)=.118, p>.05$. Table 20 presents the results of the analysis.

NH6f. There was no difference between the rural, suburban, or urban community college location and the local latent social role of the CAO. 
Table 20

ANOVA Results - Community College Location and Latent Social Role

\begin{tabular}{lccccc}
\hline Scale & SS & $d f$ & MS & $F$ & Sig. \\
\hline College Location (rural, suburban, urban) & & & & & \\
Between Groups & & & & & \\
Cosmo & .04 & 2 & .023 & .118 & .889 \\
Local & .21 & 2 & .106 & .363 & .696 \\
Within Groups & & & & & \\
Cosmo & 48.34 & 252 & .192 & -- & -- \\
Local & 73.97 & 252 & .294 & -- & -- \\
\hline
\end{tabular}

Rural was defined as not a MSA or PMSA and with a population of less than 500,000. Suburban and urban was defined as a MSA or PMSA, respectively, with a population equal to or greater than 500,000 . The hypothesis was not rejected. A one-way ANOVA analysis was conducted and the researcher determined there was not a significant difference in the local latent social role of CAOs and community college location at the .05 confidence level, $F(2,252)=.363, p>.05$. Table 20 presents the results of the analysis.

NH6g. There was no difference between the number of locations for the community college and the cosmopolitan latent social role of the CAO.

Location was defined as either a single location or multiple locations. The hypothesis was not rejected. The difference between the cosmopolitan latent social role of the $\mathrm{CAO}$ and the number of locations for the community college was not significant based on $t(287)=.309, p>.05$. Table 21 presents the results of the analysis. 
Table 21

Descriptive Statistics and t tests Results - Number of Locations and Latent Social Role

\begin{tabular}{|c|c|c|c|c|c|c|c|}
\hline Scale & $\mathrm{N}$ & $\begin{array}{l}\% \text { of } \\
\text { Total }\end{array}$ & Mean & $\begin{array}{c}\text { Std. } \\
\text { Deviation }\end{array}$ & $t$ test & $d f$ & $\begin{array}{c}\text { Sig. } \\
\text { (2-tailed) }\end{array}$ \\
\hline \multicolumn{8}{|c|}{ Number of Locations } \\
\hline Single & 120 & 42 & & & & & \\
\hline Cosmo & & & 2.73 & .42 & .31 & 287 & .76 \\
\hline Local & & & 3.94 & .59 & -3.24 & 287 & $.001 * *$ \\
\hline Multiple & 169 & 58 & & & & & \\
\hline Cosmo & & & 2.71 & .45 & .31 & 287 & .76 \\
\hline Local & & & 4.15 & .48 & -3.24 & 287 & $.001 * *$ \\
\hline
\end{tabular}

NH6h. There was no difference between the number of locations for the community college and the local latent social role of the CAO.

Location was defined as either a single location or multiple locations. The hypothesis was rejected. There was a significant difference between the local latent social role of the $\mathrm{CAO}$ and the number of locations for the community college based on $t$ (287) $=-3.24, p<.01$.

The analysis of the data indicated that the difference between the number of locations for the community college and the CAO's local latent social role was significant. CAOs at community colleges with a single or multiple locations identify themselves as locals. Further analysis of the mean and standard deviation for the local latent social role and single or multiple locations indicated that the higher mean and 
standard deviation were associated with CAOs from institutions with multiple locations $($ mean $=4.15)$. Table 21 presents the results of the analysis.

NH6i. There was no difference between the population of the state where the community college was located and the cosmopolitan latent social role of the CAO.

A state with a small population was defined as less than 5 million. A state with a large population was defined as greater than 5 million. The hypothesis was rejected. There was a difference between the cosmopolitan latent social role of the CAO and the population of the state where the institution was located, based on $t(264)=2.909, p<$ .01 . Table 22 presents the results of the analysis. The analysis of the data indicated that the difference between the population of the state where the community college was located and the CAO's cosmopolitan latent social role was significant.

NH6j. There was no difference between the population of the state where the community college was located and the local latent social role of the CAO.

A state with a small population was defined as less than 5 million. A state with a large population was defined as greater than 5 million. The hypothesis was not rejected. There was no difference indicated between the local latent social role of the CAO and the population of the state where the institution was located, based on $\mathrm{t}(264)=.808, p>.05$. Table 22 presents the results of the analysis.

Summary. The analysis of the survey data for the institutional variables indicated three significant findings. The difference between the number of employees (small - less than 1,000 or large - greater than 1,000) and the CAO's local latent social role was significant. CAOs at small and large community colleges identify themselves as locals. 
Table 22

Descriptive Statistics and t test Results - Population of State and Latent Social Role

\begin{tabular}{|c|c|c|c|c|c|c|c|c|}
\hline Scale & $\mathrm{N}$ & $\begin{array}{l}\% \text { of } \\
\text { Total }\end{array}$ & Mean & $\begin{array}{c}\text { Std. } \\
\text { Deviation }\end{array}$ & $t$ test & $d f$ & $\begin{array}{c}\text { Sig. } \\
\text { (2-tailed) }\end{array}$ & \\
\hline \multicolumn{9}{|c|}{ State Institution Located in } \\
\hline Small & 90 & 34 & & & & & & \\
\hline Cosmo & & & 2.84 & .43 & 2.909 & 264 & .004 & $* *$ \\
\hline Local & & & 4.10 & .42 & .808 & 264 & .420 & \\
\hline Large & 176 & 66 & & & & & & \\
\hline Cosmo & & & 2.68 & .42 & 2.909 & 264 & .004 & $* *$ \\
\hline Local & & & 4.04 & 4.04 & .808 & 264 & .420 & \\
\hline
\end{tabular}

The difference between the number of locations (single or multiple) for the community college and the CAO's local latent social role was significant. CAOs at community colleges with a single or multiple locations identify themselves as locals. Conversely, a difference was identified between the cosmopolitan latent social role of the CAO and the population of the state where the community college was located. States with a small population were defined as fewer than 5 million people and states with a large population were defined as greater than 5 million people.

The other environmental variables studied for public community colleges did not indicate a significant difference in the latent social role of the CAO. These variables included community college size based on unduplicated headcount, and community college location, defined as rural, suburban or urban. 
Research Question 7. Was there a difference between the public community college CAO's personal or demographic characteristics (age, birth month, gender, marital status, education, tenure in office, research and publication history) and the CAO's latent social role? Two different statistical measures were used to determine the difference between the CAO demographic factors and the CAO's latent social role. Gender, birth month (summarized as early in the year, January - April, or late in the year, May - December), year of last publication (summarized as 2006-2010, or prior to 2006), and tenure as CAO (summarized as less than 6 years or 6 years or more) were analyzed using $t$ tests. The ANOVA statistical method was used to review age (summarized as under age $30,30-39,40-49,50-59,60-69$, or over 70), marital status (single, married, divorced or widowed), and highest degree earned ( $\mathrm{PhD}, \mathrm{EdD}$, or Other).

The demographic data collected for community college CAOs in relation to age, marital status and highest degree earned are summarized in Table 23 using descriptive statistics. This includes the number of observations, percentage of the total, mean, and standard deviation of the data collected.

NH7a. There was no difference between the CAO's age and the cosmopolitan latent social role of the CAO.

$\mathrm{CAO}$ age was summarized for analysis into the following categories: under age $30,30-39,40-49,50-59,60-69$, or over 70 . The hypothesis was not rejected. A one-way ANOVA analysis was conducted and the researcher determined there was not a significant difference in the cosmopolitan latent social role of the $\mathrm{CAO}$ and the community college CAO's age at the $p<.05$ confidence level, $F(4,261)=.862, p>.05$. Table 24 presents the ANOVA results and Table 25 presents the Tukey HSD results. 
Table 23

Descriptive Statistics - Demographic Factors for CAOs

\begin{tabular}{|c|c|c|c|c|c|c|}
\hline Scale & $\mathrm{N}$ & $\%$ of Total & $\begin{array}{c}\text { Cosmo } \\
\text { Mean }\end{array}$ & $\begin{array}{c}\text { Cosmo } \\
\text { SD }\end{array}$ & $\begin{array}{l}\text { Local } \\
\text { Mean }\end{array}$ & $\begin{array}{c}\text { Local } \\
\text { SD }\end{array}$ \\
\hline \multicolumn{7}{|l|}{ Age } \\
\hline $30-39$ & 9 & 3 & 2.76 & .38 & 4.14 & .64 \\
\hline $40-49$ & 51 & 19 & 2.66 & .44 & 4.21 & .47 \\
\hline $50-59$ & 127 & 47 & 2.73 & .40 & 4.06 & .58 \\
\hline $60-69$ & 76 & 28 & .280 & .48 & 4.00 & .48 \\
\hline 70 and over & 3 & 0 & 2.62 & .30 & 3.25 & .87 \\
\hline \multicolumn{7}{|l|}{ Marital Status } \\
\hline Single & 25 & 9 & 2.71 & .48 & 3.99 & .52 \\
\hline Married & 214 & 79 & 2.70 & .42 & 4.10 & .55 \\
\hline Divorced & 29 & 11 & 2.96 & .41 & 3.92 & .50 \\
\hline Widowed & 4 & 1 & 2.93 & .27 & 4.00 & .46 \\
\hline \multicolumn{7}{|l|}{ Degree } \\
\hline $\mathrm{PhD}$ & 109 & 40 & 2.73 & .45 & 4.08 & .55 \\
\hline EdD & 82 & 31 & 2.73 & .41 & 4.11 & .53 \\
\hline Other & 81 & 29 & 2.74 & .44 & 3.99 & .56 \\
\hline
\end{tabular}

NH7b. There was no relationship between the CAO's age and the local latent social role of the CAO.

CAO age was summarized for analysis into the following categories: under age $30,30-39,40-49,50-59,60-69$, or over 70 . The hypothesis was rejected. A oneway ANOVA analysis was conducted and the researcher determined there was a significant difference in the local latent social role of the CAO and CAO age at the $p<$ .05 level, $F(4,261)=2.930, p<.05$. Table 24 presents the ANOVA results. 
Table 24

Demographic Factors - ANOVA Results for CAO Age

\begin{tabular}{lccccc}
\hline Scale & SS & $d f$ & MS & $F$ & Sig. \\
\hline Age & & & & & \\
Between Group & .642 & 4 & .161 & .862 & .49 \\
Cosmo & 3.409 & 4 & .852 & 2.930 & $.021^{*}$ \\
Local & & & & & \\
Within Groups & & & & \\
Cosmo & 48.608 & 261 & .186 & & \\
Local & 75.910 & 261 & .291 & & \\
\hline
\end{tabular}

Table 25

Tukey HSD Post Hoc Results - Cosmopolitan Latent Social Role by CAO Age

\begin{tabular}{lllcll}
\hline \multirow{2}{*}{ Scale } & $\begin{array}{c}\text { (I) intent to pursue } \\
\text { a presidency }\end{array}$ & $\begin{array}{c}\text { (J) intent to } \\
\text { pursue a } \\
\text { presidency }\end{array}$ & $\begin{array}{c}\text { Mean Difference } \\
(\mathrm{I}-\mathrm{J})\end{array}$ & SE & $p$ \\
\hline Cosmopolitan & $30-39$ & $40-49$ & .10084 & .15603 & .967 \\
& $50-59$ & .03412 & .14886 & .999 \\
& $60-69$ & -.03697 & .15213 & .999 \\
& & More than 70 & .14286 & .28770 & .998 \\
& $30-39$ & -.10084 & .15603 & .967 \\
& $40-49$ & $50-59$ & -.06672 & .07154 & .884 \\
& $60-69$ & -.13781 & .07812 & .397 \\
& & & .04202 & .25638 & 1.000
\end{tabular}

Table 25 continues 


\begin{tabular}{|c|c|c|c|c|c|}
\hline Scale & $\begin{array}{l}\text { (I) intent to pursue } \\
\text { a presidency }\end{array}$ & $\begin{array}{l}(\mathrm{J}) \text { intent to } \\
\text { pursue a } \\
\text { presidency }\end{array}$ & $\begin{array}{l}\text { Mean Difference } \\
(\mathrm{I}-\mathrm{J})\end{array}$ & SE & $p$ \\
\hline \multirow[t]{4}{*}{ Cosmopolitan } & $50-59$ & $30-39$ & -.03412 & .14886 & .999 \\
\hline & & $40-49$ & .06672 & .07154 & .884 \\
\hline & & $60-69$ & -.07109 & .06259 & .787 \\
\hline & & More than 70 & .10874 & .25208 & .993 \\
\hline \multirow[t]{4}{*}{ Cosmopolitan } & $60-69$ & $30-39$ & .3697 & .15213 & .999 \\
\hline & & $40-49$ & .13781 & .07812 & .397 \\
\hline & & $50-59$ & .07109 & .06259 & .787 \\
\hline & & More than 70 & .17982 & .25403 & .955 \\
\hline \multirow[t]{4}{*}{ Cosmopolitan } & More than 70 & $30-39$ & -.17286 & .28770 & .988 \\
\hline & & $40-49$ & -.04202 & .25638 & 1.000 \\
\hline & & $50-59$ & -.10874 & .25208 & .993 \\
\hline & & $60-69$ & -.17982 & .25403 & .955 \\
\hline
\end{tabular}

${ }^{*} p<.05$

Additional post hoc tests were necessary to determine which of the age categories represented a significant difference in the CAO local latent social role. Tukey's Honestly Significant Difference (HSD) analysis indicated a mean difference of .96 at the .05 significance level between CAOs who were age 40 - 49 and the local latent social role. The results of the Tukey HSD analysis are presented in Table 26.

NH7c. There was no difference between the CAO's birth month and the cosmopolitan latent social role of the CAO. 
Table 26

Tukey HSD Post Hoc results - Local Latent Social Role by CAO Age

\begin{tabular}{|c|c|c|c|c|c|c|}
\hline Scale & $\begin{array}{l}\text { (I) intent to } \\
\text { pursue a } \\
\text { presidency }\end{array}$ & $\begin{array}{l}\text { (J) intent to } \\
\text { pursue a } \\
\text { presidency }\end{array}$ & $\begin{array}{l}\text { Mean Difference } \\
(\mathrm{I}-\mathrm{J})\end{array}$ & & $\mathrm{SE}$ & $p$ \\
\hline \multirow[t]{4}{*}{ Local } & $30-39$ & $40-49$ & -.06699 & & 19498 & .997 \\
\hline & & $50-59$ & .07590 & & .18603 & .994 \\
\hline & & $60-69$ & .14218 & & .19011 & .945 \\
\hline & & More than 70 & .88889 & & .35953 & .100 \\
\hline \multirow[t]{4}{*}{ Local } & $40-49$ & $30-39$ & .06699 & & 19498 & .997 \\
\hline & & $50-59$ & .14289 & & .08940 & .500 \\
\hline & & $60-69$ & .20917 & & .09762 & .205 \\
\hline & & More than 70 & .95588 & $*$ & .32039 & .026 \\
\hline \multirow[t]{4}{*}{ Local } & $50-59$ & $30-39$ & -.07590 & & .18603 & .994 \\
\hline & & $40-49$ & -.14289 & & .08940 & .500 \\
\hline & & $60-69$ & .06628 & & .07821 & .915 \\
\hline & & More than 70 & .81299 & & .31502 & .077 \\
\hline \multirow[t]{4}{*}{ Local } & $60-69$ & $30-39$ & -.14218 & & .19011 & .945 \\
\hline & & $40-49$ & -.20917 & & .09762 & .205 \\
\hline & & $50-59$ & -.06628 & & .07821 & .915 \\
\hline & & More than 70 & .74671 & & .31745 & .132 \\
\hline \multirow[t]{4}{*}{ Local } & More than 70 & $30-39$ & -.88889 & & .35953 & .100 \\
\hline & & $40-49$ & -.95588 & $*$ & .32039 & .026 \\
\hline & & $50-59$ & -.81299 & & .31502 & .077 \\
\hline & & $60-69$ & -.74671 & & .31745 & .132 \\
\hline
\end{tabular}

${ }^{*} p<.05$ 
The survey data was summarized into two categories: CAOs born January April, or May - December. The hypothesis was not rejected. There was no difference indicated between the cosmopolitan latent social role of the CAO and birth month, based on $\mathrm{t}(270)=-.81, p>.05$.

NH7d. There was no difference between the CAO's birth month and the local latent social role of the CAO.

The hypothesis was not rejected. There was no difference indicated between the local latent social role of the CAO and CAO birth month, based on $t(270)=-.20, p>.05$.

Descriptive statistics indicated that 96 CAOs, or 35\%, who were born from January to April, and 176 CAOs, or 65\%, who were born May - December. Latent social roles were dominant regardless of birth month. Table 27 presents the results of the $t$ test and the descriptive statistics.

Table 27

Demographic Factors and t tests Results - CAO Birth Month

\begin{tabular}{lccccccc}
\hline Scale & $\mathrm{N}$ & $\begin{array}{c}\text { \% of } \\
\text { Total }\end{array}$ & Mean & $\begin{array}{c}\text { Std. } \\
\text { Deviation }\end{array}$ & $t$ test & $d f$ & $\begin{array}{c}\text { Sig. } \\
\text { (2-tailed) }\end{array}$ \\
\hline January - April & 96 & 35 & & & & & \\
Cosmo & & & 2.71 & .41 & -.81 & 270 & .42 \\
Local & & & 4.06 & .58 & -.20 & 270 & .84 \\
May-December & 176 & 65 & & & & & \\
Cosmo & & & 2.75 & .44 & -.81 & 270 & .42 \\
Local & & & 4.07 & .53 & -.20 & 270 & .84 \\
\hline
\end{tabular}


NH7e. There was no difference between the CAO's gender and the cosmopolitan latent social role of the $\mathrm{CAO}$.

The hypothesis was not rejected. There was no difference between CAO gender and cosmopolitan latent social roles, based on $t(270)=.11, p>.05$.

NH7f. There was no difference between the CAO's gender and the local latent social role of the CAO.

The hypothesis was not rejected. There was no difference between CAO gender and local latent social roles, based on $t(270)=.36, p>.05$.

The survey resulted in 138 female participants or 51\% of the survey total, and 134 male participants or $49 \%$ of the survey total. Table 28 presents the results of the statistical analysis. Local latent social roles were dominant in both male and female CAOs.

Table 28

Demographic Factors and t test Results - CAO Gender

\begin{tabular}{|c|c|c|c|c|c|c|c|}
\hline Scale & $\mathrm{N}$ & $\begin{array}{l}\% \text { of } \\
\text { Total }\end{array}$ & Mean & $\begin{array}{c}\text { Std. } \\
\text { Deviation }\end{array}$ & $t$ test & $d f$ & $\begin{array}{c}\text { Sig. } \\
\text { (2-tailed) }\end{array}$ \\
\hline Male & 134 & 49 & & & & & \\
\hline Cosmo & & & 2.73 & .43 & .11 & 270 & .91 \\
\hline Local & & & 4.05 & .54 & .36 & 270 & .72 \\
\hline Female & 138 & 51 & & & & & \\
\hline Cosmo & & & 2.74 & .44 & .11 & 270 & .91 \\
\hline Local & & & 4.08 & .55 & .36 & 270 & .72 \\
\hline
\end{tabular}

NH7g. There was no difference between the CAO's marital status and the cosmopolitan latent social role of the CAO. 
Marital status was defined as single, married, divorced or widowed. The hypothesis was rejected. There was a difference between marital status and the cosmopolitan latent social role, $F(3,268)=3.42, p<.05$. Table 29 presents the results of the statistical analysis.

Table 29

Demographic Factors and ANOVA Results - CAO Marital Status

\begin{tabular}{lccccc}
\hline Scale & SS & $d f$ & MS & $F$ & Sig. \\
\hline Marital Status & & & & & \\
Between Groups & & & & & \\
Cosmo & 1.85 & 3 & .62 & 3.42 & $.02^{*}$ \\
Local & .95 & 3 & .32 & 1.06 & .37 \\
Within Groups & & & & & \\
Cosmo & 48.32 & 268 & .18 & & \\
Local & 79.86 & 268 & .30 & & \\
\hline
\end{tabular}

$* p<.05$

Post hoc tests were performed to determine which marital status was impacted by the cosmopolitan latent social role. Tukey's Honestly Significant Difference (HSD) analysis indicated a mean difference of -.26 at the .05 significance level between the marital status of married and divorced and the cosmopolitan latent social role. Table 30 presents the results of the Tukey HSD post hoc analysis.

NH7h. There was no difference between the CAO's marital status and the local latent social role of the CAO. 
Table 30

Tukey HSD Post Hoc Results - Cosmopolitan Latent Social Role by Marital Status

\begin{tabular}{|c|c|c|c|c|c|}
\hline Scale & $\begin{array}{c}\text { (I) } \\
\text { Marital Status }\end{array}$ & $\begin{array}{c}(\mathrm{J}) \\
\text { Marital Status }\end{array}$ & $\begin{array}{c}\text { Mean Difference } \\
(\mathrm{I}-\mathrm{J})\end{array}$ & SE & $p$ \\
\hline \multirow[t]{3}{*}{ Cosmopolitan } & Single & Married & .0107 & .08975 & .065 \\
\hline & & Divorced & -.2463 & .11588 & .000 \\
\hline & & Widowed & -.2143 & .22866 & .000 \\
\hline \multirow[t]{3}{*}{ Cosmopolitan } & Married & Single & -.0107 & .08975 & .065 \\
\hline & & Divorced & $-.2570 *$ & .08402 & .764 \\
\hline & & Widowed & -.2250 & .21428 & .272 \\
\hline \multirow[t]{3}{*}{ Cosmopolitan } & Divorced & Single & .2463 & .11588 & .000 \\
\hline & & Married & $.2570^{*}$ & .08402 & .764 \\
\hline & & Widowed & .0320 & .22647 & .719 \\
\hline \multirow[t]{3}{*}{ Cosmopolitan } & Widowed & Single & .2143 & .22866 & .000 \\
\hline & & Married & .2250 & .21428 & .272 \\
\hline & & Divorced & -.0320 & .22647 & .719 \\
\hline
\end{tabular}

$* p<.05$

Marital status was defined as single, married, divorced or widowed. The hypothesis was not rejected. There was no difference indicated between marital status and the local latent social role, $F(3,268)=1.06, p>.05$. Table 28 presents the results of the statistical analysis.

NH7i. There was no difference between the CAO's highest level of education and the cosmopolitan latent social role of the CAO. 
The CAO's highest level of education was reported as $\mathrm{PhD}, \mathrm{EdD}$ or other. The hypothesis was not rejected. A one-way ANOVA analysis indicated there was not a significant difference in the cosmopolitan latent social role of CAO and the CAO's highest level of education, $F(2,269)=.01, p>.05$.

$\mathrm{NH} 7 \mathrm{j}$. There was no difference between the CAO's highest level of education and the local latent social role of the CAO.

The CAO's highest level of education was reported as $\mathrm{PhD}, \mathrm{EdD}$ or other. The hypothesis was not rejected. A one-way ANOVA analysis indicated there was not a significant difference in the local latent social role of the CAO and CAO's highest level of education, $F(2,269)=1.07, p>.05$. Table 31 presents the results of the analysis.

Table 31

Demographic Factors and ANOVA Results - CAO Highest Level of Education

\begin{tabular}{lccccc}
\hline Scale & SS & $d f$ & MS & $F$ & Sig. \\
\hline Degree & & & & & \\
Between Groups & & & & & \\
Cosmo & .004 & 2 & .002 & .01 & .99 \\
Local & .64 & 2 & .32 & 1.07 & .34 \\
Within Groups & & & & & \\
Cosmo & 50.16 & 269 & .19 & & \\
Local & 80.17 & 269 & .30 & & \\
\hline
\end{tabular}

$* p<.05$ 
NH7k. There was no difference between the CAO's tenure in office and the cosmopolitan latent social role of the CAO.

Tenure as a CAO was categorized as less than 5 years, or more than 5 years. The hypothesis was not rejected. There was no difference between the CAO's tenure in office and the cosmopolitan latent social role, based on $t(288)=-.98, p>.05$.

NH71. There was no difference between the CAO's tenure in office and the local latent social role of the CAO.

Tenure as a $\mathrm{CAO}$ was categorized as less than 5 years, or more than 5 years. The hypothesis was not rejected. There was no difference between CAO's tenure in office and the local latent social role, based on $t(288)=.71, p>.05$.

The survey resulted in 168 CAOs, or $58 \%$, who had been served less than 5 years and 122 CAOs, or $42 \%$, who had served more than 5 years. Local latent social roles were dominant for CAOs with a tenure of less than or greater than 5 years. Table 32 presents the results of the analysis of CAO Tenure.

NH7m. There was no difference between the CAO's publication history and the cosmopolitan latent social role of the CAO.

The data was categorized by CAOs who had published 2006 - 2010, or prior to 2006. The hypothesis was not rejected. There was no difference between the CAO's publication history and the cosmopolitan latent social role, based on $t(268)=.11, p>.05$.

NH7n. There was no difference between the CAO's publication history and the local latent social role of the CAO. 
Table 32

Demographic Factors and t test Results - CAO Tenure

\begin{tabular}{|c|c|c|c|c|c|c|c|}
\hline Scale & $\mathrm{N}$ & $\begin{array}{l}\% \text { of } \\
\text { Total }\end{array}$ & Mean & $\begin{array}{c}\text { Std. } \\
\text { Deviation }\end{array}$ & $t$ test & $d f$ & $\underset{\text { Sig. }}{\text { (2-tailed) }}$ \\
\hline \multicolumn{8}{|l|}{ Tenure as CAO } \\
\hline Less than 5 years & 168 & 58 & & & & & \\
\hline Cosmo & & & 2.70 & .42 & -.98 & 288 & .33 \\
\hline Local & & & 4.08 & .52 & .71 & 288 & .48 \\
\hline 5 Years or More & 122 & 42 & & & & & \\
\hline Cosmo & & & 2.74 & .45 & -.98 & 288 & .33 \\
\hline Local & & & 4.04 & .57 & .71 & 288 & .48 \\
\hline
\end{tabular}

The data was categorized by CAOs who had published 2006 - 2010, or prior to 2006. The hypothesis was not rejected. There was no difference between the CAO's publication history and the local latent social role, based on $t(268)=1.60, p>.05$.

The survey resulted in $190 \mathrm{CAOs}$, or $70 \%$, who have not published in the last 5 years, and $80 \mathrm{CAOs,} \mathrm{or} \mathrm{30 \% ,} \mathrm{who} \mathrm{have} \mathrm{published} \mathrm{in} \mathrm{the} \mathrm{last} 5$ years. Local latent social roles were dominant for CAOs who had published in $2006-2010$ or prior to 2005. Table 33 presents the results of the analysis.

Summary of Demographic Findings. The analysis of the survey data for the CAO demographic variables indicated two significant differences in the age and marital status variables to latent social roles. There was a significant difference in CAO age and the CAO local latent social role; specifically the age category $40-49$ and the local latent social role. There was a significant difference in the CAO's marital status of married and 
Table 33

Demographic Factors and t test Results - Year of Last Publication

\begin{tabular}{|c|c|c|c|c|c|c|c|}
\hline Scale & $\mathrm{N}$ & $\begin{array}{l}\% \text { of } \\
\text { Total }\end{array}$ & Mean & $\begin{array}{c}\text { Std. } \\
\text { Deviation }\end{array}$ & $t$ test & $d f$ & $\begin{array}{c}\text { Sig. } \\
\text { (2-tailed) }\end{array}$ \\
\hline \multicolumn{8}{|c|}{ Year of Last Publication } \\
\hline 2006- 2010 & 80 & 30 & & & & & \\
\hline Cosmo & & & 2.70 & .47 & .105 & 268 & .92 \\
\hline Local & & & 4.15 & .51 & 1.60 & 268 & .11 \\
\hline 2005 or Prior & 190 & 70 & & & & & \\
\hline Cosmo & & & 2.73 & .41 & .105 & 268 & .92 \\
\hline Local & & & 4.03 & .56 & 1.60 & 268 & .11 \\
\hline
\end{tabular}

divorced and their cosmopolitan latent social role. CAOs who were not married or divorced were more likely to have a cosmopolitan latent social role.

The other demographic variables studied for public community colleges CAOs did not indicate a significant difference in their latent social role. These variables included CAO month of birth, gender, highest level of education, tenure in the CAO position, and research/publication record. However, local social roles were found to be dominant in all of the categories studied.

Summary of All Findings. Public community college CAO's scores for the cosmopolitan and local latent social roles indicated that they were more "local" with an overall score of 4.06 on the local scale, and an overall score of 2.72 on the cosmopolitan scale. The majority, or $94 \%$, of the CAOs reported a local latent social role of greater than 3; only $20 \%$ reported a cosmopolitan latent social role of greater than 3 . Cosmopolitan and local latent social role scores were inversely related; survey 
participants with a high local latent social role score were likely to have a low cosmopolitan latent social role score.

Research hypothesis $1-5$ resulted in three significant results. A significant positive correlation was identified between CAO's with local latent social roles and higher levels of job satisfaction. CAOs with a cosmopolitan latent social role were negatively correlated to an intention to pursue a community college presidency, with the response "not at all" indicating the most significant mean difference. CAOs with a local latent social role correlated positively and strongly with an intention to pursue a community college presidency, with the significant differences in the responses "to some extent" and to a "very great extent." The analysis of the difference between the CAO's intent to turnover and their cosmopolitan or local latent social role failed to demonstrate a correlation. The analysis did not indicate any correlation between the CAO's cosmopolitan or local latent social role and the selection of the CAO as an internal or external job candidate.

The analysis of the survey data for the institutional variables indicated three significant findings. There was a significant difference between the number of employees (small - less than 1,000, or large - greater than 1,000) at public community colleges, the number of locations (single or multiple) and the local latent social role of the community college CAO. In addition, a difference was identified between the cosmopolitan latent social role of the $\mathrm{CAO}$ and the population of the state where the community college was located. The other environmental variables studied for public community colleges did not present significant differences in the latent social role of the CAO. These variables 
included community college size based on unduplicated headcount, and community college location, defined as rural, suburban or urban.

The analysis of the survey data for the CAO demographic variables indicated two significant differences in age and marital status in relation to latent social roles. The significant difference in the CAO age and their local latent social role was identified; specifically the age category $40-49$ and the CAO local latent social role scores. There was a significant difference in the CAO's marital status of married and divorced and their cosmopolitan latent social role. CAOs who were not married or divorced were more likely to have a cosmopolitan latent social role. The other demographic variables studied for public community colleges CAOs did not present a significant difference in their latent social role. These variables included CAO birth month, gender, highest level of education, tenure in the $\mathrm{CAO}$ position, and research/publication record. CAO month of birth, gender, tenure in the CAO position, and research/publication record indicated a dominant local latent social role orientation for CAOs.

These findings will be discussed further in Chapter 5. In addition, the significance of the findings and recommendations for future research and practice will be presented. 


\section{Chapter 5}

\section{Conclusions and Discussion}

\section{Summary of Study}

The impact of cosmopolitan and local latent social roles on different professional occupations and their organizational behavior has been studied since Gouldner's seminal study was published in 1957 . This study was conducted to understand the impact latent social roles may have on the community college chief academic officer's (CAO) initial selection and employment, job satisfaction, turnover, and intent to pursue a community college presidency. A better understanding of the correlation between these factors and latent social roles may help CAOs to better understand the impact of their own latent social tendencies on their professional life. This research might also increase awareness within the larger community college community and administration as to how these roles impact the CAO, who is the second in command in the community college organization.

\section{Sample, Procedure and Instruments}

The population surveyed included 932 CAOs from public community colleges in the United States; the Higher Education Directory (HED) provided the names and e-mails for the population. Dillman's (2007) suggested survey protocol of five contacts was used, adapted for an online survey. CAOs were contacted via e-mail and invited to participate in an online survey. The survey was based on a 44-item questionnaire used by Larwood et al. (1998) in their research on the impact of latent social roles on business managers. 


\section{Data Analysis}

The research questions in this study were analyzed using the survey results and quantitative statistical analysis techniques. Descriptive statistics were used to report mean, standard deviation, and percentage information for all data.

The validity of the cosmopolitan and local latent social role scales were confirmed using confirmatory factor analysis. Mean scores for the cosmopolitan related questions and local related questions were calculated to obtain a cosmopolitan and local score for each participant. The Pearson product-moment correlation statistic was used to determine the interrelationship between the CAOs cosmopolitan and local latent social roles and job satisfaction, intent to pursue a community college presidency, intent to turnover, and selection of an internal or external job candidate. Statistical methods used to determine the difference between the CAO's institution environmental factors, the CAO demographic factors, and the CAO's latent social role included the ANOVA and $t$ test methods.

\section{Limitations}

Limitations of the current study were identified by the researcher. The response rate to the survey was $30 \%$; this was adequate but the findings of this study may only be able to be generalized to the population of public community college CAOs in the United States who reported information to the Higher Education Directory (HED), as this served as the data source. Findings are limited to the studied population of public community college CAOs in the United States.

The study was conducted for CAOs serving in 2009/2010; the correlation provides a snapshot of this study group and will not represent public community college 
CAOs in the future. There was little control over responses, and survey responses reflect the individual opinions of each CAO.

Causal relationships cannot be inferred from the results that were significant due to the correlation design of the analysis.

The study was cross sectional rather than longitudinal; this study cannot report if the participant's cosmopolitan and local social roles are fixed, change over time, or are influenced by the position the participant was holding, such as the CAO position.

CAOs self reported in this study; the survey responses may reflect the participants' bias or caution in answering the research questions. Demographic variables were also collected from CAO self reports and may not be accurate.

CAOs with cosmopolitan latent social roles were a small percentage of this study. This may reflect the survey population accurately or may indicate that cosmopolitan CAOs did not respond.

\section{Summary of Findings}

- The survey identified a higher percentage (94\%) of CAOs with local latent social roles; the overall local latent social role score was a 4.06.

- The survey identified a low percentage (20\%) of community college CAOs with cosmopolitan latent social roles; the overall cosmopolitan latent social role score was a 2.72 .

- The survey identified an inverse correlation between cosmopolitan and local latent social roles of community college CAOs. Survey participants with a high local latent social role score were likely to have a low cosmopolitan latent social role score. 
- A significant positive correlation was identified between CAOs with local latent social roles and higher levels of job satisfaction.

- There was no significant correlation indicated between CAOs with a cosmopolitan latent social role and job satisfaction.

- CAOs with a cosmopolitan latent social role were negatively correlated to an intention to pursue a community college presidency, with the response "not at all" indicating the most significant mean difference.

- CAOs with a local latent social role correlated positively and strongly with an intention to pursue a community college presidency, with the significant differences in the responses "to some extent" and to a "very great extent."

- The CAO's intent to turnover and their cosmopolitan or local latent social role failed to demonstrate a correlation.

- The analysis did not indicate any correlation between the CAO's cosmopolitan or local latent social role and the selection of the CAO as internal or external job candidate.

- Descriptive statistics indicated that $48 \%$ of the survey population were internal candidates for their CAO position and 52\% were external candidates.

- The difference between the number of employees (small - less than 1,000 or large - greater than 1,000) and the CAO's local latent social role was significant. CAOs at small and large community colleges identify themselves as locals.

- The difference between the number of locations (single or multiple) for the community college and the CAO's local latent social role was significant. 
- CAOs at community colleges with a single or multiple locations identify themselves as locals.

- A difference was identified between the cosmopolitan latent social role of the $\mathrm{CAO}$ and the population of the state where the community college was located.

- There was not a significant difference between community college size, based on unduplicated headcount, and the CAO's latent social role.

- There was not a significant difference between community college location (rural, suburban, or urban) and the CAO's latent social role.

- A significant difference in CAO age and their local latent social role was identified; specifically the age category $40-49$ and the CAO local latent social role scores.

- There was a significant difference in the CAO's marital status of married and divorced and their cosmopolitan latent social role. CAOs who were not married or divorced were more likely to have a cosmopolitan latent social role.

- The other demographic variables studied for public community colleges CAOs did not present a significant difference in their latent social role. These variables included CAO month of birth, gender, highest level of education, tenure in the $\mathrm{CAO}$ position, and research/publication record.

- $\mathrm{CAO}$ month of birth, gender, tenure in the CAO position, and research/publication record indicated a dominant local latent social role orientation for CAOs. 


\section{Discussion}

The researcher used the analysis of the data to answer the seven research questions presented in this study.

\section{Research Question 1. Was there a correlation between the public} community college CAO's job satisfaction and their latent social role and does the correlation vary according to the nature of the latent social role? A correlation was identified between the public community college CAO's job satisfaction and their latent social role. Specifically, CAOs who had a predominant local latent social role correlated with higher levels of job satisfaction. The study failed to identify a correlation between CAOs with a strong cosmopolitan latent social role score and job satisfaction. The Larwood et al. (1998) study also found that job satisfaction was higher among those who were more strongly identified as local, and lower among those more strongly identified as cosmopolitan.

Gouldner's (1957) research identified individuals with a local latent social role as being loyal to the employing organization, having a lower commitment to specialized or professional skills, and having internal reference group orientations (to the organization). This loyalty and internal focus may help CAOs with a stronger local latent social role score to stay committed to their work and the organization, and this commitment may influence their job satisfaction.

CAOs with a strong cosmopolitan latent social role score would have a lower level of loyalty to the employing organization, have a high commitment to specialized or professional skills outside of the organization, and have external reference group orientations. The lack of a correlation, and the limited number of CAOs with strong 
cosmopolitan latent social roles in the study, may indicate that individuals with cosmopolitan latent social roles do not seek out the CAO position frequently, due to the organization demand of loyalty and focus on an internal reference group that runs contrary to the cosmopolitan's latent social role.

This may also indicate a community college administration preference for individuals with local latent social role orientations in selecting future CAOs. Presidents are often very influential in selecting the $\mathrm{CAO}$ and may select a $\mathrm{CAO}$ who is loyal, or has a local latent social role orientation.

\section{Research Question 2. Was there a correlation between the public} community college CAO's aspirations to pursue a community college presidency and the CAO's latent social role and does the correlation vary according to the nature of the latent social role? The study indicated an inverse relationship between CAO's with higher cosmopolitan latent social role scores and the intent to pursue a community college presidency, indicating they do not intend to do so. CAOs primarily come from an academic background; those CAOs with a higher cosmopolitan latent social role score may have a stronger commitment to their professional background rather than to the community college itself. The $\mathrm{CAO}$ with a cosmopolitan latent social role may not be interested in a community college presidency due to their lower level of loyalty to the community college organization.

CAOs with a strong local latent social role score correlated positively and strongly with an intention to pursue a community college presidency. Gouldner's (1957) local latent social role definition included loyalty to the employing organization. CAOs with local latent social roles are loyal to the employing organization, the community 
college. They are committed to helping community colleges succeed by taking a key leadership role as the $\mathrm{CAO}$, and for many of the participants surveyed, eventually plan to seek a community college presidency. Individuals with local latent social roles were also satisfied with their work; locals seek job satisfaction and promotion opportunities from their work organizations. Cosmopolitans, conversely, seek satisfaction and recognition from professional organizations.

\section{Research Question 3. Was there a correlation between the public} community college CAO's intent to turnover and the CAO's latent social role and does the correlation vary according to the nature of the latent social role? The analysis of the relationship between the CAO's intent to turnover and their latent social role failed to demonstrate a correlation. CAOs were relatively stable in their position; Table 34 summarizes the future plans of the CAOs.

Table 34

Community College Chief Academic Officer Future Plans

\begin{tabular}{lcccc}
\hline Scale & $\begin{array}{c}\text { Seek an Admin Position } \\
\text { (not Presidency) at a C }\end{array}$ & $\begin{array}{c}\text { Seek an Admin Position } \\
\text { in Higher Ed Not at a } \\
\text { CC }\end{array}$ & $\begin{array}{c}\text { Return to } \\
\text { the Faculty }\end{array}$ & Retire \\
\hline Not Planning to & 181 & 195 & 188 & 64 \\
Within one year. & 24 & 14 & 6 & 16 \\
$1-5$ years & 73 & 55 & 54 & 81 \\
$6-10$ years. & 13 & 20 & 23 & 64 \\
After 10 years & 2 & 9 & 22 & 68 \\
\hline
\end{tabular}


Although this was not one of the research hypotheses, a correlation was identified between intent to turnover and job satisfaction. The Larwood et al. (1998) study also reported a relationship between intent to turnover and job satisfaction. The correlation was to be expected, as the participants who were not satisfied with their job would be more proactively considering or actively looking for a new position.

A correlation was also identified between intent to turnover and intent to pursue a community college presidency. CAOs may be promoted internally to the presidency of the community college where they are currently working, but more often must seek a community college presidency by leaving their current positions.

CAOs plan to remain in their present administrative position, as $62 \%$ indicated they do not plan to seek another community college administrative position and $67 \%$ indicated they do not plan to seek a different higher education administrative position. Additionally, 64\% indicated they do not intend to return to the faculty. CAOs seemed content to stay where they were at, pursue a community college presidency, or eventually retire.

CAO retirement plans appear to have slowed. The survey indicated that $55 \%$ of CAOs plan to retire within 10 years. This was a lower percentage than previously reported for community college administrators; Weisman and Vaughan (2007) reported that $84 \%$ of presidents planned to retire within the next 10 years, which was an increase from those reporting plans to retire in 2001 (79\%) and in 1996 (68\%) (ACE, 2007). The economic downturn that began in 2008 may have impacted retirement plans. In addition, the large turnover in administrators may have already occurred prior to this study. 
Research Question 4. Was there a correlation between the selection of an internal or external candidate for the public community college CAO position and the CAO's latent social role and does the correlation vary according to the nature of the latent social role? The analysis did not indicate any correlation between the CAO's cosmopolitan or local latent social role and the selection of the CAO as an internal or external job candidate. The CAOs who responded to the study were almost evenly split between external and internal candidates; $48 \%$ were internal and 52\% were external. Cejda, McKenney, and Burley (2001) reported that 59\% of CAOs had been internal candidates. Amey et al. (2002) reported that 52\% of CAOs were promoted from within. The percentage of internal CAO candidates may have decreased due to a large number of retirements recently, the lack of available internal candidates, and/or a greater mobility of the workforce.

A correlation between the internal and external candidate and the CAO intent to pursue a community college presidency did occur; this was outside of the scope of the research question but was noted as being significant. The 139 internal candidates and 151 external candidates were negatively correlated to the intent to pursue a community college presidency option not at all, but were positively correlated to the intent to pursue a community college presidency to some extent and to a very great extent. The CAOs who were external candidates for their current positions had the higher mean score in the analysis. The higher mean score, and the larger number of external candidates in the study, provided the correlation between CAOs who were external candidates for their current position and their intention to pursue a community college presidency. Vaughan (1990) concluded that the pathway to the presidency was through the CAO office. The 
CAO's career plans may be influenced by career path research and recommendations by experts such as Vaughan and others, as well as by observation of the successful careers of other community college administrators.

Research Question 5. Was there a difference in intent to pursue a community college presidency and latent social role? CAOs with a cosmopolitan latent social role score displayed a difference in intention to pursue a community college presidency, with the response "not at all" indicating the most significant mean difference. CAOs with a local latent social role score presented significant differences in the responses "to some extent" and to a "very great extent" in relation to intention to pursue a community college presidency.

The intention to pursue a community college presidency was reported by time frame including (a) not planning to do this, (b) within one year, (c) $1-5$ years, (d) $6-10$ years, and (e) after 10 years. Figure 2 provides this information. A large percentage, $42 \%$, of CAOs do not plan to pursue a community college presidency; $16 \%$ indicate they plan to pursue a community college presidency within one year; $34 \%$ within $1-5$ years; $6 \%$ within $6-10$ years; and, $2 \%$ plan to pursue a community college presidency after 10 years.

Research Question 6. Was there a difference between the environmental factors of public community college size, number of employees, location (rural, suburban, urban), number of locations (single or multiple), or state of operation in relation to the latent social roles for public community college CAOs in the United States? The difference between the number of employees (small - less than 1,000, or large - greater than 1,000) at public community colleges and the local latent social role of 


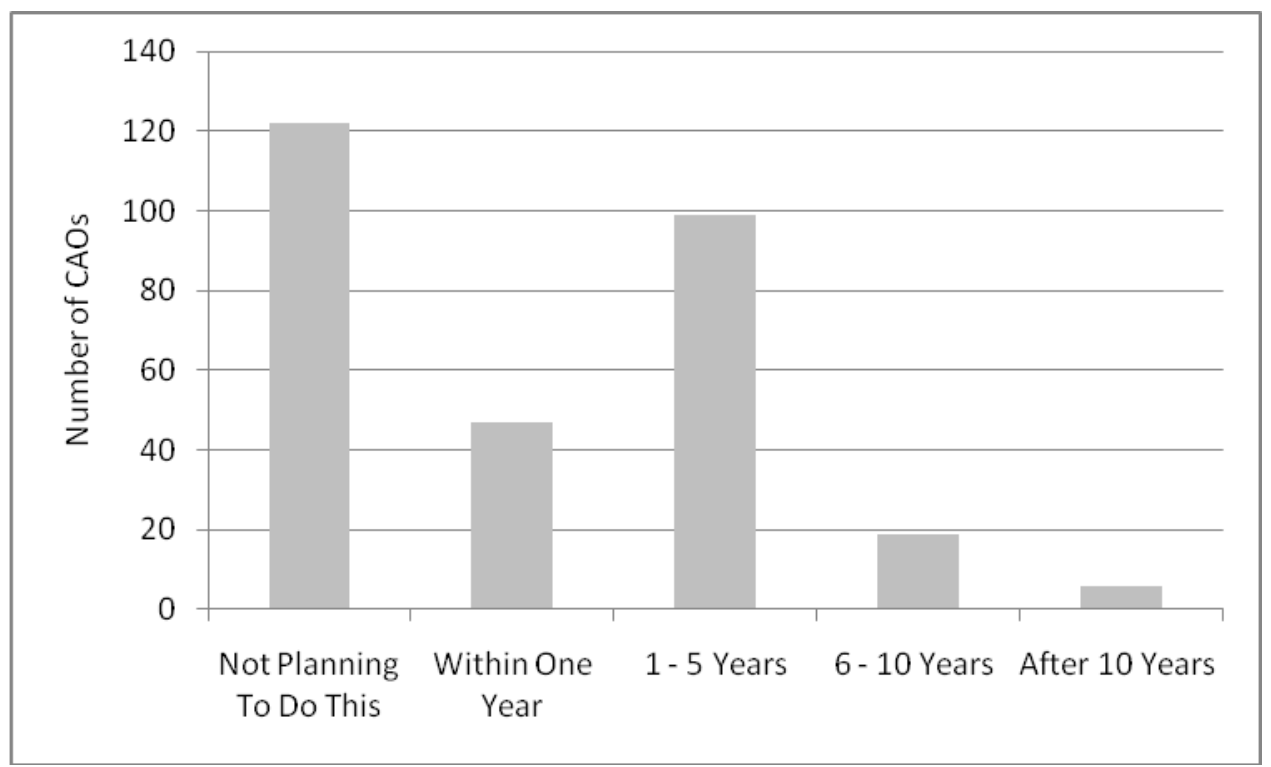

Figure 2. CAO intention to pursue a community college presidency.

the community college $\mathrm{CAO}$ was significant. CAOs at small and large community colleges identify themselves as locals. There were 229 institutions in the sample with less than 1,000 employees, and 60 with more than 1,000 employees. The CAO average local latent social role score was higher for those participants working at larger institutions (Figure 3).

The difference between the number of locations (single or multiple) and the local latent social role of the community college $\mathrm{CAO}$ was significant. CAOs at community colleges with a single or multiple locations identify themselves as locals. There were 120 institutions in the sample with a single location and 169 institutions with multiple locations under a common governance. The local latent role score was higher for CAOs at institutions with multiple locations (Figure 4). 


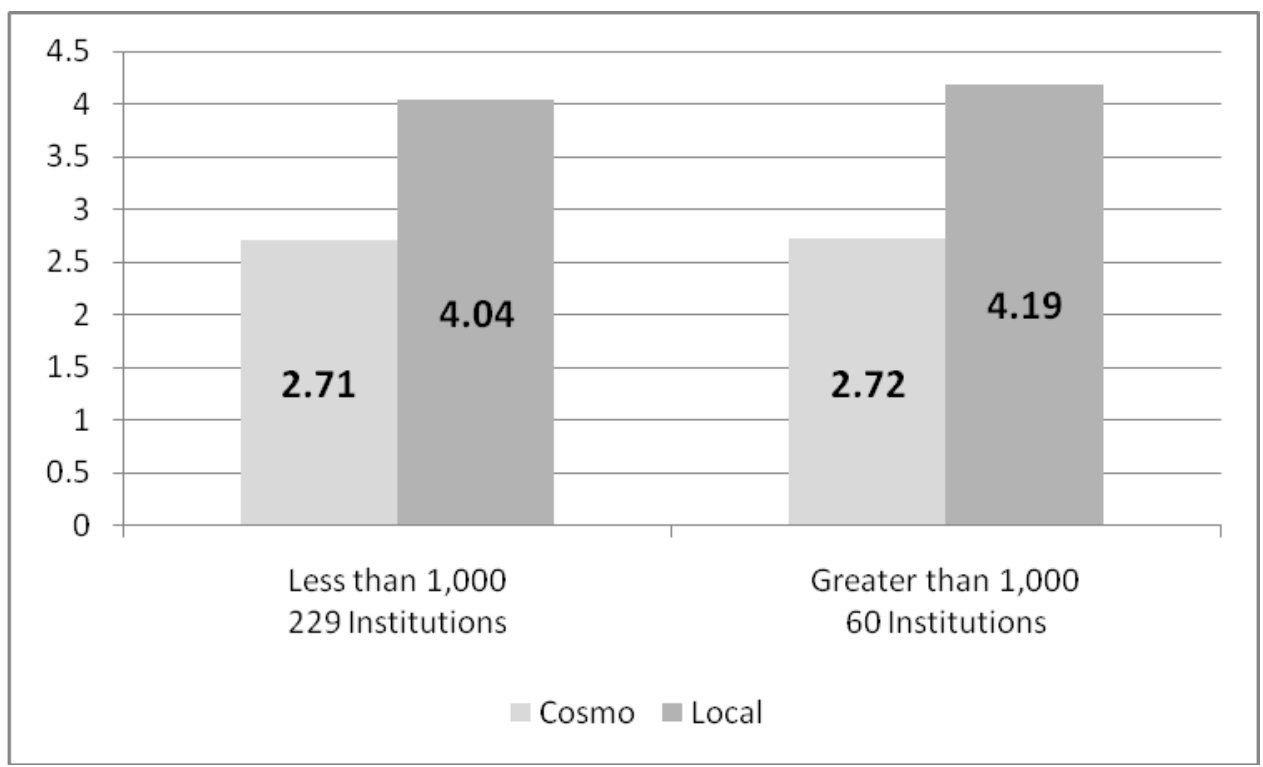

Figure 3. CAO latent social role score and number of employees.

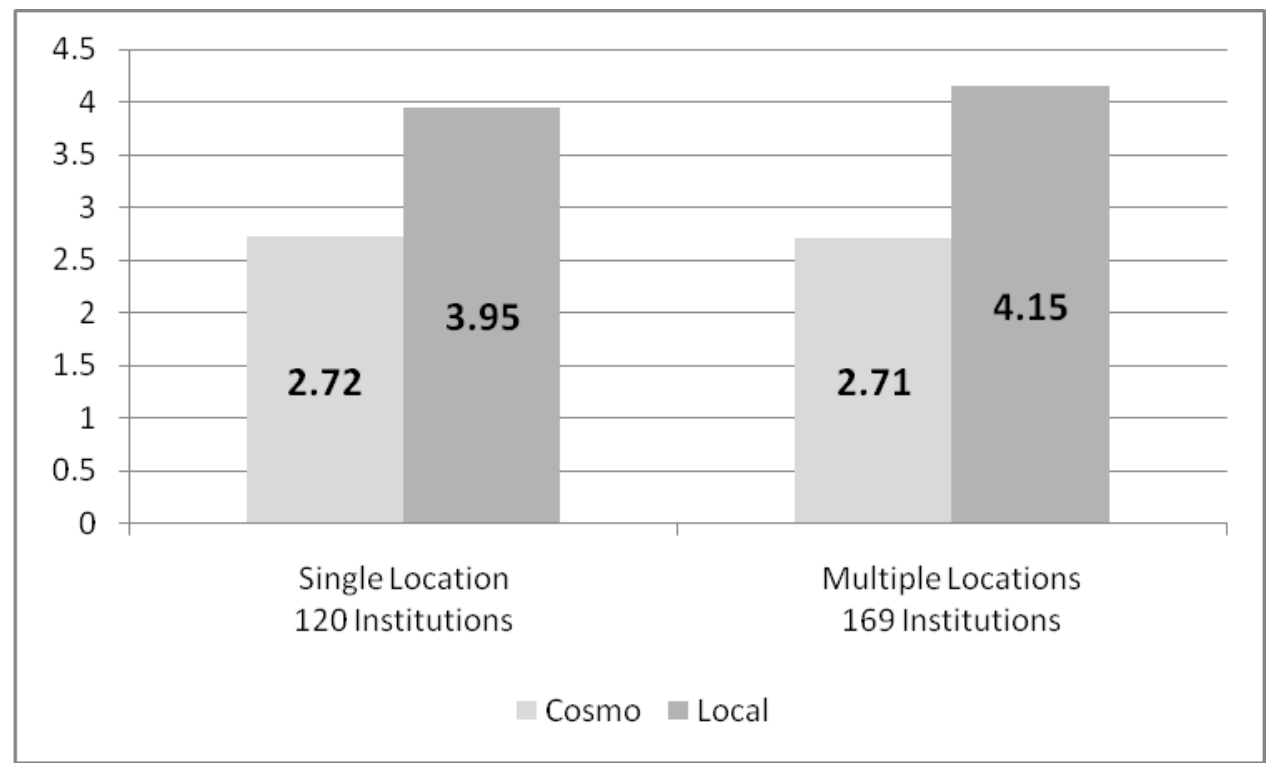

Figure 4. CAO latent social role score and number of locations. 
The difference between the population of the state where the community college was located and the CAO's cosmopolitan latent social role was significant. The CAO's cosmopolitan latent social role score was stronger (2.84) at institutions in states with a population of less than 5 million (Figure 5). Of the survey population, $90 \mathrm{CAOs}$ worked at institutions within a state with a population of less than 5 million; and, $176 \mathrm{CAOs}$ worked at institutions within a state with a population of greater than 5 million as reported by the U.S. Census.

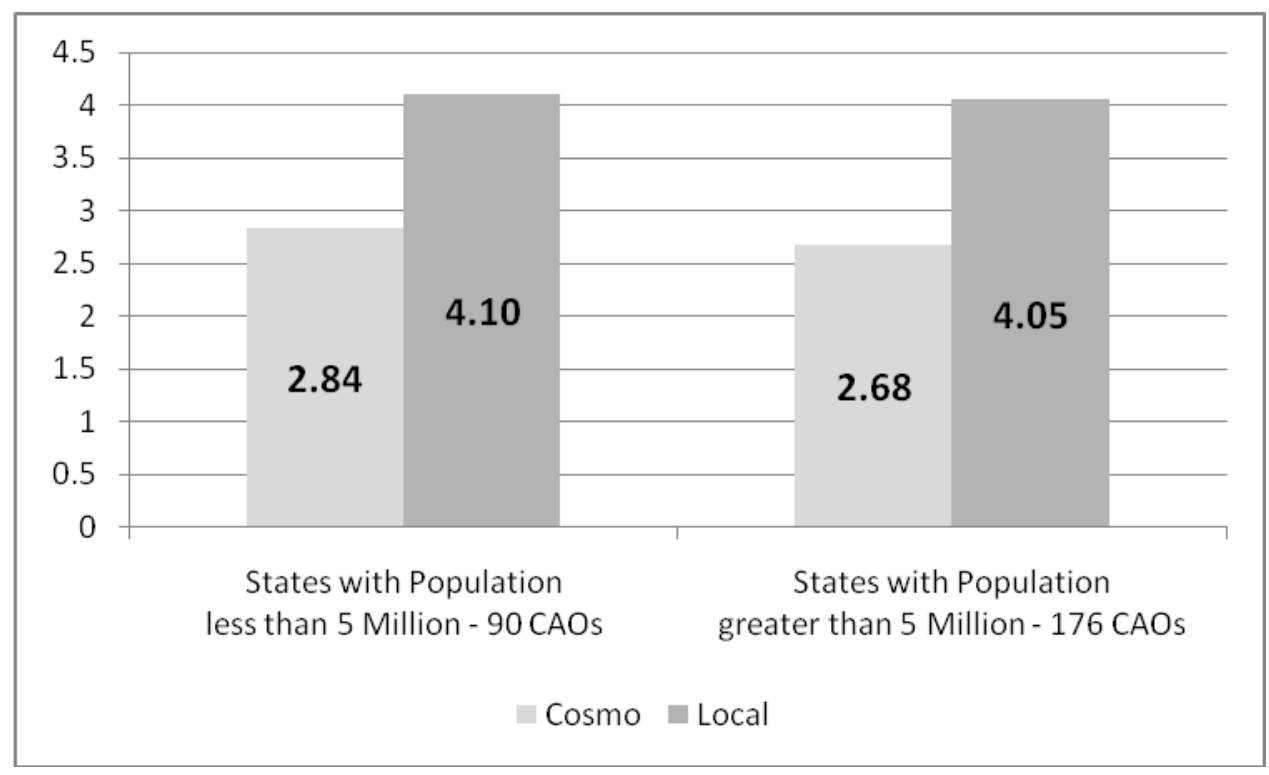

Figure 5. CAO latent social role score and state population where institution is located.

There was not a significant difference in the latent social role of CAOs and community college size. A small institution was defined as one with less than 2,500 students; a medium size institution was defined as 2,500 to 5,000 students, and a large institution was defined as more than 5,000 students. Figure 6 presents the latent social 


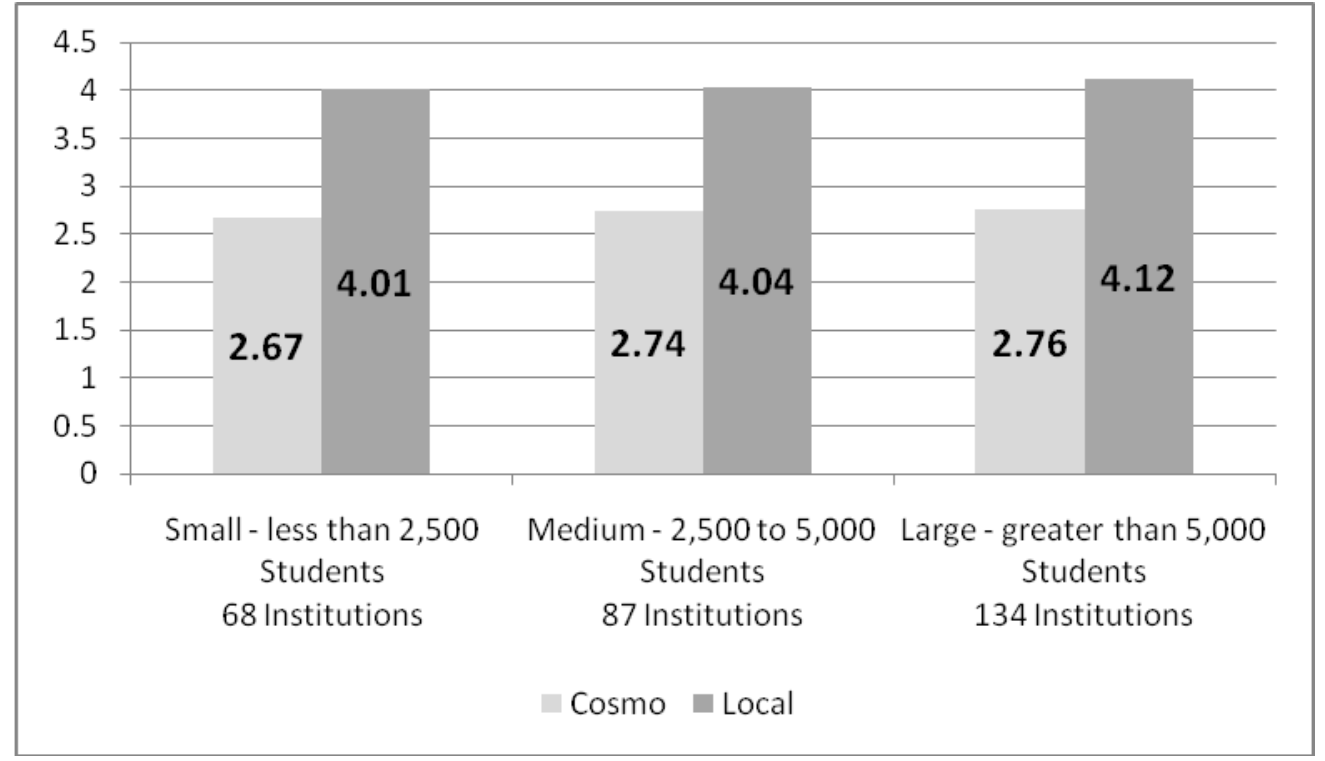

Figure 6. CAO latent social role score and institution unduplicated headcount.

role scores by community college size. There were 68 small institutions, 87 medium size institutions, and 134 large institutions within the survey population.

There was not a significant difference in community college location, defined as rural, suburban, or urban and the CAO's latent social role. Rural institutions are not in a Primary Metropolitan Statistical Area (PMSA) or Metropolitan Statistical Area (MSA) as defined by the US Census (2010) and have a population of less than 500,000. Suburban institutions are in a MSA with a population exceeding 500,000. Urban institutions are in a PMSA with a population exceeding 500,000. Figure 7 presents the latent social role scores for community college locations. In the survey sample, there were 155 CAOs working at institutions classified as rural; 62 at institutions classified as suburban, and 38 at institutions classified as urban. 


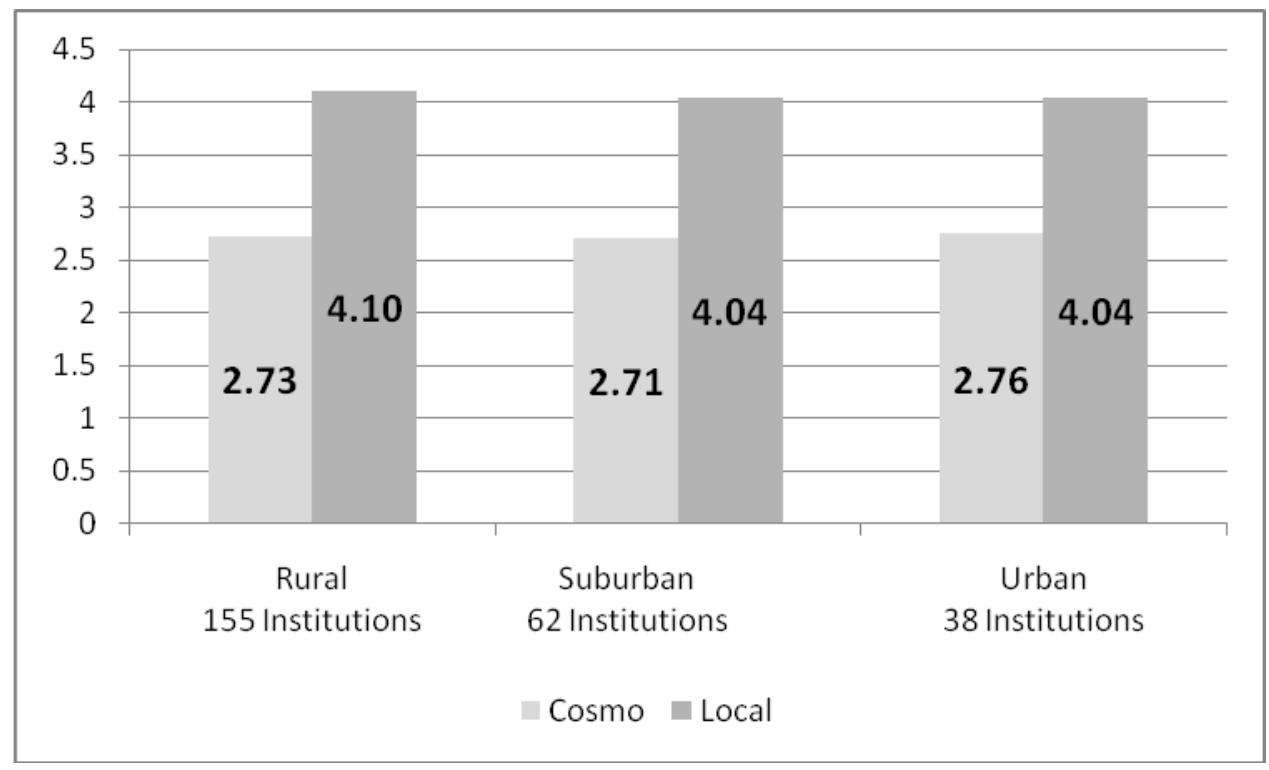

Figure 7. CAO latent social role score and institution location.

Research Question 7. Was there a difference between the public community college CAO's personal or demographic characteristics (age, birth month, gender, marital status, education, tenure in office, research and publication history) and the CAO's latent social role? Significant differences between CAO age, marital status and the CAO's latent social role were identified. The difference between the other demographic variables studied for public community colleges CAOs and their latent social role was not significant. These variables included CAO birth month, gender, highest level of education, tenure in the $\mathrm{CAO}$ position, and research/publication record.

There was a significant difference between $\mathrm{CAO}$ age and their local latent social role; specifically the age category 40 - 49 (Figure 8). Gouldner (1958) noted that individuals can change latent social roles over time, and that individuals working in academia often begin their careers as cosmopolitans but become more local in latent 


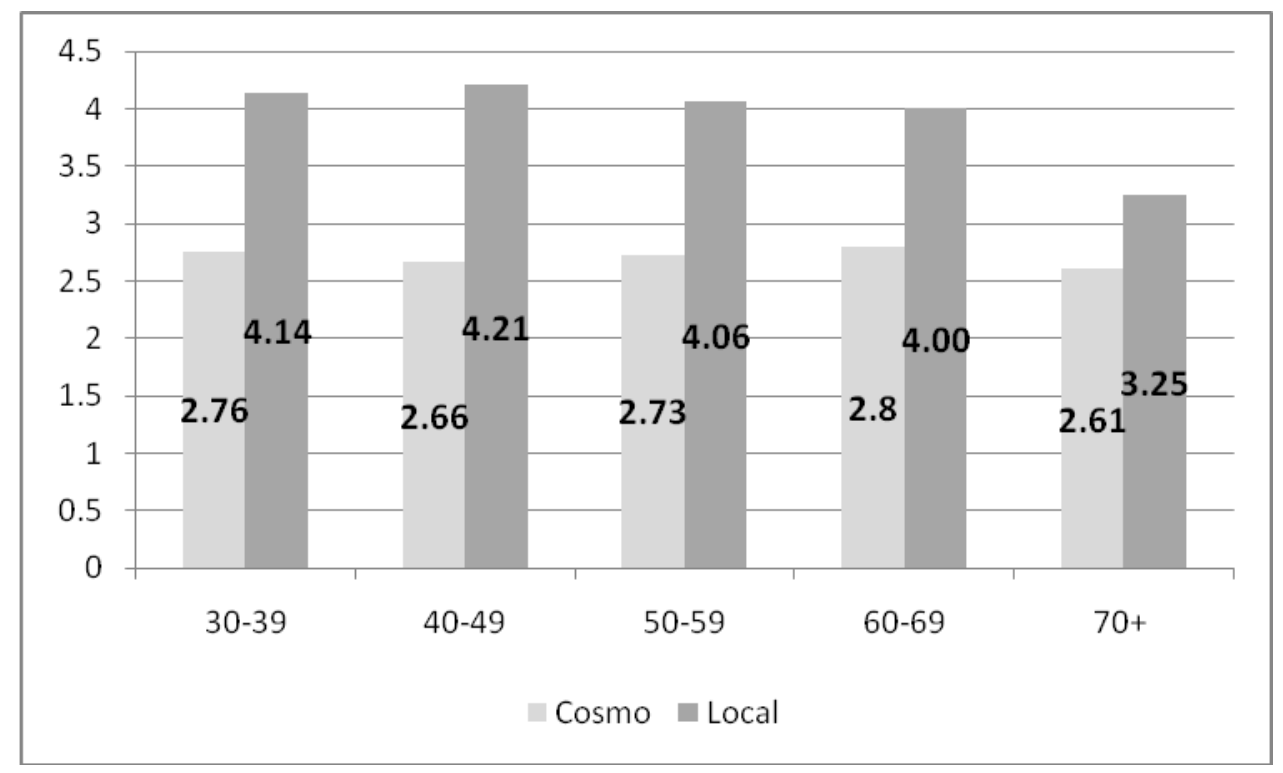

Figure 8. CAO latent social role score and age.

social role over time due to age, lack of involvement in professional organizations, and increased commitment to the institutions where they work as time passes. The data in this study indicated that the younger CAOs are more local in latent social role. A possible explanation for why the results of this study differ from Gouldner's findings is that younger CAOs who were attracted to community college administration selected a career in community college administration to, consciously or unconsciously, match their local latent social roles to the requirements of the $\mathrm{CAO}$ position, including loyalty to the organization and an inner reference group focus.

One third of CAOs were over age 60; 77\% were over 50 years old. Figure 9 presents the results. This research supports the previous research by Shults (2001), Kelly (2002), Weisman and Vaughan (2007), and Duree (2007), which indicated that a large percentage of community college administrators were near retirement age. The average 


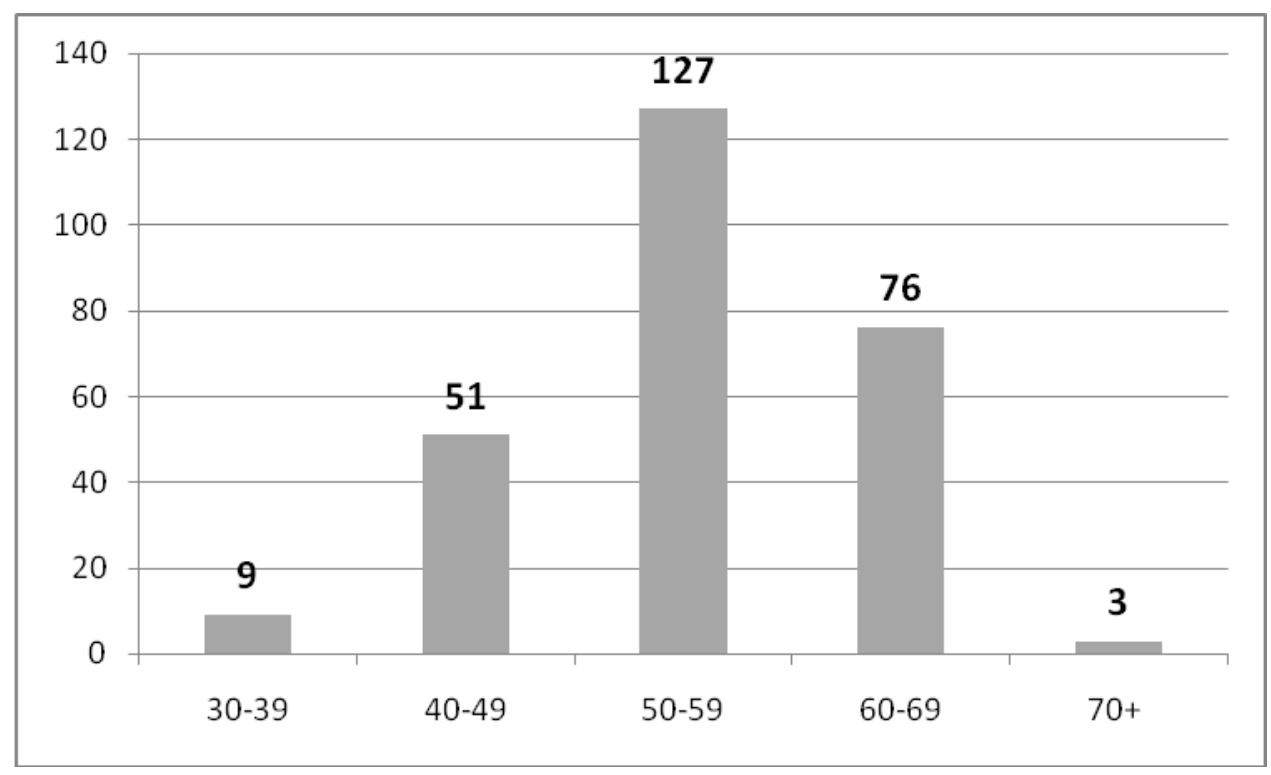

Figure 9. CAO responding by age.

age of the CAO in this study was 54, which supports the average age determined by Amey et al. (2002). The average age of CAOs in previous studies has been steadily increasing from age 49 in Moore et al. (1985) to age 54 in the Amey et al. (2002) study.

There was a significant difference in the CAO's divorced marital status and their cosmopolitan latent social role. CAOs who were divorced had a higher cosmopolitan latent social role score (Figure 10); they had a corresponding lower local latent social role score. CAOs with a cosmopolitan latent social role would have a lower level of loyalty to the organization, and have an outer reference group orientation. These two cosmopolitan orientation characteristics may interfere with marriage requirements.

CAOs who were married represented $79 \%$ of the survey participants; this is slightly lower than previous studies reported. Moore et al. (1985) reported that $89 \%$ of 


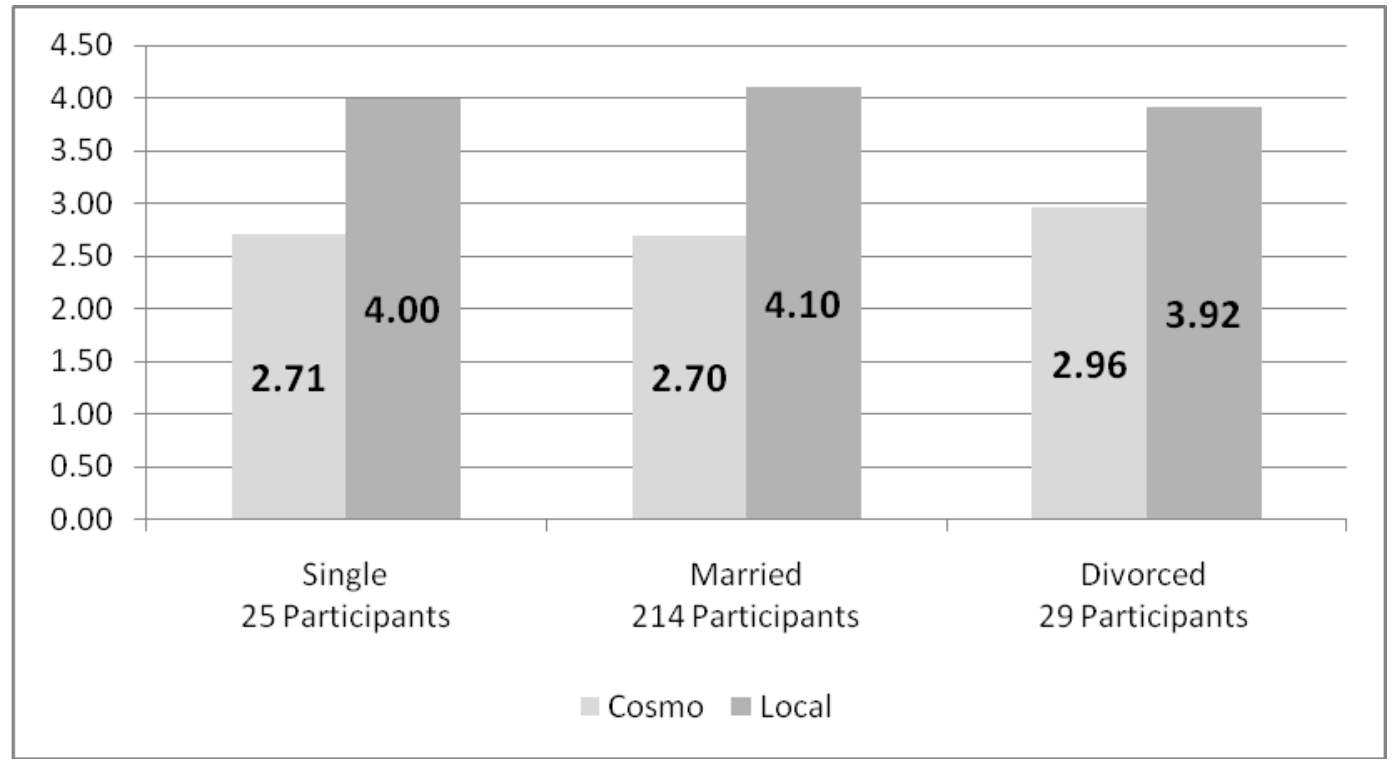

Figure 10. CAO latent social role score and marital status.

CAOs were married; Vaughan (1990) reported that $87 \%$ were married; and, McKenney and Cejda (2000) reported that $81 \%$ were married.

There was no difference indicated between the CAO's birth month and their latent social role. The CAO birth month was categorized into two groups; those born January April or May - December, based on Gladwell's (2008) theory that people born early in the year received more attention at school, and experienced lifelong benefits from this extra help. The latent social role score for those born January - April versus May December were not significantly different (Figure 11).

There was not a significant difference between the CAO's gender and their latent social role. The study included $138(51 \%)$ female and $134(49 \%)$ male participants. Males and females were virtually equal in cosmopolitan latent social role; females were slightly more local in latent social role (Figure 12). The CAOs in the study included a 


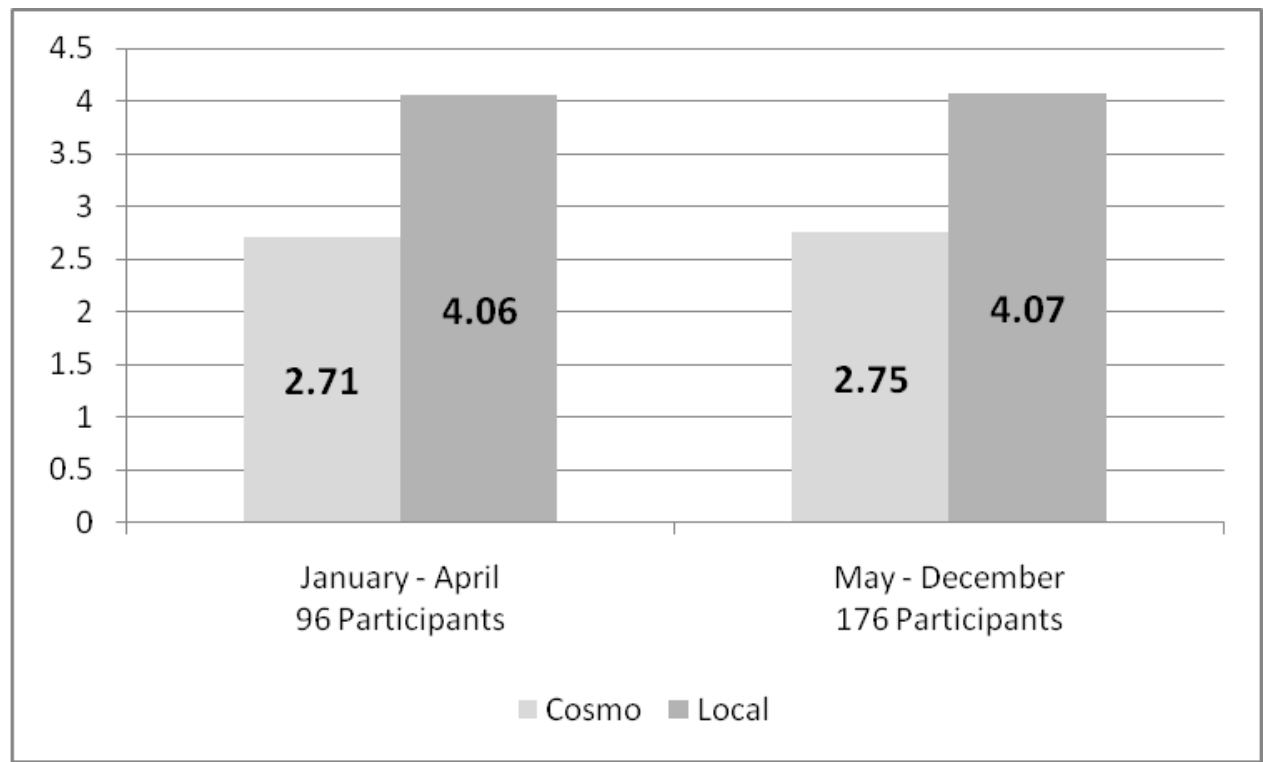

Figure 11. CAO latent social role score and birth month.

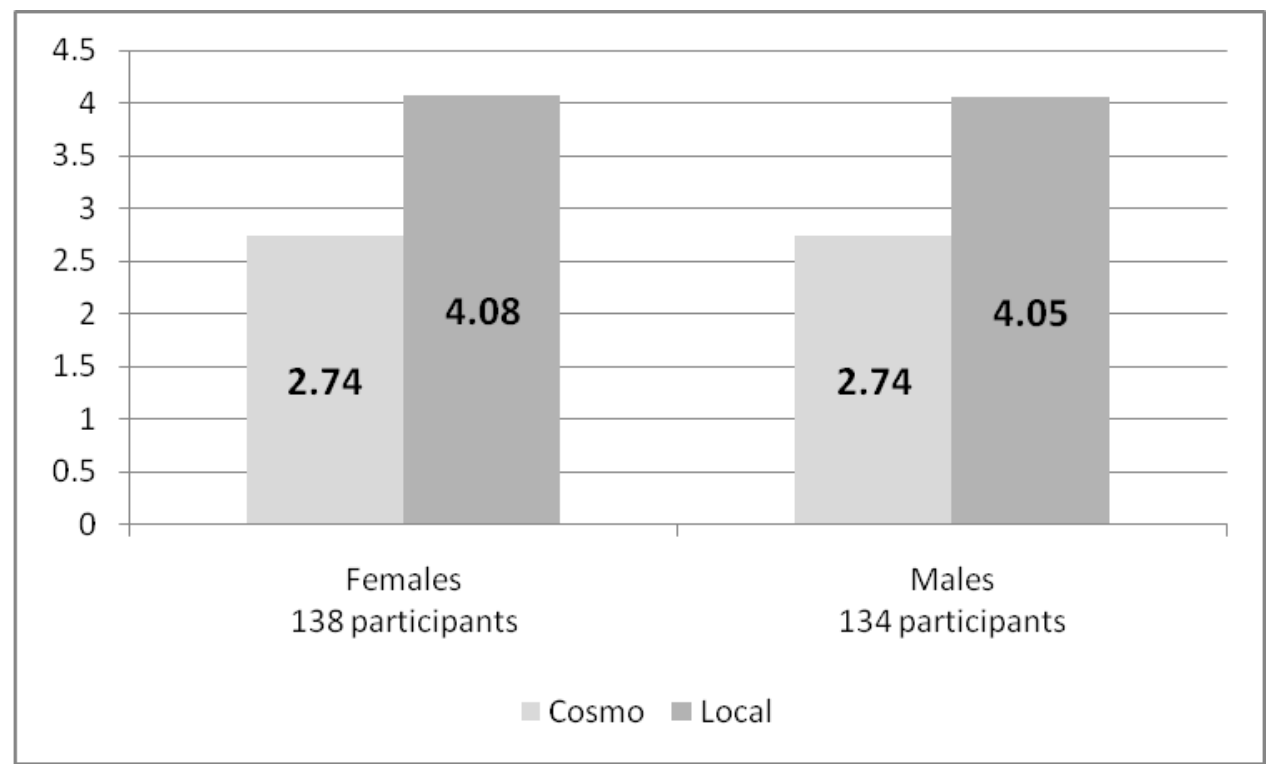

Figure 12. CAO latent social role score and gender. 
higher percentage of females than males. Previous studies, beginning with the Moore et al. (1985) study, reported more male (84\%) then female (14\%) CAOs. The increased representation of females in the $\mathrm{CAO}$ office reflects the increased percentage of women in the workforce in general, as well as the increased representation of women in academia in particular.

There was not a significant difference between the CAO's highest degree earned and their latent social role. Highest degree earned was classified into three categories: $\mathrm{PhD}, \mathrm{EdD}$ and Others. While there was not a significant difference between the highest degree earned and latent social role, the participants who had earned an EdD had the highest local latent social role score (Figure 13).

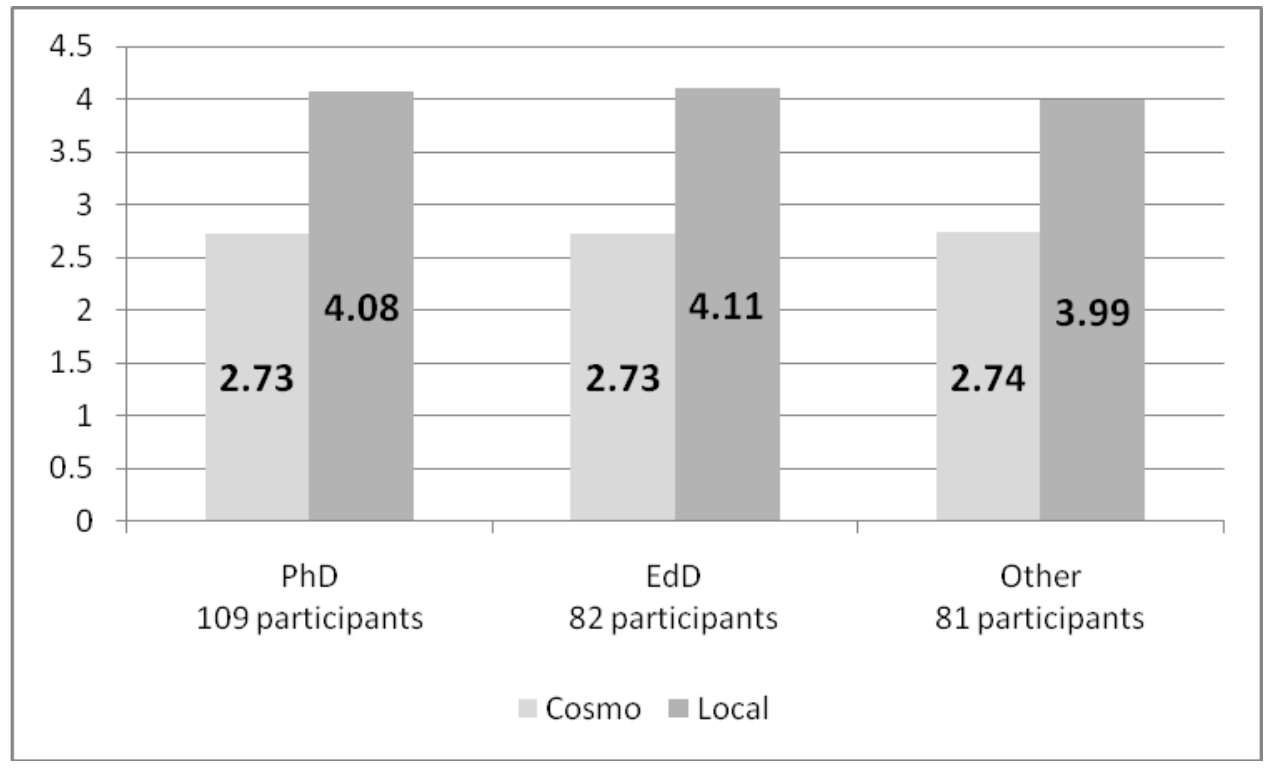

Figure 13. CAO latent social role score and highest degree earned.

The majority of survey participants, or $40 \%$, had earned a $\mathrm{PhD} ; 30 \%$ had earned an EdD; and, 30\% had earned a degree that was categorized as Other. This has similar to the McKenney and Cejda (2000) study, which reported that $41 \%$ of CAOs held a PhD 
and $35 \%$ held an EdD, and the Amey et al. (2002) study that reported that $40 \%$ held a $\mathrm{PhD}$ and $34 \%$ held an EdD. Other studies reported a higher percentage of CAOs holding a $\mathrm{PhD}$, including Moore et al. (1985) who reported 49\% of CAOs surveyed held a PhD, $40 \%$ an EdD, and 11\% Other degrees; and, Keim and Murray (2008) who reported 59\% held a $\mathrm{PhD}$ and $30 \%$ held an EdD. Two studies reported a lower percentage of CAOs who had earned a PhD; Vaughan (1990) had reported 33\% held a PhD and 36\% held an EdD; and, Hawthorne (1994) reported that $34 \%$ of CAOs surveyed held a $\mathrm{PhD}$ and $33 \%$ an EdD. This research confirms the $\mathrm{PhD}$ as the most prevalent degree for the community college $\mathrm{CAO}$. The $\mathrm{PhD}$ represents the most prestigious academic status, and CAOs can utilize this status in working with inner and outer reference groups.

The difference between the CAO's tenure in the position and their latent social role was not significant. The CAOs with less time on the job had a slightly higher local latent social role score (Figure 14). The eagerness of new CAOs to express their commitment and loyalty to the organization and their focus on inner reference groups may lead to a higher local latent social role orientation score.

The majority of the participants, 168 or $58 \%$, had been in the office less than 5 years; 122 or $42 \%$ had been in the CAO position for 5 years or more. The average tenure in office was 3.9 years, which was lower than previously reported. Previous studies by Moore et al. (1985) indicated an average tenure for CAOs of 6.2 years; Vaughan (1990) reported a tenure of 5.4 years; Hawthorne (1994) reported 6.1 years; and, McKenney and Cejda (2000) reported a tenure of 6 years. The fewer years in office could be attributed to the retirement or advancement of a number of CAOs in the past six years and their replacement with new CAOs who have not been in office for more than six years. 


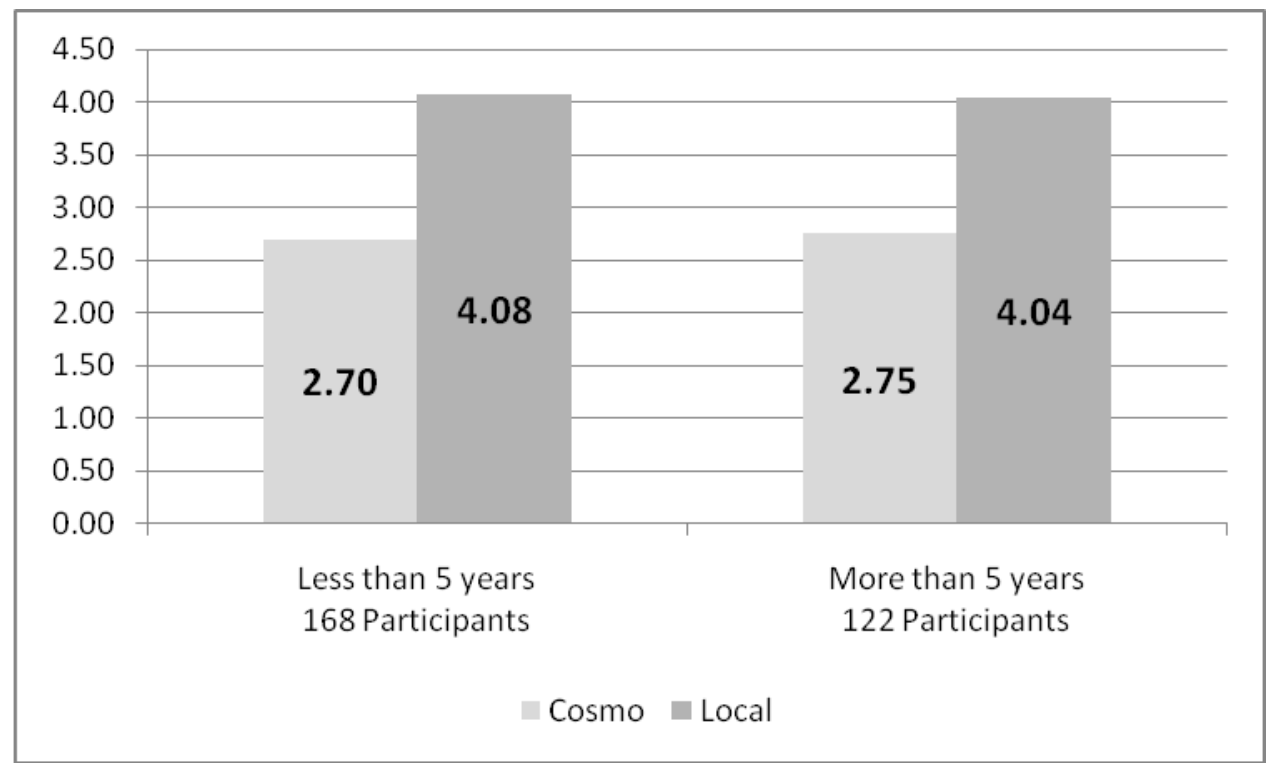

Figure 14. CAO latent social role score and tenure as CAO.

The difference between the time frame of the CAO's last publication and their latent social role was not significant. The publication information was categorized as 2006 to 2010 and prior to 2006. Figure 15 reports the cosmopolitan and local latent social role scores. The 2006 - 2010 category included 80 participants, or 30\%; 180 participants, or $70 \%$, had last published research prior to 2006 . This was similar to previous research by Moore et al. (1985) who reported 30\% of CAOs had published in the last five years. Other researchers reported a higher percentage of CAOs who had published research in the last five years; Vaughan (1990) reported 38\% and Hawthorne (1994) reported that $68 \%$ of CAOs had published research in the last five years. Based on this research, and supported by that of Moore et al. (1985), approximately 30\% of CAOS published research in the last five years, and 70\% have not. 


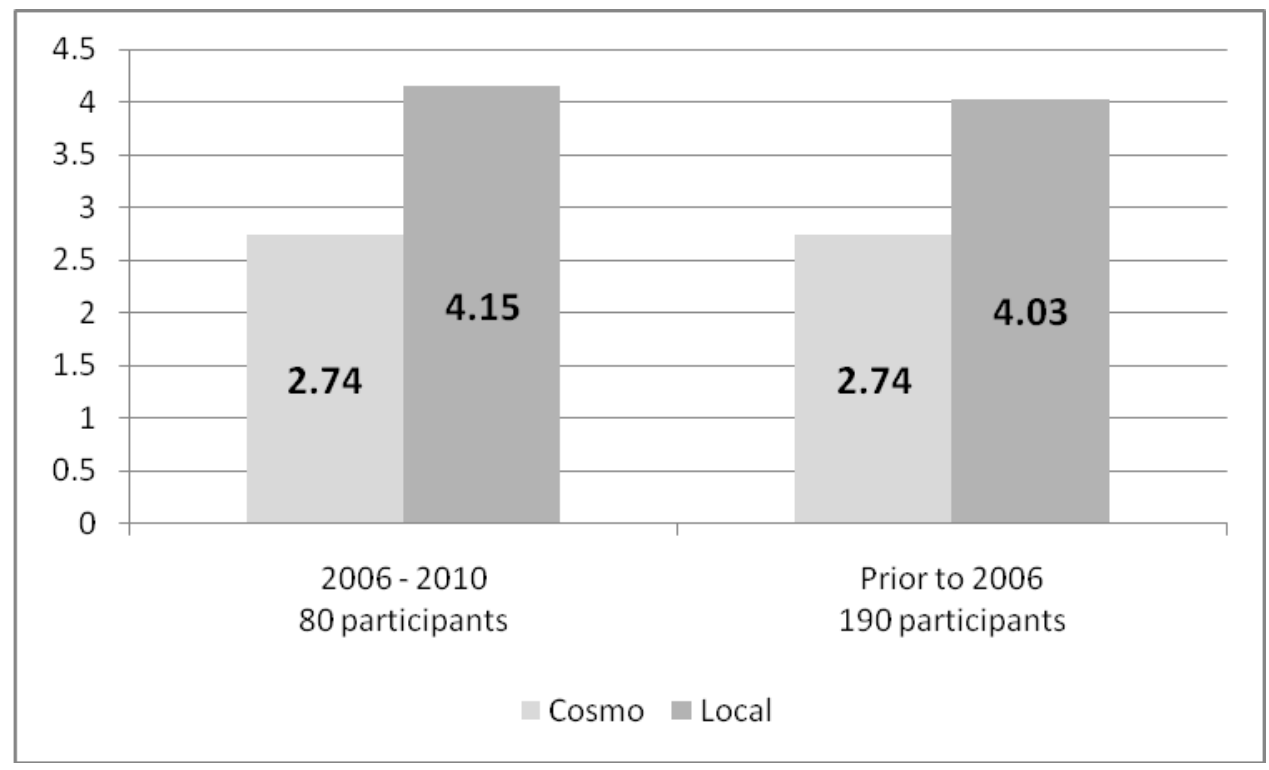

Figure 15. CAO latent social role score and research.

\section{Conclusions}

One of the significant findings of this study was the strong local latent social role scores of community college CAOs and inversely, their relatively low cosmopolitan latent social role scores. These latent social role scores correlated to key organizational behaviors, including job satisfaction and the intent to pursue a community college presidency.

The study of the CAO's institution environmental factors indicated that there were significant differences in the number of employees, number of locations, state population and the CAO's latent social role score. Consciously or unconsciously, CAOs may be selecting or matched to institutions based on their latent social role and these key environmental factors.

The study also examined the differences between CAO demographic variables and latent social roles. The differences between the CAO's age and marital status and 
their latent social role were significant; this suggests support for the theory that different life circumstances may impact and change the individual's latent social role from cosmopolitan to local and vice versa. The three variables of loyalty to the organization, commitment to specialized skills, and reference group orientation are what drives the latent social role. The variables can be influenced by personal and professional circumstances and can impact the CAO's latent social role.

\section{Future Practice}

There are immediate and long term implications of this study, as latent social roles may help predict important behavior in organizations. The immediate implications include addressing why a large number of community college CAOs are local in latent social role; if there is an appropriate match between the latent social role of administrators, the organization and the current economic environment; and what mitigating factors can be used to balance the latent social role of the CAO. The long term implications concern the selection of community college administrators in response to the need for stabilization or organization change and how public community colleges CAOs with predominately local latent social roles will succeed as community college presidents.

This research determined that public community college CAOs are predominately of a local latent social role orientation; this may be due to locals being attracted to administrative positions, as locals are loyal to the organization. CAOs with a cosmopolitan latent social role may have evolved into a local latent social role orientation to meet the requirements of the administrative position. Community colleges have developed from their Wild West days in the 1960's to a much more established 
environment (Vaughan, 1990). Individuals that have or evolve into a local latent social role may be attracted to the community college CAO position for two reasons: (a) the community college environment has stabilized over the last 20 years; and (b) the CAO position is more central to the core academic mission of the organization, less visible than the president, and relatively well defined. There is a clear career path for the community college CAO with a local latent social role orientation, even if this involves moving from one community college to another to secure a position. CAOs with local latent social roles are comfortable with relocating to another community college as selection committees are seeking CAO candidates with local latent social roles to provide a continuing stable academic environment for their organization. Individuals with cosmopolitan latent social roles may find that bureaucracy in general, and the bureaucracy that has developed with the maturing community college system, to be routine and too confining. Given the relatively stable community college environment in the last two decades, the findings suggest that individuals with cosmopolitan latent social roles have not sought out the $\mathrm{CAO}$ position in large numbers or have evolved out of the cosmopolitan latent social role orientation and into a local latent social role orientation.

However, today's economic turmoil and drastic budget cuts to education funding, as well as increased demand for services, may require a more innovative management approach. The CAO with a dominate local latent social role who develops and enforces routine policies and procedures may be pushed outside of his/her comfort zone as nonroutine, difficult decisions are required that impact students and faculty. CAOs with a cosmopolitan latent social role may have a lower level of loyalty and attachment to the organization; this may make difficult decisions involving personnel and programs easier 
for the cosmopolitan CAO to make. A cosmopolitan CAO with a large reference group outside the organization may be better connected to develop innovative ideas and solutions to current environmental challenges. Current environmental factors, such as the economy and local, state and federal policy changes, may impact what type of latent social role for an administrator is the best match for the organization at that time. In other words, as the current environment destabilizes, a CAO with a cosmopolitan latent social role may be better suited to the administrative challenges of the position. CAOs with local latent social roles may be better suited to the position when environmental conditions dictate stability.

That is not to say that a CAO with a local latent social role orientation cannot succeed in an unstable environment. The CAO's self awareness of their latent social role may initiate a desire to achieve a balance between the local and cosmopolitan latent social roles. This involves recognizing the value of a cosmopolitan latent social orientation. A CAO with a dominate local latent social role orientation may be more successful if they are innovative and are willing to look outside the organization for solutions, and become skilled at networking outside of the organization to access professional colleagues and resources. Strategies to balance the predominately local latent social role of CAOs could include the following suggestions. First, professional development opportunities for CAOs. CAOs may benefit from seeking out professional development opportunities. Presidents have many training and leadership opportunities, such as the League for Innovation in the Community College's Executive Leadership Institute, designed for administrators who want to be a community college president (League, 2011). CAOs should consider taking advantage of these opportunities as well. 
Second, CAOs may benefit from sharing information with other community college CAOs in their area and/or from across the United States. Community college presidents often maintain friendships with other presidents to serve as sounding boards. CAOs may want to consider developing this type of a network to provide an outer reference group and access to innovative solutions to community college problems. The National Council of Instructional Administrators, an AACC affiliated council, is one potential source for professional affiliation (AACC, 2011).

The long term implications of this study address the question of how latent social roles impact this statement: every leader has a time and a place (Shriberg, Shriberg, \& Kumari, 2005). Administrators with a cosmopolitan latent social role may be better at leading in unstable environments where significant change is required; the cosmopolitan leader may be better equipped (with a lower level of loyalty to the organization, external reference groups) to serve as a change agent. Administrators with local latent social roles may be better equipped to serve as leaders during time periods when the organization needs to be stabilized.

Researchers have identified a potential leadership crisis at community colleges (Duree, 2007; Kelly, 2002; Shults, 2001; Weisman \& Vaughan, 2007). The CAO is the second in command at the community college, after the president, and is considered the primary pathway to the presidency (Vaughan, 1990). This research study confirmed that many sitting CAOs intend to pursue a community college presidency, and that the majority of CAOs are locals in latent social role orientation. Community colleges are entering a challenging new era, and need dynamic, visionary leaders to succeed. 
There is some evidence that latent social roles may change over time and based on the organization role of the individual. Larwood et al. (1998) noted that the organization and situation may influence latent social role orientation and careers, and the latent social role orientation may change over time and with different jobs. Larwood et al. (1998) noted that individuals may learn to suppress their dispositional latent social tendency in their current manifest role, and in future career situations this latent social role orientation may express itself again. Awareness of their social role may assist CAOs with local latent social role orientations successfully seek presidential appointments. Development programs such as the Executive Leadership Institute or the AACC's Future Leadership Institute Advanced program may be helpful to CAOs who are seeking presidential appointments (AACC, 2011; League, 2011). CAOs who become presidents and are seeking to develop a leadership network may consider the AACC's Presidents Academy Summer Institute (AACC, 2011).

Individuals and organizations may not be aware of the impact of latent social roles on behavior. Organizations may not have considered the match between the current environment, the organization, and the cosmopolitan or local latent social role of the organization leaders. Large community college organizations, such as the California, Illinois, and North Carolina systems, may consider incorporating information about latent social roles in their Grow Your Own Leadership (GYOL) programs (Kirby, 2004). As many CAOs have a doctorate in Education, universities with these curricula may consider incorporating a module on latent social roles in their leadership coursework. Finally, additional research is needed on latent social roles to fully understand their impact on organizational behavior. 


\section{Future Research}

The study of latent social roles offers many directions for future research. As a result of this research, suggested future research opportunities include a longitudinal study of CAOs and other professionals, the study of other organizational behaviors and their relation to the latent social role of CAOs, the study of other community college administrators latent social roles, the use of different statistical methods to evaluate the research data, and continued research to revise and refine the cosmopolitan and local social role scales.

A longitudinal study of CAOs and other professionals' latent social roles at various career stages would be valuable in determining how latent social roles change over time and through different life and career circumstances. This study might follow a professional over a period of time as a faculty member, and observe changes to latent social roles at different institutions with the same position type as faculty member. The study would also evaluate changes to latent social role if the study participant followed a career path into administration as a department chair, dean, $\mathrm{CAO}$, or president. The impact on the CAO's latent social roles related to changes in their demographic factors, such as age, marital status, tenure in office, and research and publication history would also be gathered.

The study of other organizational behaviors and the relation to the latent social role of CAOs could be pursued. This study focused on job satisfaction, intent to turnover, intent to pursue a community college presidency, and selection of an internal or external job candidate. Other organizational behaviors could be identified, studied and correlated to the CAO's latent social role. 
The impact of environmental factors such as the economy and local, state and federal policy on the latent social roles of CAO's could be pursued. These factors may impact the individuals who seek CAO positions and the type of individual that community colleges are seeking to fill these positions.

The study of other community college administrator's latent social roles is another research opportunity. This could include department chairs, student affairs administrators, business affairs administrators, and presidents.

Different methods of statistical analysis could be used to evaluate the data collected in this research. Regression analysis or the use of nonlinear statistics could be used to evaluate the data collected in this study. This analysis might reveal additional relationships between latent social roles and the study variables.

Ongoing research on the impact of latent social roles might also include additional research to revise and refine the cosmopolitan and local social role scales. These scales have been developed and revised by researchers but as more information is gathered this may further improve the scales' ability to determine the latent social role of individuals. In conclusion, this research study has provided insight into the impact of latent social roles on community college administrators and community college organizations. The study indicated that the majority of sitting public community college CAOs are or have evolved into a local latent social role orientation. The implications of this study include the matching of the CAO's latent social role to the organization's needs, based on current environmental factors. Finally, the CAO position is the primary pathway to the presidency; the CAO's latent social role orientation may continue to evolve to meet the demands of the presidency. 


\section{References}

AACC. (2001). The community college presidency 2001. Retrieved on November 12, 2008 from http://www.aacc.nche.edu/Publications/Briefs/Pages/ rb062420021.aspx

AACC. (2008). Facts 2008. Retrieved on October 1, 2008, from http://www2.aacc.nche.edu/research/index.htm

AACC. (2011). National organizations. Retrieved on March 1, 2011, from http://www.aacc.nche.edu/Resources/Links/Pages/nationalorgs.aspx

Abrahamson, M. (1965). Cosmopolitanism, dependence-identification and geographical mobility. Administrative Science Quarterly, 10, 98-106.

American Council on Education (ACE). (2007). The American college president: 2007 edition. Washington, DC: American Council on Education.

Amey, M. J., \& VanDerLinden, K. E. (2002). Career paths for community college leaders. AACC Research Brief, AACC-RB-02-2.

Amey, M. J., VanDerLinden, K. E., \& Brown, D. F. (2002). Perspectives on community colleges: Twenty years in the making. Community College Journal of Research \& Practice, 26, 573-589.

Anderson, P., Murray, J. P., \& Olivarez, A. (2002). The managerial roles of public community college chief academic officers. Community College Review, 30(2), $1-26$.

Anderson, W.H. (1973). Characteristics, preparation, and attitudes of selected public junior-community college deans of instruction. Carbondale, IL: Southern Illinois University. 
Bassoppo-Moyo, S., \& Townsend, B. (1997). The effective community college academic administrator: necessary competencies and attitudes. Community College Review, 25(3), 41-56.

Bennis, W. G., Berkowitz, N., Affinito, M., \& Malone, M. (1958). Reference groups and loyalties in the out-patient department. Administrative Science Quarterly, 2, 481-500.

Berger, P. K., \& Grimes, A. J. (1973). Cosmopolitan-local: A factor analysis of the construct. Academy of Management Journal, 16, 187-206.

Bernardin-Demougeot, K. (2008). The turnover of community college presidents. Baltimore, MD: Morgan State University.

Birnbaum, R. (1971). Presidential succession: An interinstitutional analysis. Educational Record, 52, 2, 133-145.

Birnbaum, R. (1988). How colleges work: The cybernetics of academic organization and leadership. San Francisco, CA: Jossey-Bass.

Birnbaum, R., \& Umbach, P. D. (2001). Scholar, steward, spanner, stranger: The four career paths of college presidents. The Review of Higher Education, 24(3), 203-217.

Blocker, C., Plummer, R., \& Richardson, R. (1965). The two-year college: A social synthesis. Englewood Cliffs, NJ: Prentice-Hall.

Boggs, G. R. (2003). Leadership context for the 21st century. In W. Piland \& D. Wolf (Eds.), Help wanted: Preparing community college leaders in a new century (New Directions for Community Colleges, 123, 15-25). San Francisco, CA: JosseyBass. 
Buller, J. L. (2007). The essential academic dean: A practical guide to college leadership. San Francisco, CA: Jossey-Bass.

Brumbaugh, R. B., \& Flango, V. E. (1973, March). Local-cosmopolitanism and collective bargaining in a state college system. Paper presented at the annual meeting of the American Educational Research Association, New Orleans, Louisiana.

Camman, C., Fichman, M., Jenkins, D., \& Klesh, J. (1979). The Michigan organizational assessment questionnaire. Unpublished manuscript. Ann Arbor, MI: University of Michigan.

Campbell, D. F. (Ed.). (2002). Leadership gap: Model strategies for developing community college leaders. Washington, DC: Community College Press.

Carnegie Foundation. (2010). Basic classification technical details. The Carnegie Foundation for the Advancement of Teaching. Retrieved on March 9, 2010, from http://classifications.carnegiefoundation.org/methodology/basic.php

Caplow, T., \& McGee, R. (1958). The academic marketplace. New York, NY: Basic Books.

Carroll, C. (2004). Succession planning: Developing leaders for the future of the organization. Leadership Abstracts, 17, 2, 1-2.

Carroll, J. B. (1991). Career paths of department chairs: A national perspective. Research in Higher Education, 32, 6, 669-688.

Cejda, B. D. (2007). In their own words: Women chief academic officers discuss the community college and their career experiences. Women in Educational Leadership, 6(3), 171-185. 
Cejda, B. D., \& Leist, J. (2006). Challenges facing community colleges: Perceptions of chief academic officers in nine states. Community College Journal of Research and Practice, 30, 253-274.

Cejda, B. D., McKenney, C. B., \& Burley, H. (2001). The career lines of chief academic officers in public community colleges. Community College Review, 28, 4, 31-46.

Cejda, B. D., McKenney, C. B., \& Fuller, C. W. (2001). Leaving office: Position changes of chief academic officers. Community College Journal of Research \& Practice, $25,137-146$.

Chappell, C. (2008, January 4). The new wave of young presidents. Community College Times. Retrieved on May 28, 2009, from http://ww.communitycollegetimes.com/article.cfm?ArticleID=685\&PF=Y

Cohen, A., \& Brawer, F. (1996). The American community college. San Francisco, Jossey-Bass.

Cohen, M. D., \& March, J. G. (1974). Leadership and ambiguity. New York, NY: McGraw-Hill.

Cook, J. D., Hepworth, S. J., Wall, T. D., \& Warr, P. B. (1981). Experience of work: A compendium and review of 249 measures and their use. New York, NY: Academic Press.

Cornwall, J. R., \& Grimes, A. J. (1987). Cosmopolitan-local: A cross-lagged correlation analysis of the relationship between professional role orientations and behaviors in an academic organization. Human Relations, 40, 281-298. 
Creswell, J. (2008). Educational research: Planning, conducting, and evaluating quantitative and qualitative research. Upper Saddle River, NJ: Pearson Education.

Dillman, D. A. (2007). Mail and internet surveys: The tailored design method. Hoboken, NJ: John Wiley.

Dowd, K. O., \& Kaplan, D. M. (2005). The career life of academics: Boundaried or boundaryless? Human Relations, 58, 699-721.

Duree, C. (2007). The challenges of the community college presidency in the new millennium: Pathways, preparation, competencies, and leadership programs needed to survive (Doctoral dissertation, Iowa State, 2007). Dissertation Abstracts International, 68, 11.

Dye, T. R. (1966). The local-cosmopolitan dimension and the study of urban politics. Social Forces, 41, 239-246.

Eells, W. C. (1931). The junior college. New York, NY: Houghton Mifflin.

Flango, V. E., \& Brumbaugh, R. B. (1974). The dimensionality of the cosmopolitan-local construct. Administrative Science Quarterly, 19(2), 198-210.

Friedlander, F. (1971). Performance and orientation structures of research scientists. Organizational Behavior and Human Performance, 6, 169-183.

Garza Mitchell, R. L., \& Eddy, P. L. (2008). In the middle: Career pathways of midlevel community college leaders. Community College Journal of Research and Practice, 32, 10, 793-811.

Gladwell, M. (2008). Outliers: The story of success. New York, NY: Little, Brown and Company. 
Goldberg, A. I. (1976). The relevance of cosmopolitan/local orientations to professional values and behavior. Sociology of Work and Occupations, 3(3), 331-356.

Goldberg, L. C., Baker, F., \& Rubenstein, A. H. (1965). Local-cosmopolitan: Uni-dimensional or multi-dimensional? American Journal of Sociology, 70, 704-710.

Gouldner, A. W. (1957). Cosmopolitans and locals: Toward an analysis of latent social roles, I. Administrative Science Quarterly, 2(3), 281-306.

Gouldner, A. W. (1958). Cosmopolitans and locals: Toward an analysis of latent social roles, II. Administrative Science Quarterly, 2(4), 444-480.

Gravetter, F. J., \& Wallnau, L. B. (2007). Statistics for the behavioral sciences. Belmont, CA: Thomson Wadsworth.

Grimes, A. J., \& Berger, P. K. (1970). Cosmopolitan-local: Evaluation of the construct. Administrative Science Quarterly, 15, 407-416.

Hawthorne, E. M. (1994). Leaders in teaching and learning: A profile of chief academic officers in 2-year colleges. Community College Journal of Research and Practice, $18,269-278$.

HEP. (2010). About the higher education directory. Retrieved on April 1, 2010, from http://www.hepinc.com/about_HED.php

Jencks, C., \& Riesman, D. (1968). The academic revolution. New York: Doubleday. Joliet Junior College. (2009). History of Joliet Junior College. Retrieved on December 29, 2009, from http://www.jjc.edu/about/college-info/Pages/history.aspx

Keim, M. C., \& Murray, J. P. (2008). Chief academic officers' demographics and educational backgrounds. Community College Review, 36(2), 116-132. 
Kelly, E. (2002, May 27). The changing of the guard. Community College Week, 6-9.

Kirby, C. (2004). Survey of “Grow Your Own” leadership opportunities in Illinois community colleges. Update Newsletter, Office of Community College Research and Leadership. University of Illinois at Urbana-Champaign.

Larwood, L., Wright, T. A., Desrochers, S., \& Dahir, V. (1998). Extending latent role and psychological contract theories to predict intent to turnover and politics in business organizations. Group \& Organization Management, 23(3), 100-124.

League. (2011). Executive leadership institute. Retrieved on March 1, 2011, from http://www.league.org/eli/

Lutz, F. W., \& Arney, L. K. (1987). Changing higher education: Unraveling the Gordian knot. Journal of Research and Development in Education, 20, 32-39.

Martin, J., Samels, J. E., \& others. (1997). First among equals. Baltimore, MD: Johns Hopkins University Press.

McGregor Burns, J. (1979) Leadership. New York: Harper and Row.

McKenney, C. B., \& Cejda, B. D. (2000). Profiling chief academic officers in public community colleges. Community College Journal of Research \& Practice, 24, 745-758.

McMillan, J. H., \& Schumacher, S. (2006). Research in education: Evidence- based inquiry. Boston, MA: Allyn and Bacon.

Mech, T. (1997). The managerial roles of chief academic officers. Journal of Higher Education, 68(3), 282-298.

Merton, R. K. (1957). Patterns of influence: Local and cosmopolitan influential's. In R.K. Merton (Ed.), Social theory and social structure. Glencoe, IL: Free Press. 
Mintzberg, H. (1973). The nature of managerial work. New York, NY: Harper \& Row. Mooney, C. J. (1993). Study examines turnover rates in 12 campus jobs. Chronicle of Higher Education, 39(23), 3.

Moore, K. M. (1983) The top-line: A report on presidents', provosts', and deans' careers as part of the Leaders in Transition: A National Study of Higher Education Administration. University Park, PA: The Pennsylvania State University in cooperation with The American Council on Education.

Moore, K. M., \& Twombly, S. B. (1985). Administrator mobility: Crossing the boundary between two-year and four-year colleges and universities. Center for the Study of Higher Education. University Park, PA: Pennsylvania State University.

Moore, K.M., Twombly, S. B., \& Martorana, S. V. (1985). Today's academic leaders: A national study of administrators in community and junior colleges. Center for the Study of Higher Education. University Park, PA: The Pennsylvania State University in cooperation with The American Association of Community and Junior Colleges.

Morris, V. C. (1981). Deaning. Urbana, IL: University of Illinois Press.

Murray, J. P., Murray, J. I., \& Summar, C. (2000). The propensity of community college chief academic officers to leave an institution. Community College Review, 28(3), 22.

National Center for Education Statistics (NCES). (2010). The integrated postsecondary education data system (IPEDS). Retrieved on November 1, 2010, from http://nces.ed.gov/ipeds/ 
Petersen, L. R., \& Takayama, K. P. (1983). Local-cosmopolitan theory and religiosity among catholic nuns and brothers. Journal for the Scientific Study of Religion, 22(4), 303-315.

Petersen, L. R., \& Takayama, K. P. (1984). Community and commitment among Catholics: A test of local-cosmopolitan theory. The Sociological Quarterly, 25(1), 97-112.

Piland, W. E., \& Wolf, D. B. (2003). In-house leadership development: Placing the colleges squarely in the middle. New Directions for Community Colleges, 123, 93-99.

Pursley, R. D. (1974). Leadership and community identification attitudes among two categories of police chiefs: An exploratory inquiry. Journal of Police Science and Administration, 2, 414-422.

Raelin, J. A. (1989). Professional and business ethics: Bridging the gap. Management Review, 78(11), 39-43.

Raelin, J. A. (1991). The clash of cultures: Managers managing professionals. Boston, MA: Harvard Business School Press.

Rhoades, G. (2009). Carnegie, Dupont Circle, and the AAUP: (Re)shaping a cosmopolitan, locally engaged professoriate. Change, 41, 1, 8-15.

Rhoades, G., Kiyama, J. M., McCormick, R., \& Quiroz, M. (2008). Local cosmopolitans and cosmopolitan locals: New models of professionals in the academy. The Review of Higher Education, 31(2), 209-235. 
Robillard, D. (2000). Toward a definition of deaning. In D. Robillard (Ed.), Dimensions of managing academic affairs in the community college. New Directions for Community Colleges, 109, 9-17. San Francisco: Jossey-Bass.

Roe, M. A., \& Baker, G. A. (1989). The development of community college leaders: A challenge for our future. Community College Review, 16, 4, 5-16.

Romero, M. (2004). Who will lead our community colleges? Change, 36, 6, 30-34.

Roof, W. C. (1972). The local-cosmopolitan orientation and traditional religious commitment. Sociological Analysis, 22(1), 1-15.

Roof, W. C. (1976). Traditional religion in contemporary society: A theory of localcosmopolitan plausibility. American Sociological Review, 41(2), 195-208.

Ross, M., \& Green M. F. (1988). The American college president: A contemporary profile. Washington, DC: Center for Leadership Development, American Council on Education.

Rotundi, T. (1977). Reference groups and local-cosmopolitanism. Social Behavior and Personality, 5(2), 257-262.

Seashore, S. E., Lawler, E. E., Mirvis, P., \& Camman, C. (1982). Observing and measuring organizational change: A guide to field practice. New York, NY: John Wiley.

Shaffer, D. F. (2008). The states and their community colleges. The Nelson A. Rockefeller Institute of Government - Education Policy Brief. Retrieved on October 15, 2008, from www.rockinst.org

Shriberg, A., Shriberg, D. L., \& Kumari, R. (2005). Practicing leadership: Principles and applications. New York, NY: John Wiley. 
Shults, C. (2001). Research brief: The critical impact of impending retirements on community college leadership. Washington, DC: American Association of Community Colleges.

Smith, L. I. (2002, February 26). A tutorial on principal components analysis. Retrieved on October 31, 2010, from http://www.cs.otago.ac.nz/cosc453/student_tutorials/principal_components.pdf

Spilerman, S. (1977, November). Careers, labor market structure, and socioeconomic achievement. American Journal of Sociology, 551-593.

Stahl, M. J., Manley, T. R., \& McNichols, C. W. (1978). Operationalizing the Moskos Institution-Occupation Model: An application of Gouldner's cosmopolitan-local research. Journal of Applied Psychology, 63, 422-427.

Stapleton, C. (1997, January). Basic concepts and procedures in confirmatory factor analysis. College Station, TX: Texas A \& M University.

Stat/Math Center. (2006). Confirmatory factor analysis. Indiana University Information Technology Services. Retrieved on January 1, 2011, from http://www.indiana.edu/ statmath/stat/all/cfa/cfa1.html

Statistics-help-for-students.com (2008). Statistics help for students. Retrieved on October 29, 2010, from http://statistics-help-for-students.com/

Tillery, D., \& Deegan, W. (1985). The evolution of two -year colleges through four generations. In W. Deegan \& D. Tillery (Eds.), Renewing the American community college: priorities and strategies for effective leadership (pp. 3-33). San Francisco, CA: Jossey-Bass.

Tucker, A., \& Bryan, R. A. (1988). The academic dean. New York, NY: Macmillan. 
Tuma, N. B., \& Grimes, A. J. (1981). A comparison of models of role orientations of professionals in a research-oriented university. Administrative Science Quarterly, 26, 187-206.

Twombly, S. B. (1986). Theoretical approaches to the study of career mobility: Applications to administrative career mobility in colleges and universities. Paper presented at the Annual Meeting of the American Educational Research Association.

Twombly, S. B. (1987) The importance of beginnings: The relationship of entry positions to career outcomes for two-year college presidents. Community College Review, $15,2,14-21$.

Twombly, S. B. (1988). Administrative labor markets: A test of the existence of internal labor markets in two-year colleges. The Journal of Higher Education, 59(6), 668-689.

Twombly, S. B. (1990). Career maps and institutional highways. New Directions for Higher Education. 72, 5-18.

Underwood, C., \& Hammons, J. O. (1999). Past, present and future variations in community college organizational structure. Community College Review, 26(4), 39-60.

US Census. (2010). United States census 2010. Retrieved on January 3, 2011, from http://2010.census.gov/2010census/data/apportionment-pop-text.php

Vaughan, G. B. (1986). In pursuit of scholarship. Community, Technical, and Junior College Journal, 56, 12-16. 
Vaughan, G. B. (1989). Leadership in transition: The community college presidency. New York, NY: American Council on Education and MacMillan.

Vaughan, G. B. (1990). Pathway to the presidency: Community college deans of instruction. Washington, DC: American Association of Community and Junior Colleges.

Vaughan, G. B. (2001). Scholarship in community colleges. Teaching English in the Two-year College, 28(4), 413-417.

Weisman, I. M., \& Vaughan, G. B. (2002). The community college presidency: 2001. Washington, DC: Community College Press.

Weisman, I. M., \& Vaughan, G. B. (2007). The community college presidency: 2006. Washington, DC: American Association of Community Colleges.

Witt, A., Wattenbarger, J., Collattscheck, J., \& Suppiger, J. (1994). America's community colleges: The first century. Washington, DC: Community College Press.

Wright, T. A., \& Larwood, L. (1997). Further examination of the cosmopolitan-local latent role construct. Psychological Reports, 81, 897-898. 
Appendix A

\section{Initial E-Mail Contact}




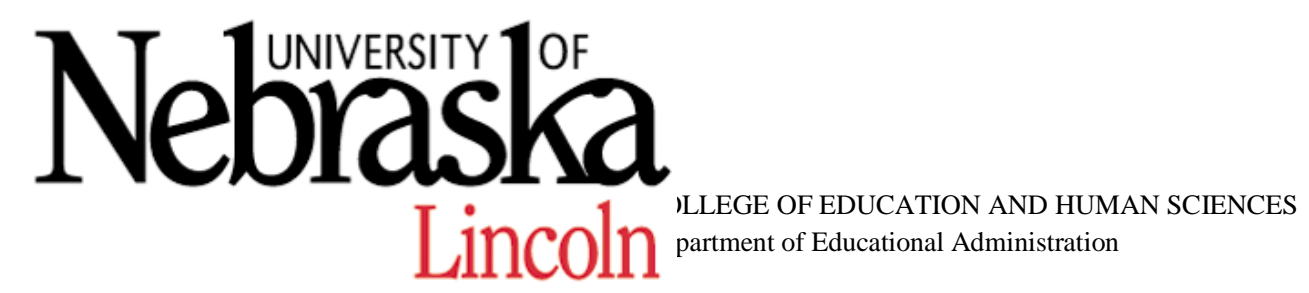

Dear $<$ Name $>$ :

As a doctoral student at the University of Nebraska-Lincoln, I am conducting a study to understand the impact of latent social roles on the community college chief academic officer. This is the sole purpose of the study. Latent social roles are the internalized shared expectations that, although not always seen as relevant on face value, are predicted to affect an individual's attitudes and behavior. The results of this research should be of interest and value to those interested in the leadership of community colleges, including aspiring chief academic officer, presidents, selection committees, and others interested in community college leadership.

As a community college chief academic officer, your input on the chief academic officer position is important. We would like to invite you to spend 15 - 30 minutes to complete a web based survey questionnaire. We will keep your identity and the identity of your organization confidential. You are free to decide not to participate in this study or to withdraw at any time without adversely affecting your relationship with the investigators or the University of Nebraska-Lincoln.

If you have any questions or concerns, you may contact me at (814) 827-4415 or at moanders@ pitt.edu. You may contact my advisors, Dr. Richard Hoover at (402) 472 3058, rhoover2@unl.edu or Dr. William Nunez at (402) 472-2097, wnunez2@unl.edu at the University of Nebraska-Lincoln for further clarification or should you have any concerns about this study. You can contact the Institutional Review Board at University of Nebraska-Lincoln at (402)472-6965.

Thank you for your kind consideration and participation in this survey.

Sincerely,

Melanie O. Anderson, Principal Investigator

Please click here to participate in this survey. 
Appendix B

Informed Consent Form and Survey Instrument 


\section{Community College Chief Academic Oficer July 2010 Survey}

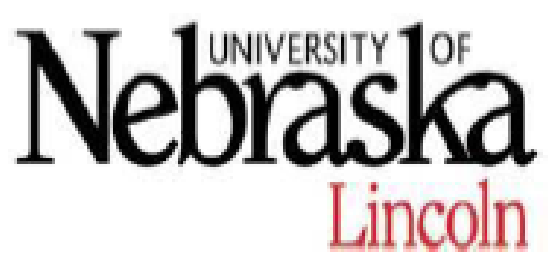

141 Teachers College Hall / P.O. Box 880360 / Lincoin, NE 68589-0360 / (402) 472-3726 / FAX (402) $472-4300$ COLLEOE OF EDUCATION AND HUMAN SCIENCES

Department of Educational Adminiztration

INFORMED CONSENT FORM

IRB Approva: $20100410696 \mathrm{EX}$

Tite: The Impact of Latent Social Roles on the Community Colege Chief Academic Orficer Purpose of the Research:

The purpose of this quantitative study is to determine if there was a relationahip between Couldiner's (1957, 1958) theory of coamopoitan and local Istent socis' roles and identrication of, Intereat in, and seiection of the public community college chief academic officer. You are invited to participate in this study because you are a community college chief academic officer.

Procedure:

Participation in this web based survey will require $15-30$ minutes of your time.

Ricks andior Dlacomforts:

There are no known riaks or decomforts associated with thia research.

Benefts:

The outcome of this research will have reievance to community college faculty and administrators who are considering pursuing the public community college chief academic onicer poaltion, as wel as the search commiltee and board of trustees involved in the seiection of the chief academic offlcer. It will also add to the body of research that has been developed using Gouldner's theory of cosmopolitan and local latent socis: roies.

Confidentalty:

Ary information obtained during this atudy which could identify you will be kept stricty conflidentis. The data will only be seen by the Investgators during the study. The information obtained in tois study may be published in scientfic joumals or presented at acientific meetings but the data will be reported in agaregate. There will be no Identifying information in the reported dato.

Opportunity to Aak Queetions:

You may ask any questiona conceming this research and have thoze questions answered before agresing to participate in or during the study. You may cal the investigators at any time with questions; contact information and phone numbers are contained below. Sometmes study participants have questions or concems about their rights. In that case, you should cal the University of Nebraska-Lincoin Inatitutional Review Board at $402-472-6965$.

Freedom to Withdraw:

You are free to decide not to participate in this atudy or to withdras at any time without adverzely affecting your reiationahip with the inveatlgators or Unlveraty of Nebraska-Uncoin or your institution. Your decialon will not result in any losa of benefts to which you are otherwise entitied.

Consent, Fight to Recelve a Copy:

You are voluntarily making a decieion whether or not to participate in thia rezearch atudy. Clicking on the community college chief academic eurvey link certfles that you have decided to participate having read and understood the information presented in the informed consent document. You may print or save a copy of this consent form for future reference. 


\section{Community College Chief Academic Oficer July 2010 Survey} Name and te Ephone number of Inveatgsion(a)

Melanie O. Anderzon Otilce: (814) 827-4415, moanderggpitt.edu

Prrmary investgator

Richard E. Hoover, Ph.D. Oence: (402) 472-3058, moover2@unl.edu

Secondary Inveatigator

Willsm A. Nunez, Fh. D. Oemce: (402) 472-2097, wnunez2gunl.edu

secondary Investigstor

1. Please read the informed consent document above. If you agree to participate in this survey, please click on the link below to continue.

C Yes, I agree to participate in the survey.

C. No, I do not agree to partelpate. 


\section{Community College Chief Academic Oficer Juby 2010 Survey}

2. Please indicate your response to these questions, based on the scale shown:

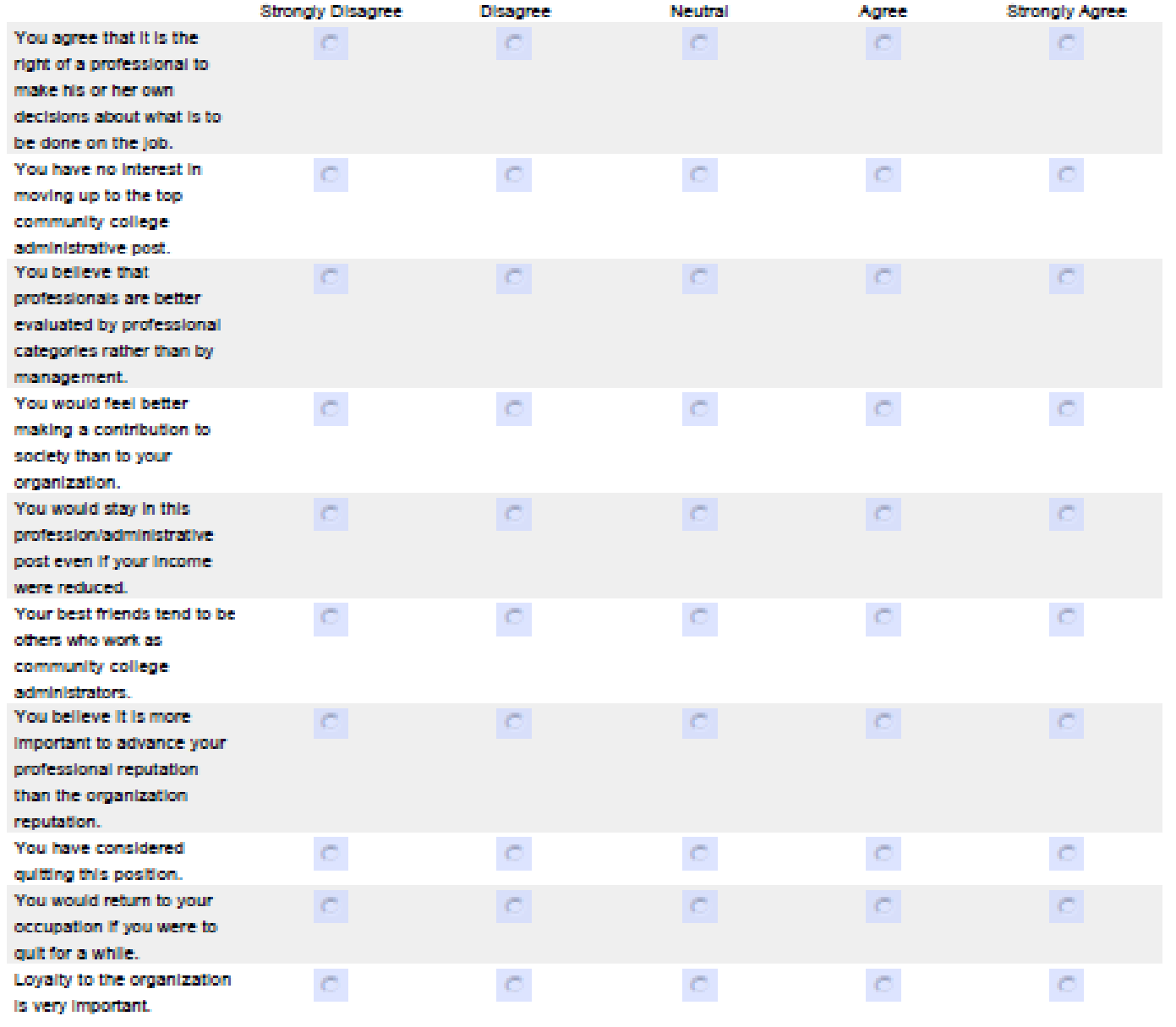

is very important. 


\section{Community College Chief Academic Oficer July 2010 Survey}

3. Please rate your extent of interest in the following:

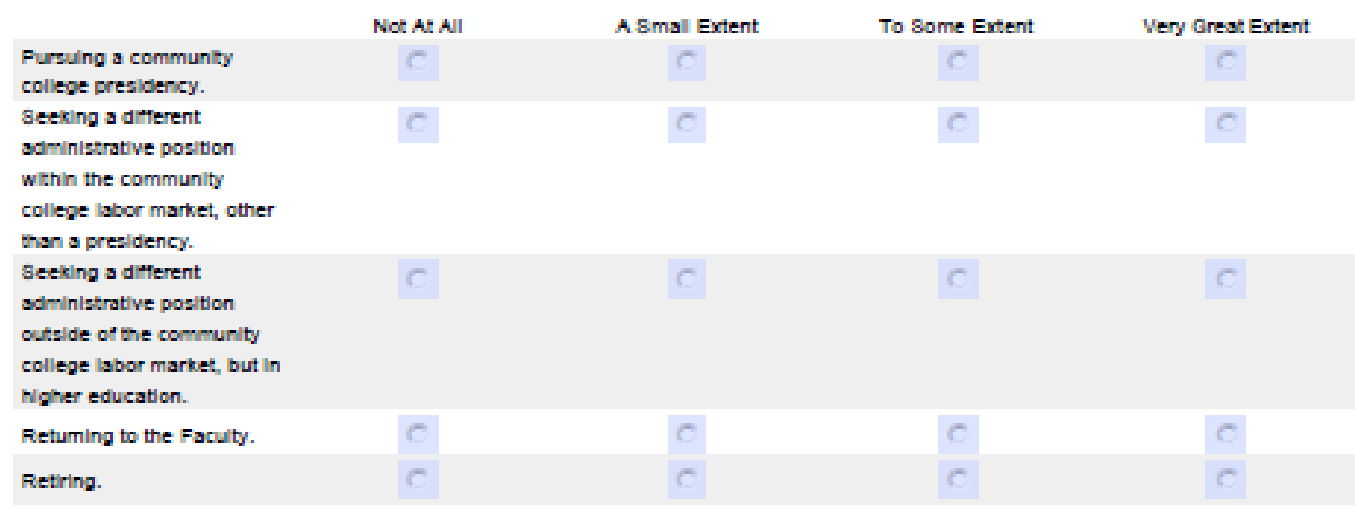

4. Please consider your career plans to:

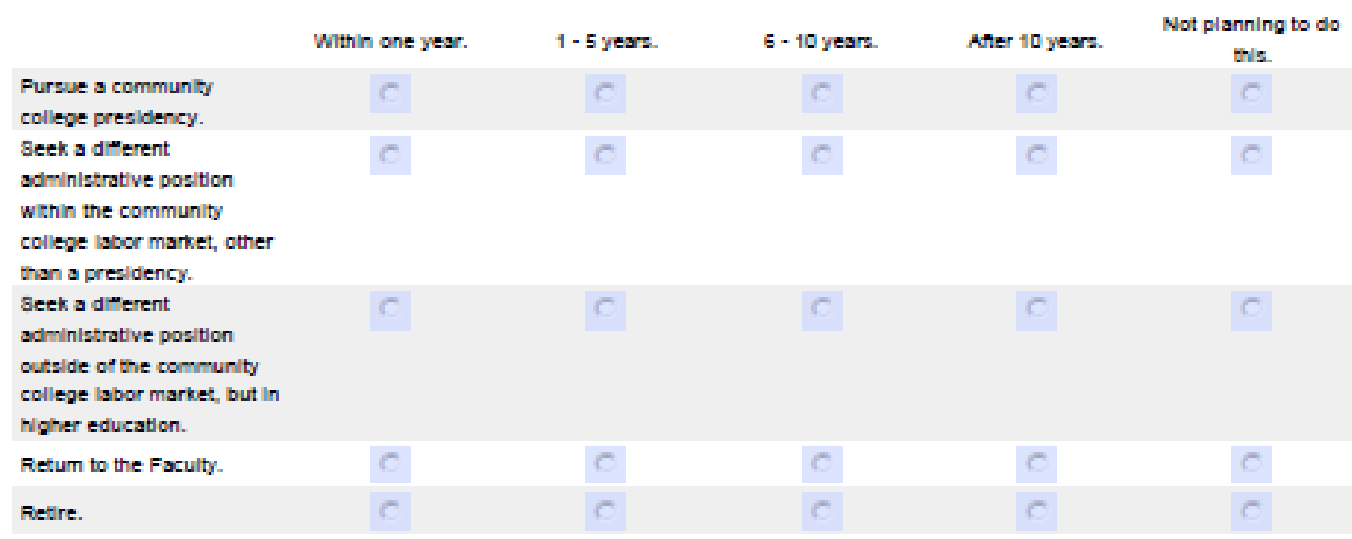

5. Please consider the following questions and rank their importance:

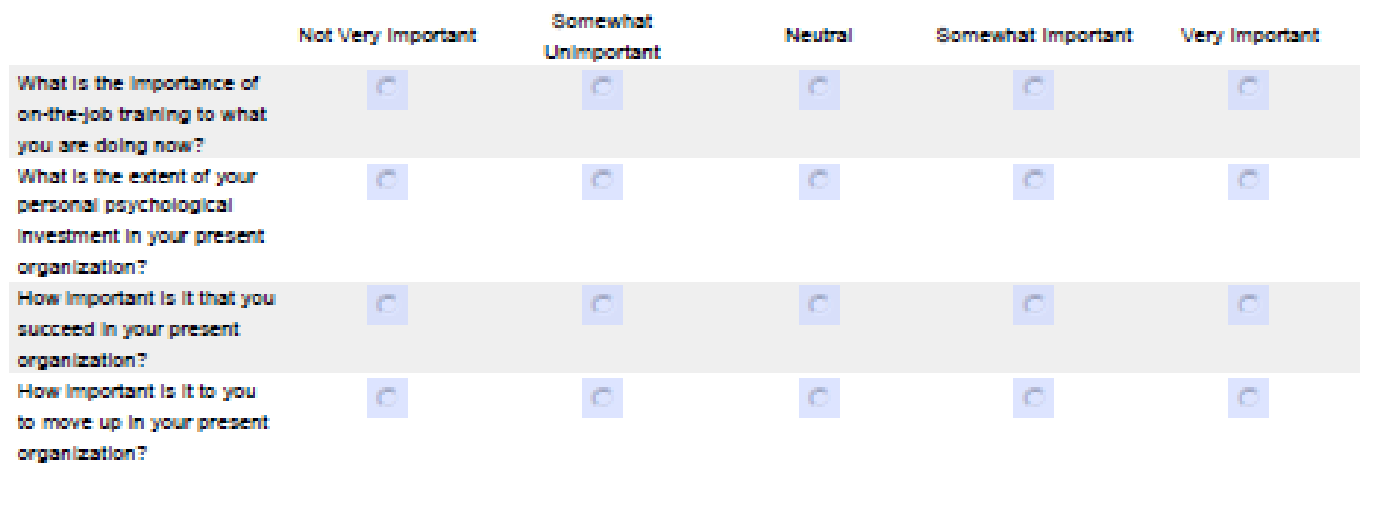




\section{Community College Chief Academic Oficer July 2010 Survey}

6. How satisfied are you:

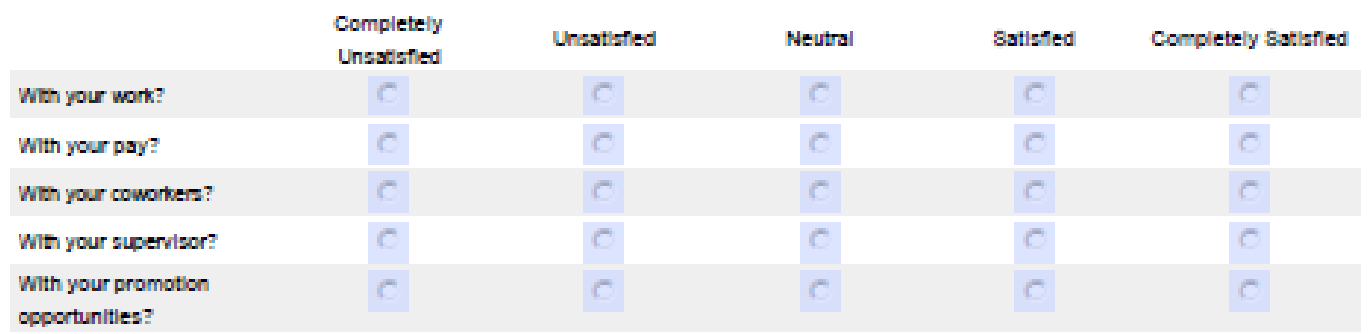

7. Were you an external candidate or internal candidate for your current position?

Intemal

Externa:

8. Please select a response from the list of options.

Number of years in your

current position.

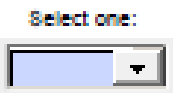

If more than 10 years, please indlcate number of years.

9. Please select a response from the list of options for each of your three most recent previous positions.

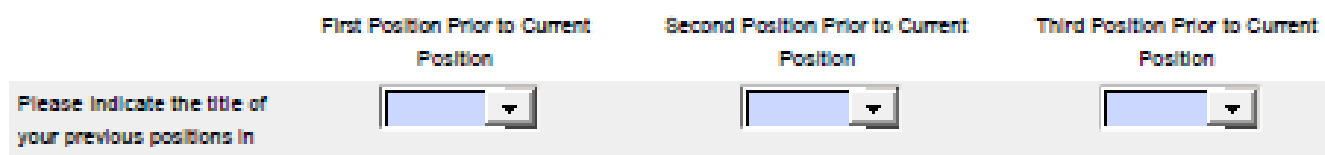

each column.

10. Community college size in number of students - unduplicated headcount.

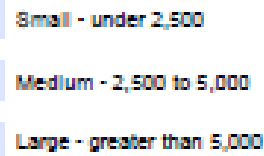

11. Number of total employees at your community college.

Less than 1,000.

Greater than 1,000 . 


\section{Community College Chief Academic Ofiicer July 2010 Survey}

12. The community college type where you are currently employed.

single location.

Multiple locationa under a common govemance.

13. What state is the community college located in where you are currently employed?

$\div$

Other (plesse specith)

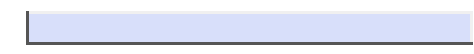

Demographic information.

14. This information is only being collected to follow up with those who have not completed the survey.

Your Name:

Community College:

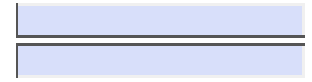

15. Your age.

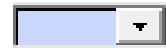

Other (plesse specity)

|

16. Your Birth Month.

$\square$

17. Your Gender.

Female

Male

18. Your Marital Status.

$\square$

19. Your Highest Level of Education Completed.

$\square$

Other (plesse mecity)

20. Education Discipline - please list:

L 


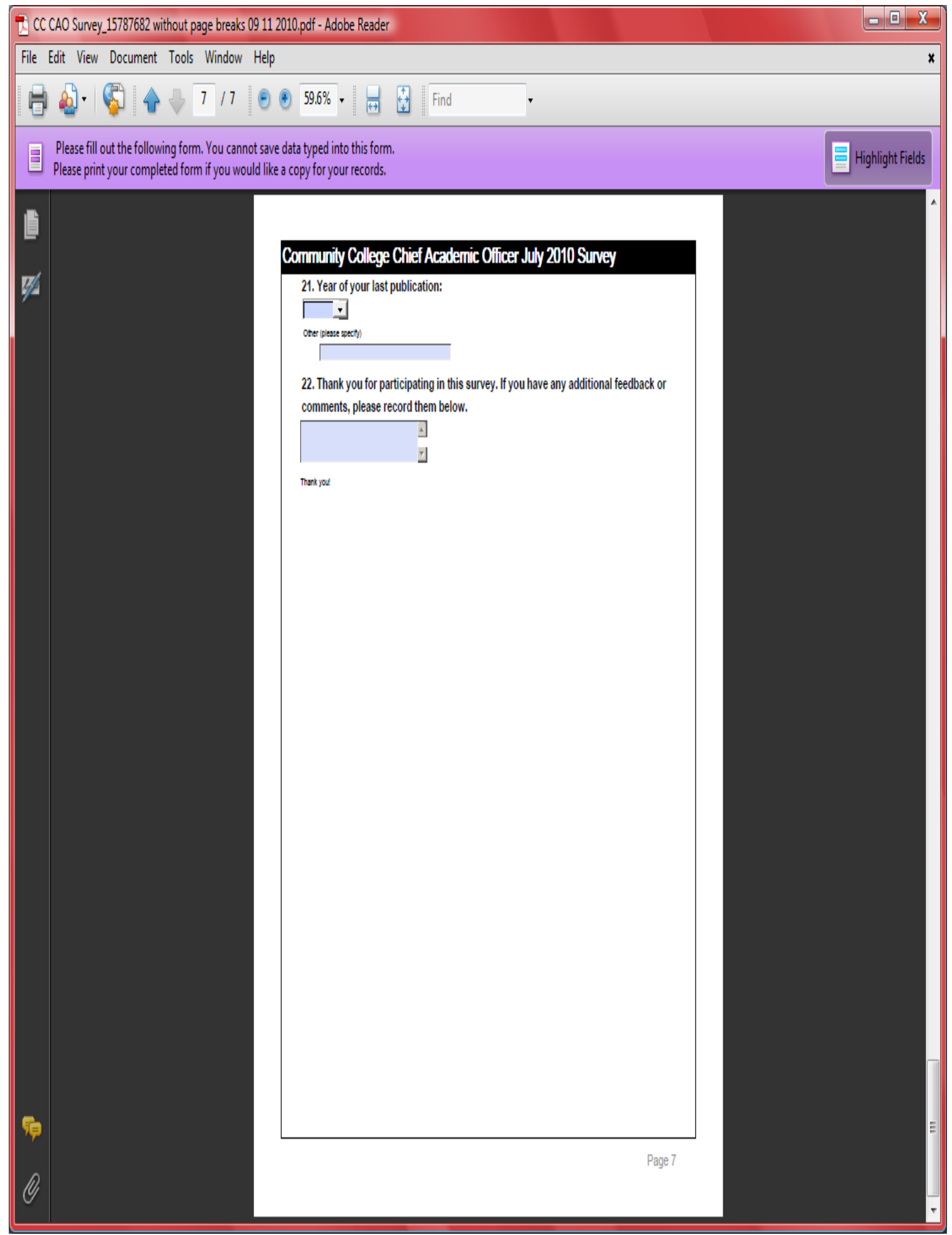


Appendix C

First Follow-up E-Mail 


\section{NebraSka Lincoln}

COLLEGE OF EDUCATION AND HUMAN SCIENCES

Department of Educational Administration

\section{Dear $<$ Name $>$ :}

I contacted you on July 14, 2010 regarding your participation in a study I am conducting as a doctoral student at the University of Nebraska-Lincoln, and am following up to request your kind assistance with my research.

The study's sole purpose is to understand the impact of latent social roles on the community college chief academic officer. Latent social roles are the internalized shared expectations that, although not always seen as relevant on face value, are predicted to affect an individual's attitudes and behavior. The results should be of interest and value to those interested in the leadership of community colleges, including aspiring chief academic officers, presidents, selection committees, and others interested in community college leadership.

As a community college chief academic officer, your input on the chief academic officer position is important. We would like to invite you to spend 15-30 minutes to complete a web based survey questionnaire. We will keep your identity and the identity of your organization confidential. You are free to decide not to participate in this study or to withdraw at any time without adversely affecting your relationship with the investigators or the University of Nebraska-Lincoln.

If you have any questions or concerns, you may contact me at (814) 827-4415 or at moanders@ @itt.edu. You may contact my advisors, Dr. Richard Hoover at (402) 472-3058, rhoover2@unl.edu or Dr. William Nunez at (402) 472-2097, wnunez2@unl.edu at the University of Nebraska-Lincoln for further clarification or should you have any concerns about this study. You can contact the Institutional Review Board at University of Nebraska-Lincoln at (402) 4726965.

Sincerely,

Melanie O. Anderson, Investigator

Please click below to participate in this survey.

https://www.surveymonkey.com/s/ZH69ZJY 
Appendix D

Second Follow-up E-Mail 


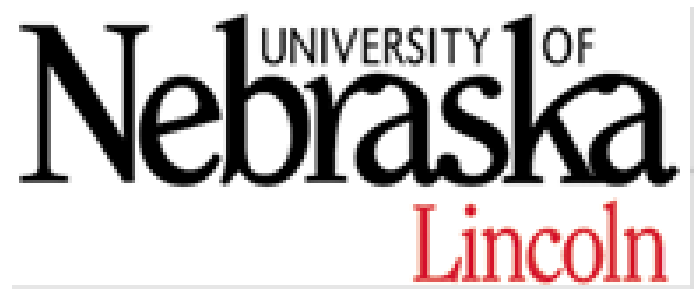

COLLEGE OF EDUCATION AND HUMAN SCIENCES

Department of Educational Administration

Dear $\langle$ Name $>$ :

I contacted you on July 28, 2010 requesting your participation in a study, and am following up to request your kind assistance with my research. Your response is very important to this research in achieving adequate response rates. Please consider completing this survey; your response is greatly appreciated!

As a doctoral student at the University of Nebraska-Lincoln, I am conducting a study to understand the impact of latent social roles on the community college chief academic officer. This is the sole purpose of the study. Latent social roles are the internalized shared expectations that, although not always seen as relevant on face value, are predicted to affect an individual's attitudes and behavior.

As a community college chief academic officer, your input on the chief academic officer position is important. We would like to invite you to spend 15-30 minutes to complete a web based survey questionnaire. We will keep your identity and the identity of your organization confidential. You are free to decide not to participate in this study or to withdraw at any time without adversely affecting your relationship with the investigators or the University of Nebraska-Lincoln.

If you have any questions or concerns, you may contact me at (814) 827-4415 or at moanders@ @itt.edu. You may contact my advisors, Dr. Richard Hoover at (402) 472 3058, rhoover2@unl.edu or Dr. William Nunez at (402) 472-2097, wnunez2@unl.edu at the University of Nebraska-Lincoln for further clarification or should you have any concerns about this study. You can contact the Institutional Review Board at the University of Nebraska-Lincoln at (402) 472-6965.

Sincerely,

Melanie O. Anderson, Investigator

Please click below to participate in this survey.

https://www.surveymonkey.com/s/ZH69ZJY 
Appendix E

Tukey HSD Post Hoc Procedure 
Table 35

Comparison of Total Community College per State to Survey Response by State

\begin{tabular}{|c|c|c|c|c|c|}
\hline $\begin{array}{c}\text { State } \\
\text { Abbreviation }\end{array}$ & $\begin{array}{c}\text { Total } \\
\text { Community } \\
\text { Colleges } \\
\text { By State } \\
\end{array}$ & $\begin{array}{c}\text { Percentage of } \\
\text { Total Number of } \\
\text { Community } \\
\text { Colleges by State } \\
\end{array}$ & $\begin{array}{c}\text { Responses by } \\
\text { Community } \\
\text { College CAO } \\
\text { per State } \\
\end{array}$ & $\begin{array}{c}\text { Percentage } \\
\text { Response } \\
\text { by State }\end{array}$ & $\begin{array}{c}\text { Percentage } \\
\text { Difference (Total } \\
\text { Population - } \\
\text { Survey Response) } \\
\end{array}$ \\
\hline AK & 1 & $0 \%$ & 0 & 0 & \\
\hline $\mathrm{AL}$ & 27 & $3 \%$ & 4 & $1 \%$ & $1 \%$ \\
\hline AR & 22 & $2 \%$ & 5 & $2 \%$ & $1 \%$ \\
\hline AS & 1 & $0 \%$ & 0 & $0 \%$ & $0 \%$ \\
\hline AZ & 19 & $2 \%$ & 6 & $2 \%$ & $0 \%$ \\
\hline CA & 105 & $11 \%$ & 29 & $10 \%$ & $1 \%$ \\
\hline $\mathrm{CO}$ & 15 & $2 \%$ & 6 & $2 \%$ & $0 \%$ \\
\hline CT & 12 & $1 \%$ & 2 & $1 \%$ & $1 \%$ \\
\hline $\mathrm{DE}$ & 3 & $0 \%$ & 0 & $0 \%$ & $0 \%$ \\
\hline FL & 15 & $2 \%$ & 7 & $2 \%$ & $-1 \%$ \\
\hline FM & 1 & $0 \%$ & 0 & $0 \%$ & $0 \%$ \\
\hline GA & 34 & $4 \%$ & 6 & $2 \%$ & $2 \%$ \\
\hline GU & 1 & $0 \%$ & 0 & $0 \%$ & $0 \%$ \\
\hline HI & 6 & $1 \%$ & 1 & $0 \%$ & $0 \%$ \\
\hline IA & 18 & $2 \%$ & 12 & $4 \%$ & $-2 \%$ \\
\hline ID & 3 & $0 \%$ & 2 & $1 \%$ & $0 \%$ \\
\hline IL & 46 & $5 \%$ & 16 & $6 \%$ & $-1 \%$ \\
\hline IN & 14 & $2 \%$ & 8 & $3 \%$ & $-1 \%$ \\
\hline KS & 22 & $2 \%$ & 8 & $3 \%$ & $0 \%$ \\
\hline KY & 15 & $2 \%$ & 5 & $2 \%$ & $0 \%$ \\
\hline LA & 20 & $2 \%$ & 3 & $1 \%$ & $1 \%$ \\
\hline MA & 15 & $2 \%$ & 4 & $1 \%$ & $0 \%$ \\
\hline MD & 16 & $2 \%$ & 6 & $2 \%$ & $0 \%$ \\
\hline ME & 7 & $1 \%$ & 1 & $0 \%$ & $0 \%$ \\
\hline MH & 1 & $0 \%$ & 0 & $0 \%$ & $0 \%$ \\
\hline MI & 24 & $3 \%$ & 9 & $3 \%$ & $-1 \%$ \\
\hline MN & 29 & $3 \%$ & 18 & $6 \%$ & $-3 \%$ \\
\hline MO & 18 & $2 \%$ & 5 & $2 \%$ & $0 \%$ \\
\hline MS & 16 & $2 \%$ & 6 & $2 \%$ & $0 \%$ \\
\hline MT & 8 & $1 \%$ & 2 & $1 \%$ & $0 \%$ \\
\hline $\mathrm{NC}$ & 58 & $6 \%$ & 14 & $5 \%$ & $1 \%$ \\
\hline ND & 4 & $0 \%$ & 1 & $0 \%$ & $0 \%$ \\
\hline $\mathrm{NE}$ & 5 & $1 \%$ & 3 & $1 \%$ & $0 \%$ \\
\hline $\mathrm{NH}$ & 7 & $1 \%$ & 2 & $1 \%$ & $0 \%$ \\
\hline NJ & 17 & $2 \%$ & 8 & $3 \%$ & $-1 \%$ \\
\hline NM & 17 & $2 \%$ & 1 & $0 \%$ & $2 \%$ \\
\hline NV & 1 & $0 \%$ & 0 & $0 \%$ & $0 \%$ \\
\hline NY & 35 & $4 \%$ & 11 & $4 \%$ & $0 \%$ \\
\hline $\mathrm{OH}$ & 27 & $3 \%$ & 6 & $2 \%$ & $1 \%$ \\
\hline
\end{tabular}

Table 35 continues 


\begin{tabular}{lrrrrr}
\hline $\begin{array}{c}\text { State } \\
\text { Abbreviation }\end{array}$ & $\begin{array}{c}\text { Total } \\
\text { Community } \\
\text { Colleges } \\
\text { By State }\end{array}$ & $\begin{array}{c}\text { Percentage of } \\
\text { Total Number of } \\
\text { Community } \\
\text { Colleges by State }\end{array}$ & $\begin{array}{c}\text { Responses by } \\
\text { Community } \\
\text { College CAO } \\
\text { per State }\end{array}$ & $\begin{array}{c}\text { Percentage } \\
\text { Response } \\
\text { by State }\end{array}$ & $\begin{array}{c}\text { Percentage } \\
\text { Difference (Total } \\
\text { Population- } \\
\text { Survey Response) }\end{array}$ \\
\hline OK & 11 & $1 \%$ & 5 & $2 \%$ & $-1 \%$ \\
OR & 15 & $2 \%$ & 5 & $2 \%$ & $0 \%$ \\
PA & 15 & $2 \%$ & 6 & $2 \%$ & $0 \%$ \\
RI & 1 & $0 \%$ & 0 & $0 \%$ & $0 \%$ \\
SC & 19 & $2 \%$ & 8 & $3 \%$ & $-1 \%$ \\
SD & 5 & $1 \%$ & 1 & $0 \%$ & $0 \%$ \\
TN & 12 & $1 \%$ & 3 & $1 \%$ & $0 \%$ \\
TX & 66 & $7 \%$ & 17 & $6 \%$ & $1 \%$ \\
UT & 4 & $0 \%$ & 1 & $0 \%$ & $0 \%$ \\
VA & 19 & $2 \%$ & 4 & $1 \%$ & $1 \%$ \\
VT & 1 & $0 \%$ & 0 & $0 \%$ & $0 \%$ \\
WA & 27 & $3 \%$ & 7 & $2 \%$ & $0 \%$ \\
WI & 17 & $2 \%$ & 4 & $1 \%$ & $0 \%$ \\
WV & 8 & $1 \%$ & 2 & $1 \%$ & $0 \%$ \\
WY & 7 & $1 \%$ & 5 & $2 \%$ & $-1 \%$ \\
\hline
\end{tabular}

